DANIEL LINS DA SILVA

SISTEMA DE INFORMAÇÃO PARA RASTREABILIDADE DE PRODUTOS FLORESTAIS BASEADO EM UMA ARQUITETURA ORIENTADA A SERVIÇOS

SÃO PAULO

2012 
DANIEL LINS DA SILVA

\title{
SISTEMA DE INFORMAÇÃO PARA RASTREABILIDADE DE PRODUTOS FLORESTAIS BASEADO EM UMA ARQUITETURA ORIENTADA A SERVIÇOS
}

\author{
Dissertação de mestrado em Engenharia Elétrica \\ apresentada à Escola Politécnica da Universidade \\ de São Paulo para obtenção do título de Mestre. \\ Área de Concentração: \\ Sistemas Digitais \\ Orientador: \\ Prof. Dr. Pedro Luiz Pizzigatti Corrêa
}

SÃO PAULO 
Este exemplar foi revisado e alterado em relação à versão original, sob responsabilidade única do autor e com a anuência de seu orientador.

São Paulo, de janeiro de 2012.

Assinatura do autor

Assinatura do orientador

FICHA CATALOGRÁFICA

Silva, Daniel Lins da

Sistema de informação para rastreabilidade de produtos florestais baseado em uma arquitetura orientado a serviços I D.L. da Silva. -- ed.rev. -- São Paulo, 2012. $125 \mathrm{p}$.

Dissertação (Mestrado) - Escola Politécnica da Universidade de São Paulo. Departamento de Engenharia de Computação e Sistemas Digitais.

1. Arquitetura de software 2. Sistemas distribuídos 3. Especificação de sistemas e programas 4 . Cadeia de suprimentos I. Universidade de São Paulo. Escola Politécnica. Departamento de Engenharia de Computação e Sistemas Digitais II. t. 


\section{DEDICATÓRIA}

Dedico este trabalho

à minha esposa e meu eterno amor, Naiandra Tuyla de Amorim Lins, por estar sempre ao meu lado.

Aos meus pais, Teodorico José da Silva e Marilene Lins da Silva, pelo constante apoio, incentivo e por todos os ensinamentos que me fizeram crescer como pessoa e evoluir como profissional.

Ao meu pequeno filho, Daniel de Amorim Lins, que com um simples sorriso, me faz esquecer todos os problemas. 


\section{AGRADECIMENTOS}

Primeiramente a Deus, por me dar tranquilidade, força e foco para superar todos os problemas e adversidades durante a realização desta pesquisa.

A minha família, que sempre foi verdadeiramente o meu equilíbrio e que mostrou os valores de um homem e a importância do estudo e do crescimento constante.

A Família Amorim, por ter me acolhido como um filho, me apoiando em todos os momentos, com um amor e um carinho indescritíveis.

Ao Prof. Dr. Pedro Luiz Pizzigatti Corrêa, pelos ensinamentos, apoio, paciência e incentivo durante todo o período desta jornada, onde nos tornamos verdadeiros amigos.

Aos professores Carlos Eduardo Cugnasca, Adriana Maria Nolasco e Edson José Vidal da Silva pelo apoio na realização deste trabalho.

Aos coordenadores do programa, em especial ao Prof. Dr. Marco Túlio, pelo entusiasmo e disposição constante na solução dos problemas ocorridos durante o programa.

A Coordenação de Aperfeiçoamento de Pessoal de Nível Superior - CAPES pela criação e regulamentação do programa de Mestrado Interinstitucional, Minter.

A Fundação de Amparo e Pesquisas do Amazonas - FAPEAM, pela concessão da Bolsa de Mestrado ao autor.

A Superintendência da Zona Franca de Manaus - SUFRAMA, pelo apoio financeiro prestado ao programa Minter.

A Escola Politécnica da USP e a Universidade do Amazonas, que nos presenteou com este programa de mestrado interinstitucional, possibilitando a realização de um sonho. 


\section{EPÍGRAFO}

"A mente que se abre a uma nova ideia, jamais voltará ao seu tamanho original."

Albert Einstein 


\section{RESUMO}

A produção florestal é uma atividade de importância fundamental para a economia brasileira. Estudos mostram que a ilegalidade na produção da madeira chega a $80 \%$ do total produzido. Esta madeira ilegal se transforma em legalizada durante a sua cadeia de suprimentos, graças às falhas nos sistemas de controle e monitoramento. Este trabalho analisa os problemas computacionais existentes no gerenciamento e no monitoramento do processo produtivo florestal na Floresta Amazônica e apresenta a modelagem de um sistema computacional, baseado em uma arquitetura orientada a serviços, que busca por meio da integração dos sistemas envolvidos o registro de informações das diversas etapas produtivas. Para isso, foi criado um modelo de informação que utiliza o padrão de metadados eFIDS, projetado para controlar transações eletrônicas na indústria florestal e uma base de dados centralizada, onde as informações deste processo são registradas e relacionadas, possibilitando a manutenção da rastreabilidade dos produtos e insumos florestais durante todo seu ciclo de vida, garantindo a identificação da origem florestal destes produtos para as empresas e consumidores finais.

Palavras-chaves: Sistemas Distribuídos, Serviços Web, Cadeia de Suprimentos, Rastreabilidade, Madeira. 


\begin{abstract}
The Forest production is an activity with fundamental importance for the Brazilian economy. Studies show that the illegality in timber production is around $80 \%$ of total productive. This illegal wood becomes legalized in your supply chain due the failures in control and monitoring systems. This paper analyzes a computational problems existing in managing and monitoring productive process in the Amazon Forest and presents the modeling of a computational system, based on a serviceoriented architecture, which seeks through the involved systems integration the recording of information about the various productive stages. For this was created an information model that uses the eFIDS metadata standard, designed to handle electronic transactions in the forestry industry, and a centralized database, where the process information are recorded and linked, enabling the maintenance of product and raw material traceability throughout its lifecycle, ensuring identification of the forest products origin for businesses and consumers.
\end{abstract}

Key-words: Distributed Systems, Web Services, Supply Chain Management, Traceability, Wood. 


\section{LISTA DE ILUSTRAÇÕES}

Figura 1 - Imagem de Satélite demonstrando a intensidade do desmatamento da Amazônia no ano de 2008. Fonte: PORTAL ECODEBATE (2009)..............................29 Figura 2 - Imagem de Satélite demonstrando a intensidade do desmatamento da Amazônia no ano de 2009. Fonte: PORTAL ECODEBATE (2009)...............................29 Figura 3 - Representação da cadeia de custódia da madeira, mostrando os estágios de um processo típico. As caixas à direita descrevem os movimentos dos materiais entre seus estágios de processamento. Fonte: Extraído e adaptado de Dykstra et al. (2002).

Figura 4- Exemplo de uma etiqueta com um código Universal Product Code (UPC). Fonte: Dykstra et al. (2002)........

Figura 5 - Exemplos de Códigos de Barra 2D. Fonte: Dykstra et al. (2002)................. 40

Figura 6 - Exemplo de código EPC (SGTIN). Fonte: PMA (2006)................................ 41

Figura 7- Especificação simplificada da WSDL. Fonte: Extraído e adaptado de

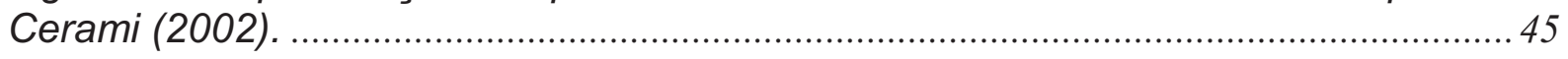
Figura 8 - Troca de mensagens utilizando o SOAP. Fonte: Extraído e adaptado de

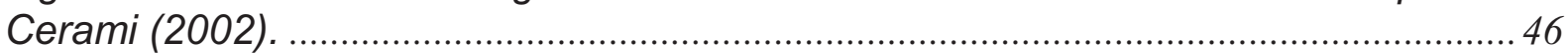

Figura 9 - Fornecedor, Consumidor e Broker. Fonte: Josuttis (2008)........................ 47 Figura 10 - Cadeia de suprimentos simplificada de produtos florestais. Fonte: Extraído e adaptado de Dykstra et al. (2002).

Figura 11 - Divisão da área de manejo florestal em talhões. Fonte: Amaral et al. (1998).

Figura 12 - Modelo de plaqueta de identificação de árvores para exploração comercial. Fonte: Amaral et al. (1998)...................................................................... 52 Figura 13 - Ficha de campo preenchida. Fonte: Extraído e adaptado de Amaral et al. (1998).

Figura 14 - Mapa do censo florestal. Fonte: Amaral et al. (1998). ................................ 53 Figura 15 - Identificação de toras no pátio de estocagem de uma madeireira. Fonte: Conselho Brasileiro de Manejo Florestal (2010). ............................................................ 55

Figura 16 - Arquitetura simplificada do sistema............................................................ 63 Figura 17 - Principais etapas do método de modelagem SOA. Fonte: Extraído e

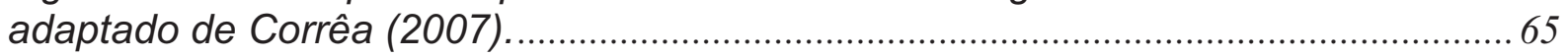

Figura 18 - Decomposição do Domínio da Cadeia de Valor em áreas funcionais. .... 66 Figura 19 - Fluxo resumido de atividades do processo de planejamento e autorização de exploração florestal............................................................................... 69 Figura 20 - Diagrama de caso de uso do processo de planejamento e autorização de

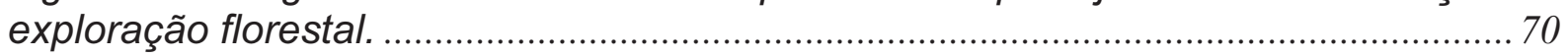
Figura 21 - Fluxo resumido do processo de exploração da madeira............................ 73 Figura 22 - Diagrama de caso de uso do processo de exploração de madeira.......... 73 Figura 23 - Fluxo resumido de atividades do processo de licenciamento ambiental para beneficiamento.................................................................................................... 75 Figura 24 - Diagrama de casos de uso do processo de licenciamento ambiental para

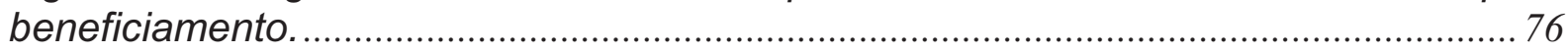
Figura 25 - Processo de transformação de madeira em produto final. Fonte: Extraído

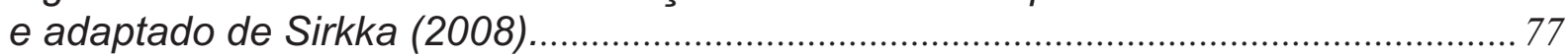
Figura 26 - Processo resumido de transformação de produtos florestais...................... 78 Figura 27 - Diagrama de casos de uso do processo de transformação de produtos florestais. 
Figura 28 - Processo de negociação/venda de produtos florestais.

Figura 29 - Diagrama de casos de uso do processo de negociação/venda de

produtos florestais.

Figura 30 - Processo de destinação de produtos florestais.

Figura 31 - Diagrama de casos de uso do processo de destinação de produtos florestais.

Figura 32 - Diagrama de casos de uso da integração entre o sistema de monitoramento e os sistemas de apoio.

Figura 33 - Diagrama de casos de uso do Portal WEB.

Figura 34 - Diagrama de caso de uso do sistema de rastreabilidade de produtos florestais.

Figura 35 - Representação das relações da entidade Lote do modelo de dados. .... 90 Figura 36 - Representação das relações da entidade Processo em uma atividade de transformação.

Figura 37 - Relação das entidades Processo e Estoque na atividade de transformação.

Figura 38 - Relações da entidade Processo em uma atividade de venda.

Figura 39 - Esquema Relacional do banco de dados do sistema de rastreabilidade. 94

Figura 40 - Domínio da aplicação e seus respectivos componentes.

Figura 41 - Diagrama de classes do sistema e suas relações.

Figura 42 - Arquitetura desenvolvida para o Sistema de Monitoramento do Protótipo

Funcional.

Figura 43 - Fragmento do Arquivo WSDL gerado pelo protótipo.

Figura 44 - Portal Web para validação da origem de um produto florestal.

Figura 45 - Aplicativo embarcado para a consulta da origem de um produto florestal.

Figura 46 - Mensagens SOAP 1.2 de solicitação e resposta do serviço GetProdutOrigin 


\section{LISTA DE TABELAS}

Tabela 1- Estados e Sistemas de Controle florestais utilizados. Fonte: Chaves (2009).

Tabela 2- Palavras-Chave utilizadas na Revisão Sistemática da literatura.

Tabela 3- Os 20 principais exportadores mundiais de produtos florestais em 20062007. Fonte: FAO (2009).

Tabela 4- Quantidade produzida e variação percentual dos produtos da extração vegetal e da silvicultura - Brasil - 2007-2008. Fonte: IBGE (2009).

Tabela 5 - Desmatamento por estado na Amazônia Legal no período de 2001-2009. Fonte: INPE (2009)

Tabela 6 - Estados do Amazonas e seus respectivos sistemas de controle florestal em utilização. Fonte: Aliança da Terra et al. (2007).

Tabela 7- Casos de Uso do processo de planejamento e autorização de exploração.

Tabela 8 - Casos de uso do processo de extração da madeira.

Tabela 9 - Casos de uso do processo de licenciamento ambiental para

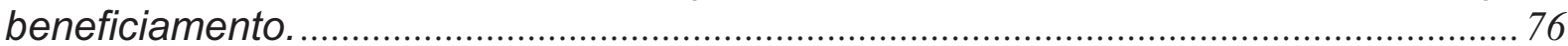

Tabela 10 - Casos de uso do processo de transformação de produtos florestais. ..... 79 Tabela 11 - Casos de uso do processo de negociação/venda de produtos florestais.

Tabela 12 - Casos de uso do processo de destinação de produtos florestais.

Tabela 13 - Casos de uso da integração entre o sistema de rastreabilidade e os sistemas de apoio.

Tabela 14- Casos de Uso relacionados ao Portal Web proposto.

Tabela 15- Mapeamento do padrão eFIDS com a base de dados do sistema de monitoramento. 


\section{SUMÁRIO}

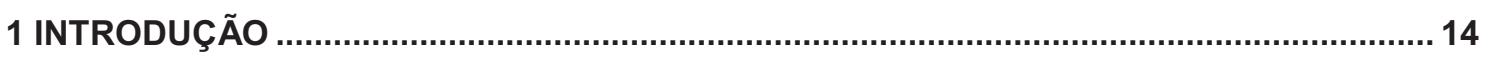

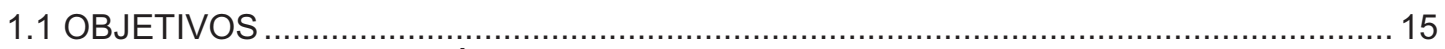

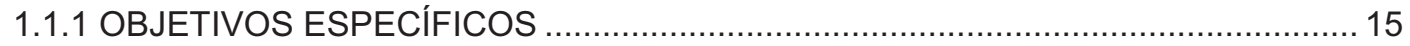

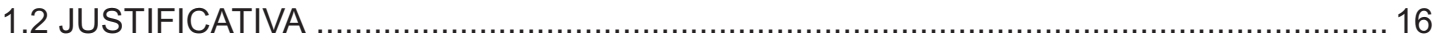

1.2.1 AVALIAÇÃO DOS SISTEMAS DE CONTROLE FLORESTAL .............................. 16

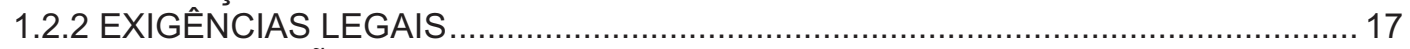

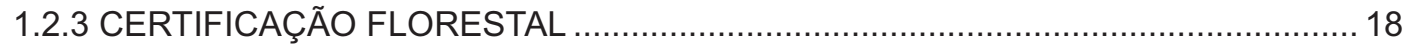

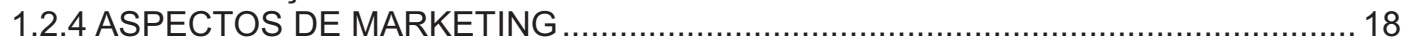

1.2.5 FORNECIMENTO DE DADOS AO CONSUMIDOR …........................................ 19

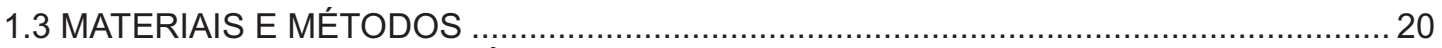

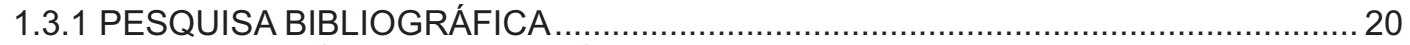

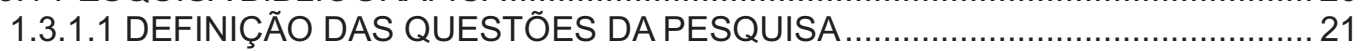

1.3.1.2 SELEÇẨO DAS FONTES ………………............................................ 22

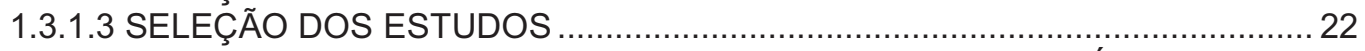

1.3.2 CONTATOS COM O SETOR PRODUTIVO E ESPECIALISTAS NA ÁREA ................ 24

1.3.3 IDENTIFICAÇÃO DOS COMPONENTES E SERVIÇOS PARA GERENCIAMENTO

DA CADEIA DE SUPRIMENTOS DA MADEIRA ….......................................................... 24

1.3.4 IDENTIFICAÇÃO DOS PADRÕES DE METADADOS PARA TROCA DE

INFORMAÇÕES ENTRE OS SISTEMAS ENVOLVIDOS …........................................ 24

1.3.5 IDENTIFICAÇÃO DOS PADRÕES PARA CODIFICAÇÃO DE PRODUTOS E

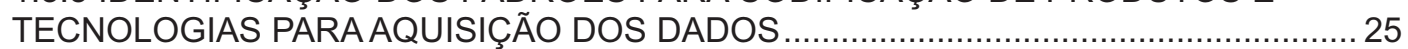

1.3.6 DESENVOLVIMENTO DE UM PROTÓTIPO PARA AVALIAÇÃO …......................... 25

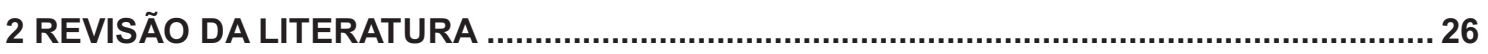

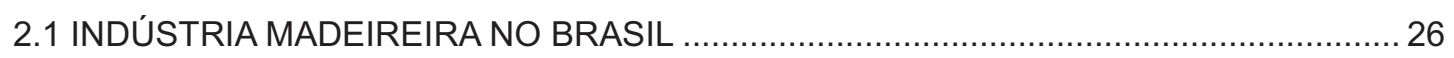

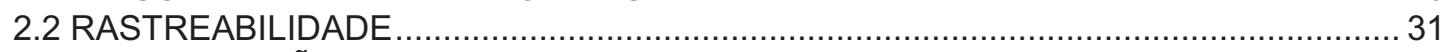

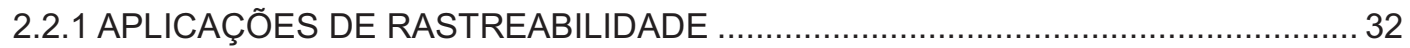

2.3 RASTREABILIDADE DE PRODUTOS FLORESTAIS ….......................................... 32

2.3.1 SISTEMAS DE RASTREABILIDADE FLORESTAL NO BRASIL ............................. 32

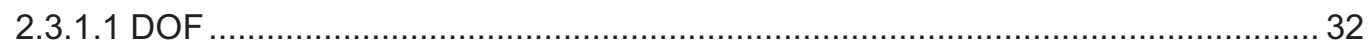

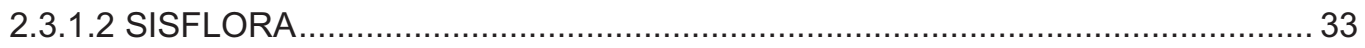

2.3.2 SISTEMAS DE RASTREABILIDADE FLORESTAL NO MUNDO …...................... 33

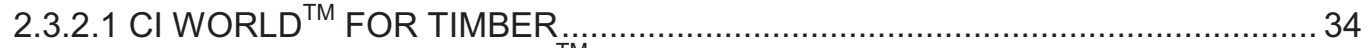

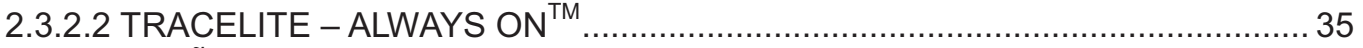

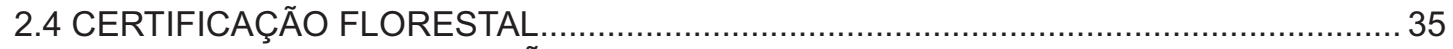

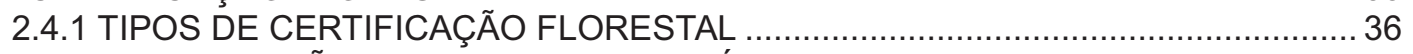

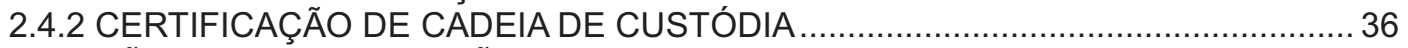

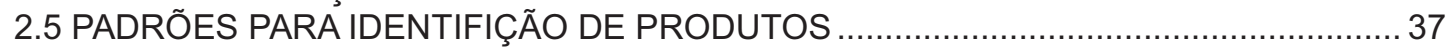

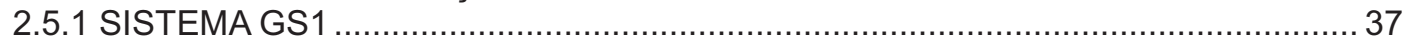

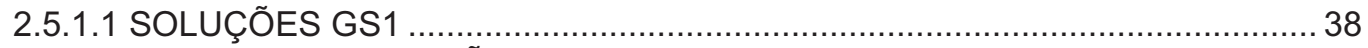

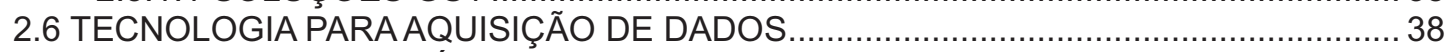

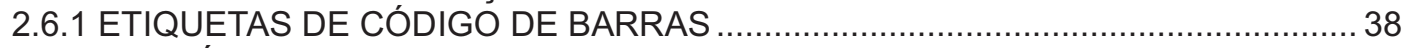

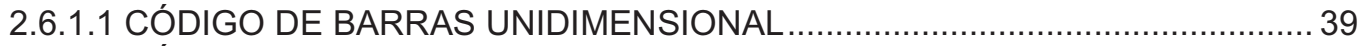

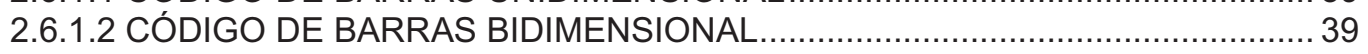

2.6.2 RADIO FREQUENCY IDENTIFICATION - RFID ............................................ 40

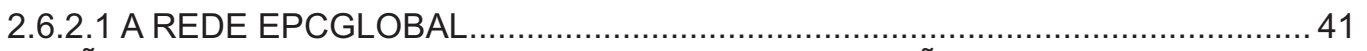

2.7 PADRÕES DE METADADOS PARA TROCA DE INFORMAÇÕES …...........................42

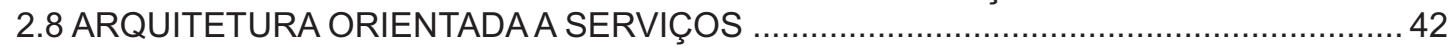

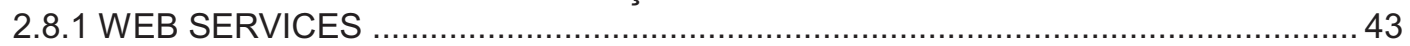

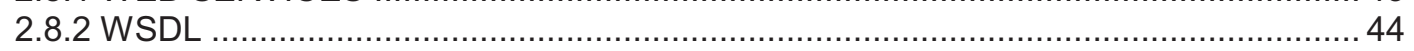

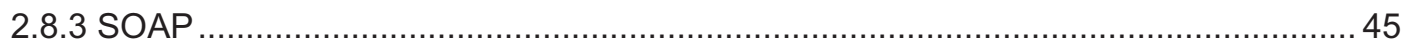

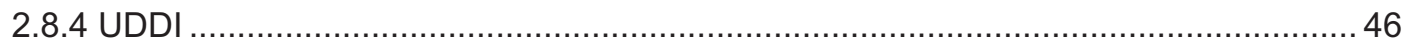

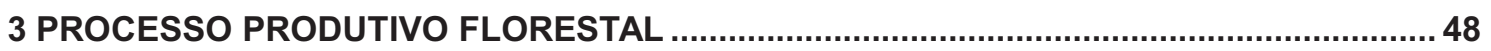

3.1 CADEIA DE SUPRIMENTOS DE PRODUTOS FLORESTAIS .................................... 48 3.1.1 PLANO DE MANEJO FLORESTAL SUSTENTÁVEL (PMFS) E AUTORIZAÇÃO DE

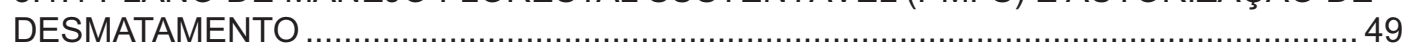




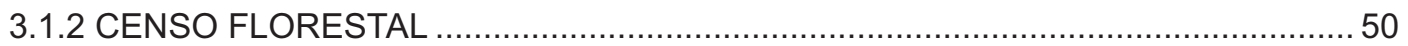

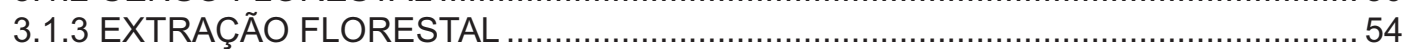

3.1.4 LICENCIAMENTO AMBIENTAL PARA BENEFICIAMENTO .................................. 55

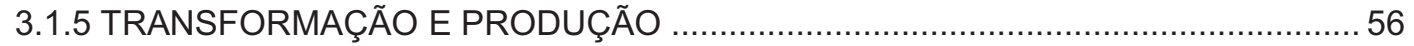

3.1.6 SISTEMAS COMPUTACIONAIS NO PROCESSO PRODUTIVO FLORESTAL

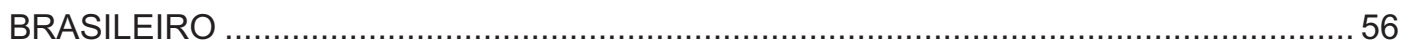

3.1.7 ANÁLISE DO PROCESSO PRODUTIVO FLORESTAL …................................. 57

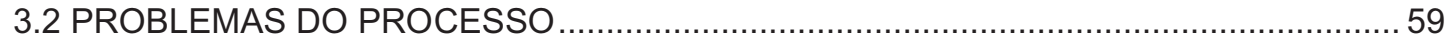

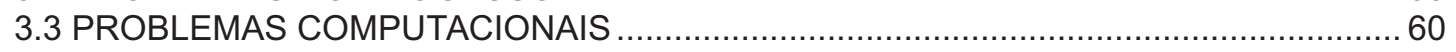

4 MODELAGEM DO SISTEMA PROPOSTO

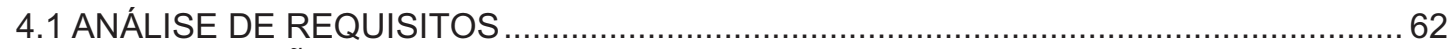

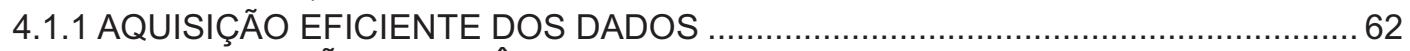

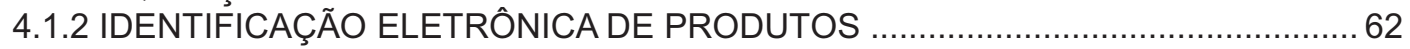

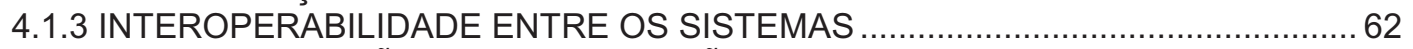

4.1.4 DISPONIBILIZAÇÃO DAS INFORMAÇÕES DO PRODUTO NA CADEIA DE

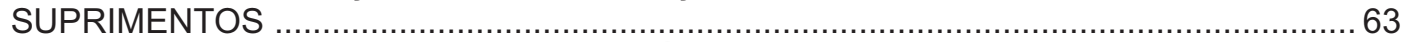

4.1.5 UTILIZAÇÃO DE DISPOSITIVOS MÓVEIS PARA A FISCALIZAÇÃO DO

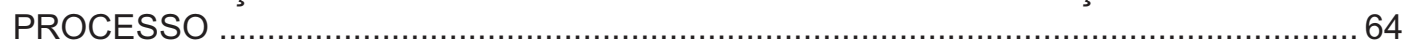

4.1.6 FACILITAR O PROCESSO DE CERTIFICAÇÃO DA CADEIA DE CUSTÓDIA.........64

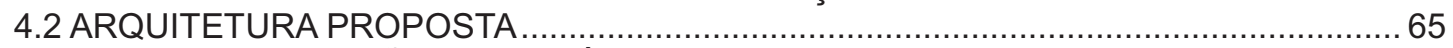

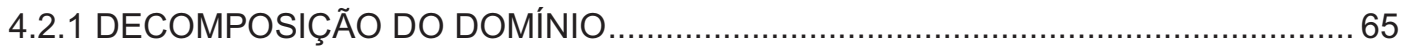

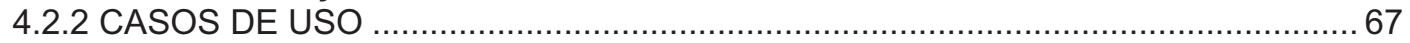

4.2.2.1 PROCESSO DE PLANEJAMENTO E AUTORIZAÇÃO DE EXPLORAÇÃO..... 68

4.2.2.2 PROCESSO DE EXTRAÇÃO DA MADEIRA ................................................ 72

4.2.2.3 PROCESSO DE LICENCIAMENTO AMBIENTAL PARA BENEFICIAMENTO.. 74

4.2.2.4 PROCESSO DE TRANSFORMAÇÃO/FABRICAÇÃO DE PRODUTOS

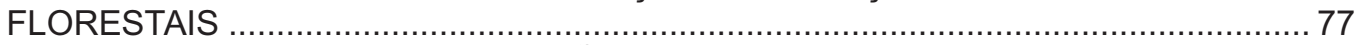

4.2.2.5 PROCESSO DE NEGOCIAÇÃO/VENDA DE PRODUTOS FLORESTAIS ........80

4.2.2.6 PROCESSO DE DESTINAÇÃO DE PRODUTOS FLORESTAIS....................... 83

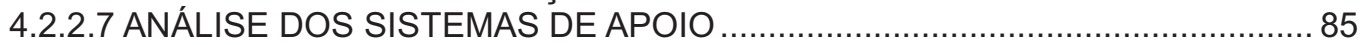

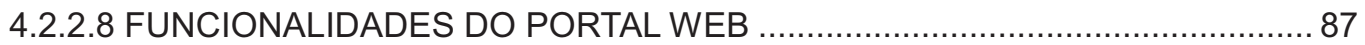

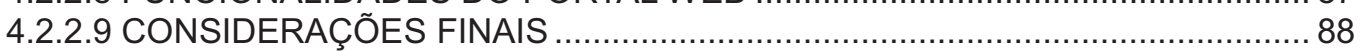

4.2.3 MODELO DE INFORMAÇÃO DO SISTEMA DE MONITORAMENTO …......................90

4.2.3.1 METADADOS PARA INTEROPERABILIDADE DE DADOS ENTRE OS

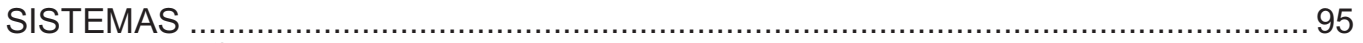

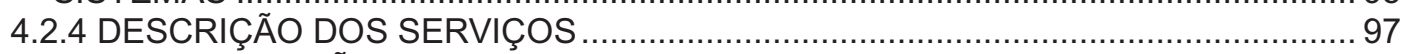

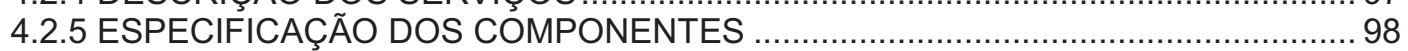

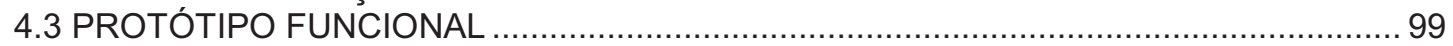

4.3.1 DESENVOLVIMENTO DA APLICAÇÃO DO SERVIDOR …............................... 101

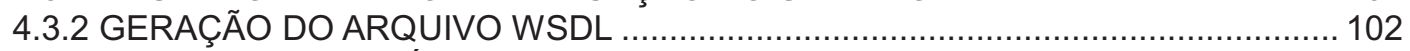

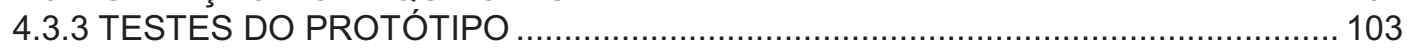

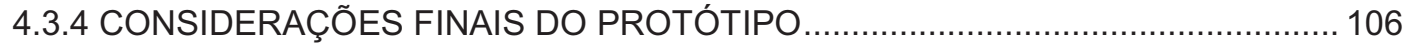

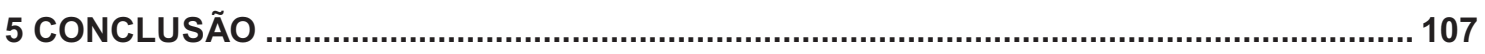

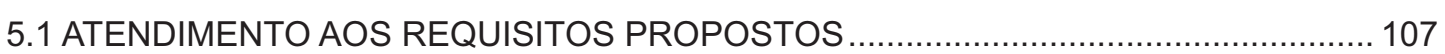

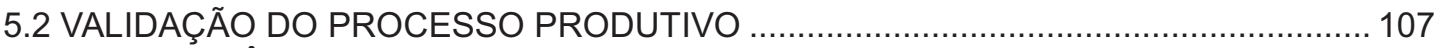

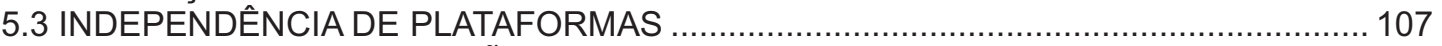

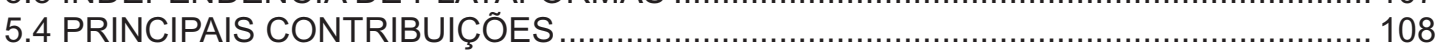

5.5 PERSPECTIVAS PARA CONTINUIDADE DO TRABALHO ........................................ 109

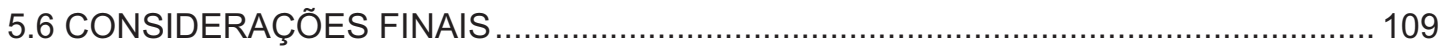

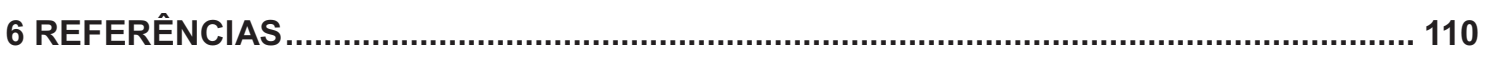

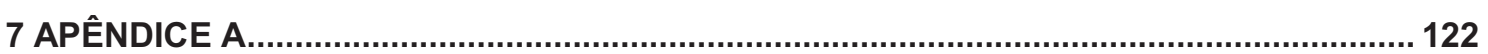




\section{INTRODUÇÃO}

As florestas tropicais do mundo estão diminuindo a uma taxa de aproximadamente $5 \%$ por década, devido sua exploração para abastecimento dos mercados nacionais e internacionais da madeira, além da utilização de suas áreas para a produção agrícola, pecuária e, mais recentemente, para biocombustíveis (ALIANÇA DA TERRA et al., 2007). Este desmatamento florestal também é responsável pela emissão de aproximadamente 2 bilhões de toneladas de carbono para a atmosfera a cada ano. Somente na Amazônia brasileira, o desmatamento liberou nesta década, uma média de 200 milhões de toneladas de carbono anualmente, o que representa aproximadamente $55 \%$ das emissões totais do Brasil (MOUTINHO, 2009).

A produção florestal brasileira possui um papel importante na economia do país. Dados da Organização das Nações Unidas para Agricultura e Alimentação (FAO) (FAO, 2009) mostram que o Brasil ocupa a $10^{\mathrm{a}}$ colocação no ranking mundial de exportadores de produtos florestais, chegando ao número de US $\$ 7,2$ bilhões em exportações no ano de 2007. Sendo que se estima que a ilegalidade na produção da madeira chegue a $80 \%$ do total produzido. Esta madeira ilegal se transforma em legalizada durante a sua cadeia de suprimentos, graças às falhas nos sistemas de controle e monitoramento (MILLER; TAYLOR; WHITE, 2006), (GREENPEACE, 2008a).

A cadeia de suprimentos corresponde a todas as atividades envolvidas até a entrega do produto, desde a matéria-prima até o consumidor final, incluindo compras de matérias-primas, fabricação e montagem, armazenagem e rastreamento de estoques, distribuição através de todos os canais, entrega ao consumidor; e os sistemas de informações necessários para monitorar todas estas atividades (LUMMUS; VOKURKA, 2009).

A falta de controle desse mercado contribui para o aumento do desmatamento ilegal. A rastreabilidade destes produtos permitirá contribuir com a diferenciação no mercado entre a madeira produzida legalmente e a ilegalmente. Sem esse controle, as empresas que seguem as boas práticas produtivas são obrigadas a competir em condições iguais com empresas ilegais, que não pagam impostos, possuem baixos custos operacionais e simplesmente extraem a madeira nativa sem nenhuma 
preocupação com o meio ambiente (DYKSTRA et al., 2002).

Iniciativas tecnológicas para buscar a solução destes problemas foram desenvolvidas apoiando-se nos conceitos de rastreabilidade e gerenciamento da cadeia de suprimentos. No Brasil destacam-se o Documento de Origem Florestal (DOF) (IBAMA, 2006a) (IBAMA, 2006b), de responsabilidade do Instituto Brasileiro do Meio Ambiente e dos Recursos Naturais Renováveis (IBAMA) e o Sistema de Comercialização e Transporte de Produtos Florestal (SISFLORA) (SEMA, 2008), criado pela Secretaria de Estado do Meio Ambiente (SEMA) do Mato Grosso. Porém a falta de meios eficientes para a aquisição dos dados e de padronizações para a troca de informações mútuas e entre os demais sistemas envolvidos no processo produtivo e de monitoramento florestal tornaram estes sistemas pouco eficientes (GREENPEACE, 2009), (FLORESTA VIDA AMAZONAS, 2009).

É neste contexto que se apoia a elaboração desta pesquisa, que propõe a modelagem de uma arquitetura orientada a serviços para o gerenciamento das informações de rastreabilidade da madeira, possibilitando sua integração com os sistemas produtivos e de fiscalização florestal. Faz parte do estudo a análise de padrões de metadados que poderão ser utilizados na comunicação entre os diversos sistemas que compõem a cadeia de suprimentos dos produtos florestais.

\subsection{OBJETIVOS}

O objetivo desta pesquisa é contribuir para a solução dos problemas computacionais existentes na rastreabilidade de produtos florestais, identificando mecanismos que permitam gerenciar e monitorar as diversas etapas desta cadeia de suprimentos, possibilitando também a troca de informações entre os diversos sistemas participantes deste processo, os sistemas de fiscalização e monitoramento e os sistemas que buscam a comprovação da origem destes produtos.

\subsubsection{OBJETIVOS ESPECÍFICOS}

Os objetivos da pesquisa são:

- Caracterizar os sistemas de informação brasileiros atuais, utilizados no 
processo de gerenciamento da cadeia de suprimentos da madeira nativa;

- Modelar uma arquitetura de software orientada a serviços destinada ao gerenciamento das informações de rastreabilidade dos produtos florestais.

- Identificar padrões de metadados para a comunicação entre os diversos sistemas envolvidos no processo produtivo florestal e no seu monitoramento e fiscalização.

- Identificar padrões e tecnologias para a aquisição de dados dos produtos e matérias-primas, gerenciados em cada uma das etapas da cadeia de custódia.

- Desenvolver um protótipo para validação da arquitetura proposta.

\subsection{JUSTIFICATIVA}

\subsubsection{AVALIAÇÃO DOS SISTEMAS DE CONTROLE FLORESTAL}

Atualmente no Brasil existem sistemas computacionais que realizam o controle do Plano de Manejo Florestal Sustentável (PMFS), do licenciamento para desmate florestal e do transporte destes insumos e produtos. Na Tabela 1, são listados os sistemas utilizados em cada um dos estados da Amazônia Legal, de acordo com Chaves (2009).

Tabela 1- Estados e Sistemas de Controle florestais utilizados. Fonte: Chaves (2009).

\begin{tabular}{|l|l|l|l|}
\hline \multicolumn{4}{|c|}{ Amazônia Legal } \\
\hline Estado & PMFS & Desmate & Transporte \\
\hline MT & CEPROF & CEPROF & SISFLORA \\
\hline AC & SISPROF & Sistema Próprio & DOF \\
\hline AP & SISPROF & SISPROF & DOF \\
\hline AM & Sem sistema & Sem sistema & DOF \\
\hline MA & Sem sistema & Sem sistema & SISFLORA \\
\hline PA & CEPROF & CEPROF & SISFLORA \\
\hline RO & CEPROF & CEPROF & SISFLORA \\
\hline RR & SISPROF & SISPROF & DOF \\
\hline TO & Sistema Próprio & Sistema Próprio & DOF \\
\hline
\end{tabular}


Esta heterogeneidade de sistemas passou a tornar-se um problema para o controle e a fiscalização do processo. A falta de integrações mútuas e de padronizações das regras e convenções aplicadas nestes sistemas tornou difícil a fiscalização do PMFS, dos desmates e do transporte destes produtos. Além disso, estas falhas são utilizadas por criminosos para a exploração, transporte e consumo de produtos ilegais e na legalização de produtos (madeira, carvão e lenha) de origem inicialmente ilegal, por meio da manipulação dos créditos virtuais utilizados nestes sistemas (CHAVES, 2009), (IBAMA, 2009), (GLOBO AMAZÔNIA, 2009a), (FÓRUM BRASILEIRO DE SEGURANÇA PÚBLICA, 2009).

Outras falhas verificadas são em relação à segurança em alguns destes sistemas. No relatório publicado pelo GREENPEACE (GREENPEACE, 2009) foi constatado que o SISFLORA não é um sistema seguro, de acordo com as normas ISO/IEC 15408:2005, que trata dos critérios mínimos para avaliação de segurança da informação, ISO/IEC 17799:2005 e ISO/IEC 27001:2005, ambos sobre sistemas de gestão de segurança da informação. Já o DOF, teve seu sistema invadido por Hackers que falsificaram os registros on-line do sistema para aumentar a quantidade de madeira permitida para comercialização por 107 madeireiras e carvoarias do Pará (GREENPEACE, 2008b).

\subsubsection{EXIGÊNCIAS LEGAIS}

No dia 19 de Outubro de 2006 foi publicada a resolução 379/2006 (BRASIL, 2006b) que entre outras obrigações define a utilização de sistemas eletrônicos para o controle florestal, o uso de um padrão para os documentos de transporte florestal (que acompanham os produtos florestais no transporte entre as empresas da cadeia de suprimentos), a transparência de informações de rastreabilidade dos produtos florestais na WEB e a integração entre os diversos sistemas de controle florestal.

Até a realização desta pesquisa pouco foi realizado de concreto em relação a estas questões. Conforme Chaves (2009), as principais dificuldades para a integração destes sistemas são a carência de pessoas na área de informática, dificuldades tecnológicas (servidores, rede, etc.), padronização de nomenclaturas e a padronizações dos sistemas. 


\subsubsection{CERTIFICAÇÃO FLORESTAL}

Conforme o Instituto de Manejo e Certificação Florestal e Agrícola (IMAFLORA) (IMAFLORA, 2002), a certificação de um produto florestal exige, além da certificação da operação florestal (certificação de manejo florestal), a rastreabilidade da matéria-prima da floresta em todas as etapas de transformação do produto até o consumidor final, também chamada de cadeia de custódia. Os padrões para a certificação do Forest Stewardship Council (FSC) para a cadeia de custódia são baseados em 6 princípios:

1. Sistema de controle documentado;

2. Confirmação de entradas de matérias-primas;

3. Separação e/ou demarcação de entradas certificadas e não certificadas;

4. Rotulagem segura do produto;

5. Identificação da produção certificada;

6. Manutenção dos registros.

Com a utilização de um sistema de informação computacional eficiente para a rastreabilidade da cadeia de custódia, o gerenciamento destes produtos e a obtenção da certificação tornam-se mais simples e menos custosos, pois a identificação, a segregação e o registro das movimentações e transformações dos insumos e produtos, exigências da certificação, já são os princípios de um sistema de rastreabilidade.

\subsubsection{ASPECTOS DE MARKETING}

O mercado está cada vez mais exigente em relação aos benefícios sociais, ambientais e econômicos da compra de produtos florestais com origem legal. $\mathrm{Na}$ União Europeia esta tendência já é uma realidade. No Brasil, a procura aumenta a cada ano e, em um futuro próximo, tornar-se-á uma exigência do mercado. A manutenção das informações do processo produtivo destes produtos e a sua disponibilização para os consumidores será um crescente diferencial mercadológico. 
Conforme pesquisa realizada em Jacovine et al. (2006), onde foram identificadas as principais vantagens alcançadas com a certificação florestal em diversas empresas, foi constatado que a melhoria da imagem institucional foi o grande benefício alcançado, seguido da abertura de novos mercados e o aumento da demanda sobre seus produtos.

A melhoria da imagem empresarial, além de possibilitar uma grande contribuição para o marketing da empresa, possibilita uma diferenciação no mercado, por meio de uma imagem que demonstra os compromissos ambientais e sociais desta empresa perante a sociedade.

\subsubsection{FORNECIMENTO DE DADOS AO CONSUMIDOR}

A disponibilização de informações sobre a rastreabilidade dos produtos florestais aos seus clientes pode gerar um aumento significativo no seu valor agregado e possibilitar a sua entrada em novos mercados, restringidos a produtos com origem garantida, como por exemplo, em alguns países da União Europeia (UE). Com a Arquitetura Orientada a Serviços (SOA - Service Oriented Architecture) (OASIS, 2006), informações dos produtos rastreados poderão ser disponibilizadas na WEB por meio de serviços públicos que usarão, como fontes de informações e de serviços, dados das bases de dados dos sistemas responsáveis pela rastreabilidade do processo produtivo. Isto possibilitará ao consumidor final verificar a origem do produto antes mesmo da realização da sua compra.

Portais na Internet, aplicações embarcadas em dispositivos móveis (celulares, smartphones, pocket PCs) ou novos dispositivos eletrônicos, criados especificamente para esta finalidade, podem ser os meios para a consulta destas informações. 


\subsection{MATERIAIS E MÉTODOS}

A metodologia adotada no desenvolvimento da pesquisa seguiu as seguintes etapas:

- Revisão da literatura;

- Contatos com o setor produtivo e especialistas na área;

- Identificação dos componentes e serviços para gerenciamento da cadeia de custódia da madeira;

- Identificação dos padrões de metadados para troca de informações entre os sistemas envolvidos;

- Identificação de padrões de codificação de produtos e tecnologias para a aquisição dos dados;

- Construção de um protótipo para avaliação.

\subsubsection{PESQUISA BIBLIOGRÁFICA}

A primeira etapa da revisão da literatura consistiu no estudo do atual mercado nacional e internacional de produtos florestais, dos problemas existentes e das iniciativas e ações em andamento que buscam solucionar estes problemas. Estas pesquisas foram realizadas em diversos sites de órgãos governamentais, Organizações Não Governamentais (ONGs) e jornais. Posteriormente foi realizada uma revisão na literatura técnica nacional e internacional com foco no tema e nas áreas relacionadas. Para sistematizar este levantamento bibliográfico e a identificação dos estudos existentes nas áreas em questão, foram utilizados os conceitos de revisão sistemática da literatura.

Kitchenham (2004) introduziu este conceito na área de Tecnologia, método que já era utilizado em outras áreas de pesquisa, como a Medicina. Este conceito foi consolidado como uma forma de sumarizar evidências em uma área de interesse e verificar possíveis lacunas nas pesquisas desta área.

O processo de revisão sistemática utilizado nesta pesquisa se apoiou nas recomendações apresentadas por Biolchini et al. (2005), que sugere um processo de 
revisão sistemática em cinco fases: formulação da questão, seleção das fontes, seleção dos estudos, extração da informação e síntese dos resultados.

\subsubsection{DEFINIÇÃO DAS QUESTÕES DA PESQUISA}

$\mathrm{Na}$ área da rastreabilidade de produtos florestais, buscou-se identificar o cenário atual brasileiro, as soluções existentes e suas deficiências, bem como as principais necessidades e tendências na busca de melhorias neste processo. As seguintes questões foram levantadas em relação à pesquisa:

1. Quais os problemas existentes no controle da produção dos produtos florestais no Brasil e no mundo?

2. Quais as principais necessidades (legais e econômicas) que devem ser alcançadas com a utilização de um sistema de rastreabilidade de produtos florestais?

3. Quais são os serviços e padrões da indústria adequados para a especificação de uma Arquitetura Orientada a Serviços que possibilite a integração dos diversos sistemas envolvidos nesta cadeia de suprimentos?

4. Quais as abordagens têm sido utilizadas para a aquisição e análise das informações provenientes de uma cadeia de suprimentos de produtos florestais?

Baseado nestas perguntas identificou-se a questão foco da pesquisa como sendo:

"Quais são as deficiências das iniciativas existentes atualmente para o controle da rastreabilidade de produtos florestais, e como estas dificuldades podem ser resolvidas apoiando-se em um novo sistema, baseado em uma arquitetura orientada a serviços?" 


\subsubsection{SELEÇÃO DAS FONTES}

Foram realizadas buscas na língua portuguesa disponíveis em Jornais, entrevistas e sites de ONGs. Já na língua inglesa, foram utilizados os seguintes mecanismos de busca como fonte de pesquisa: IEEE Xplore ${ }^{1}$, Compendex ${ }^{2}$, Springer Link $^{3}$, Science Direct ${ }^{4}$ e $\mathrm{ACM}^{5}$. O critério utilizado para seleção de referências foi a relevância das bases de dados nas áreas de interesse da pesquisa, a possibilidade de acesso aos artigos completos e a facilidade destes mecanismos utilizarem palavras chaves e expressões booleanas nas suas pesquisas.

\subsubsection{SELEÇÃO DOS ESTUDOS}

Conforme a Tabela 2 foi utilizada as seguintes palavras-chave para a revisão sistemática da pesquisa:

Tabela 2- Palavras-Chave utilizadas na Revisão Sistemática da literatura.

\begin{tabular}{|l|l|}
\hline \multicolumn{2}{|c|}{ Pesquisas na Língua Inglesa } \\
\hline Categoria & Palavras-Chave \\
\hline Produtos Florestais & $\begin{array}{l}\text { "wood", "timber", "logging", "forestry", "traceability", "wood chain", } \\
\text { "manufacturing chain" }\end{array}$ \\
\hline Certificação Florestal & $\begin{array}{l}\text { "FSC", "product certification", "forest stewardship council", "CoC", "Chain } \\
\text { of Custody" }\end{array}$ \\
\hline $\begin{array}{l}\text { Tecnologia \& } \\
\text { Produção }\end{array}$ & "SOA", "ESB", "web services", "RFID", "EAN", "GS1", "XML", "patterns" \\
\hline \multicolumn{1}{|c|}{ Pesquisas na Língua Portuguesa } \\
\hline Categoria & Palavras-Chave \\
\hline Produtos Florestais & $\begin{array}{l}\text { "madeira", "desmatamento", "rastreabilidade", "Cadeia Produtiva da } \\
\text { Madeira", "IBGE", "Produtos Florestais", "Manejo Florestal" }\end{array}$ \\
\hline Certificação Florestal & $\begin{array}{l}\text { "FSC", "certificação florestal", "Conselho Brasileiro de Manejo Florestal", } \\
\text { "Cadeia de Custódia", "IMAFLORA", "IMAZON", "IPAAM", } \\
\text { "GREENPEACE", "IPAM", "IBAMA", "SEMA" }\end{array}$ \\
\hline $\begin{array}{l}\text { Tecnologia \& } \\
\text { Produção }\end{array}$ & $\begin{array}{l}\text { "DOF", "SISFLORA", "Documento de Origem Florestal", "DETER", } \\
\text { "PRODES" }\end{array}$ \\
\hline
\end{tabular}

\footnotetext{
${ }^{1}$ http://ieeexplore.ieee.org/search/advsearch.jsp

${ }^{2}$ http://www.engineeringvillage.com

${ }^{3}$ http://www.springerlink.com/home/main.mpx

${ }^{4}$ http://www.sciencedirect.com/

${ }^{5}$ http://portal.acm.org/dl.cfm
} 
Para a validação e definição dos principais termos utilizados nas pesquisas, foram realizadas inicialmente buscas utilizando-se de expressões simples para a verificação da quantidade e relevância do conteúdo resultante. Posteriormente, com a confirmação das palavras-chave mais adequadas, foram criadas expressões compostas que abrangem todo, ou boa parte, do assunto que se deseja realizar a revisão. Abaixo, duas das expressões criadas:

\section{Expressão para levantamento bibliográfico das abordagens de gerenciamento da cadeia produtiva da madeira:}

("traceability" OR "supply chain" OR "control" OR "'management") AND ("forestry" OR "wood" OR "logging" OR "forest" OR "timber") AND ( "model" OR "method" OR "architecture" OR "system" OR "process" OR "approach")

\section{Expressão para levantamento bibliográfico das abordagens e iniciativas de certificação do processo produtivo e dos produtos finais derivados da madeira:}

("certification") AND ("wood" OR "timber" OR "forestry" OR "forest")

Foi verificado que documentos técnicos na área de rastreabilidade de produtos florestais são escassos, sendo a maioria das pesquisas na área de rastreabilidade de produtos voltada para as áreas alimentícia e agropecuária. Por isso, foram realizadas buscas menos específicas para se localizar documentos nas diversas áreas relacionadas que fossem relevantes para a presente pesquisa.

Já os dados referentes ao processo produtivo florestal no Brasil, problemas de desmatamento ilegal e análise dos sistemas computacionais existentes foram levantados em relatórios e demais publicações de órgãos governamentais, ONGs e de empresas de certificação florestal, além de sites de notícias e jornais. Também foi verificada a escassez de documentos técnicos na área florestal que detalhassem estes informações. 


\subsubsection{CONTATOS COM O SETOR PRODUTIVO E ESPECIALISTAS NA ÁREA}

Foram realizadas reuniões com pelo menos uma empresa, de cada uma das etapas produtivas da madeira, para que fossem levantados os requisitos para o modelo proposto.

Inicialmente foi realizado o contato com o Prof. Dr. Edson Vidal, do Departamento de Ciências Florestais da Escola Superior de Agricultura "Luiz de Queiroz" (ESALQ), que realiza pesquisas na área de silvicultura. Também foi realizado o contato com o Sr. Gerson Leme, gerente técnico da empresa Honeywell Scanning \& Mobility, com escritórios no Brasil nas cidades de São Paulo e Rio de Janeiro, líder mundial no fornecimento de soluções em coleta de dados e comunicação wireless.

\subsubsection{IDENTIFICAÇÃO DOS COMPONENTES E SERVIÇOS PARA GERENCIAMENTO DA CADEIA DE SUPRIMENTOS DA MADEIRA}

Inicialmente, por meio das entrevistas com empresas do setor produtivo e especialistas, foi realizada a modelagem da cadeia de suprimentos dos produtos florestais madeireiros.

Posteriormente foi realizada a identificação e a modelagem dos serviços e componentes que fazem parte da arquitetura proposta. Este modelagem foi baseada no modelo de referência para Arquitetura Orientada a Serviços definido pela Organization for the Advancement of Structured Information Standards (OASIS) (OASIS, 2006) e o processo de modelagem deste sistema foi baseado no método apresentado em Endrei et al. (2004), que define boas práticas para a implementação de soluções de software usando este paradigma.

\subsubsection{IDENTIFICAÇÃO DOS PADRÕES DE METADADOS PARA TROCA DE INFORMAÇÕES ENTRE OS SISTEMAS ENVOLVIDOS}

Foram analisados padrões de metadados utilizados na área florestal e em 
áreas relacionadas para que fossem identificados os mais adequados para a troca de informações entre os sistemas envolvidos na produção e monitoramento de produtos florestais. Os principais padrões de metadados analisados foram: o AgroXML (KUNISCH et al., 2009), criado para a troca de dados entre sistemas agrícolas, o PAPINET (PAPINET, 2003), criado para a indústria de papel e celulose e o e-Forestry (OASIS, 2009), criado pela OASIS para a troca de dados na indústria florestal.

\subsubsection{IDENTIFICAÇÃO DOS PADRÕES PARA CODIFICAÇÃO DE PRODUTOS E TECNOLOGIAS PARA AQUISIÇÃO DOS DADOS}

Foram analisados e identificados os padrões de codificação de produtos e as tecnologias de aquisição dos dados que mais se adéquam ao processo produtivo de produtos florestais e como os mesmos poderiam ser aplicados.

Neste trabalho foram considerados apenas os padrões de codificação para identificação de produtos definidos pelo sistema GS1 (GS1, 2009), por ser o conjunto de normais e padrões mais utilizado em sistemas de gerenciamento de cadeias de suprimentos no mundo.

As tecnologias para identificação e aquisição de dados que foram analisadas se limitaram às que possibilitam a leitura de dados de forma eletrônica, como as baseadas em códigos de barras e Radio Frequency Identification (RFID) (KORTEN; KAUL, 2008).

\subsubsection{DESENVOLVIMENTO DE UM PROTÓTIPO PARA AVALIAÇÃO}

Foi desenvolvido, a partir da modelagem proposta, um protótipo de sistema de informação para avaliação dos resultados. Estes resultados forneceram subsídios para a continuidade e evolução deste trabalho. 


\section{REVISÃO DA LITERATURA}

O desenvolvimento do presente trabalho iniciou-se com o levantamento bibliográfico sobre o tema, que foi dividido entre os diversos tópicos a serem considerados.

- Indústria Madeireira no Brasil

- Rastreabilidade e suas aplicações

- Rastreabilidade de produtos florestais

- Certificação Florestal

- Padrões para identificação de produtos

- Tecnologias para aquisição de dados

- Padrões de metadados para troca de informações

- Arquitetura Orientada a Serviços

\subsection{INDÚSTRIA MADEIREIRA NO BRASIL}

O Brasil está entre os grandes produtores e consumidores de produtos florestais do mundo. Em 2007, segundo dados da FAO (FAO, 2009), o mercado mundial de produtos florestais alcançou aproximadamente 229 bilhões de dólares. Este valor inclui tanto produtos madeireiros como não madeireiros (frutos, sementes, fibras, etc.) a partir de matérias-primas extraídas tanto de florestas nativas como florestas plantadas. Conforme a Tabela 3, o Brasil ocupa a $10^{\mathrm{a}}$ colocação, chegando ao número de US\$7,2 bilhões em exportações no ano de 2007.

Tabela 3- Os 20 principais exportadores mundiais de produtos florestais em 2006-2007. Fonte: FAO (2009).

\begin{tabular}{|l|c|c|}
\hline \multicolumn{1}{|c|}{ País } & $\begin{array}{c}\text { Valores Exportados em } \\
\text { 2006 (em milhares de } \\
\text { dólares) }\end{array}$ & $\begin{array}{c}\text { Valores Exportados em } \\
\text { 2007 (em milhares de } \\
\text { dólares) }\end{array}$ \\
\hline Canada & $28.222 .864,00$ & $26.250 .342,00$ \\
Germany & $18.379 .958,00$ & $20.995 .879,00$ \\
United States of America & $18.481 .541,00$ & $20.899 .163,00$ \\
Sweden & $14.552 .528,00$ & $16.591 .883,00$
\end{tabular}




\begin{tabular}{|lrr|} 
Finland & $14.342 .817,00$ & $15.895 .730,00$ \\
Russian Federation & $8.739 .661,00$ & $11.231 .175,00$ \\
China & $8.874 .014,00$ & $10.788 .695,00$ \\
France & $7.699 .409,00$ & $8.615 .128,00$ \\
Austria & $6.649 .247,00$ & $8.383 .536,00$ \\
Brazil & $\underline{5.618 .474,00}$ & $\underline{7.186 .667,00}$ \\
Indonesia & $6.169 .814,00$ & $6.572 .861,00$ \\
Belgium & $5.632 .656,00$ & $5.793 .381,00$ \\
Italy & $4.785 .429,00$ & $5.521 .357,00$ \\
Netherlands & $4.030 .448,00$ & $4.725 .044,00$ \\
Spain & $4.014 .447,00$ & $4.596 .972,00$ \\
Chile & $3.134 .401,00$ & $4.260 .573,00$ \\
Malaysia & $4.034 .716,00$ & $4.033 .622,00$ \\
United Kingdom & $2.780 .947,00$ & $3.273 .306,00$ \\
Japan & $2.581 .402,00$ & $2.898 .991,00$ \\
\hline
\end{tabular}

Conforme o Instituto Brasileiro de Geografia e Estatística (IBGE) (IBGE, 2009), os dados apurados pela pesquisa de Produção de Extração Vegetal e Silvicultura 2008, a última realizada pelo instituto até a revisão deste documento, mostrou que a produção florestal do país somou $\mathrm{R} \$ 12,7$ bilhões no ano, onde 69,3\% (R\$ 8,8 bilhões) são provenientes do segmento da silvicultura (exploração de florestas plantadas) e 30,7\% (R\$ 3,9 bilhões) do extrativismo vegetal.

No segmento do extrativismo vegetal, a produção madeireira totalizou $R \$ 3,3$ bilhões, enquanto que o valor da extração vegetal não madeireira contabilizou apenas $\mathrm{R} \$ 635,7$ milhões.

Os principais produtos não madeireiros que se destacam em funções dos valores de suas produções são os coquilhos de açaí ( $R$ \$ 133,7 milhões), as amêndoas de babaçu ( $R$ \$115,6 milhões), e fibras de piaçava ( $R$ \$ 104,1 milhões).

A Tabela 4 mostra que a maior parte da madeira em tora produzida $(87,8 \%)$ foi proveniente de florestas cultivadas e o restante $(12,2 \%)$ coletado em vegetações nativas. Este número é $13,8 \%$ menor que o registrado em 2007, que já havia sido considerado o menor número já registrado de extração de madeira nativa desde o ano de 2000 (VILLELA, 2008). Sendo que existem algumas contestações sobre estes resultados. 
Tabela 4- Quantidade produzida e variação percentual dos produtos da extração vegetal e da silvicultura - Brasil - 2007-2008. Fonte: IBGE (2009).

\begin{tabular}{|c|c|c|c|}
\hline \multirow{2}{*}{ Produtos } & \multicolumn{2}{|c|}{ Quantidade Produzida (t) } & \multirow{2}{*}{ Variação (\%) } \\
\hline & 2007 & 2008 & \\
\hline \multicolumn{4}{|l|}{ Extração Vegetal } \\
\hline \multicolumn{4}{|l|}{ Madeiras } \\
\hline Carvão Vegetal & 2.530 .425 & 2.221 .990 & $-12,2$ \\
\hline Lenha (1) & 43.910 .054 & 42.117 .639 & $-4,1$ \\
\hline Madeira em Tora (1) & 16.388 .609 & 14.127 .359 & $-13,8$ \\
\hline \multicolumn{4}{|l|}{ Pinheiro Brasileiro } \\
\hline Nó-de-pinho (1) & 9.656 & 9.138 & $-5,4$ \\
\hline Árvores Abatidas (2) & 60 & 50 & $-16,7$ \\
\hline Madeira em Tora (1) & 125.118 & 90.648 & $-27,5$ \\
\hline \multicolumn{4}{|l|}{ Oleaginosos } \\
\hline Babaçu (amêndoa) & 114.874 & 110.636 & $-3,7$ \\
\hline \multicolumn{4}{|l|}{ Alimentícios } \\
\hline Açaí (fruto) & 108.033 & 120.890 & 11,9 \\
\hline \multicolumn{4}{|l|}{ Fibras } \\
\hline Piaçava & 82.096 & 78.167 & $-4,8$ \\
\hline \multicolumn{4}{|l|}{ Silvicultura } \\
\hline Carvão Vegetal & 3.806 .044 & 3.975 .393 & 4,4 \\
\hline Lenha (1) & 39.089 .275 & 42.037 .848 & 7,5 \\
\hline Madeira em Tora & 105.131 .741 & 101.261.900 & $-3,7$ \\
\hline Para papel e celulose (1) & 60.964 .307 & 58.181 .842 & $-4,6$ \\
\hline Para outras finalidades (1) & 44.167 .434 & 43.080 .058 & $-2,5$ \\
\hline
\end{tabular}

(1) Quantidade declarada em $\mathrm{m}^{3}$. (2) Quantidade em 1000 árvores.

O Instituto Nacional de Pesquisas Espaciais (INPE) apontou aumento do desmatamento da Amazônia no segundo semestre de 2007. Esta divergência dos dados é justificada em decorrência do levantamento do IBGE não contemplar a extração de madeira ilegal, pois são pesquisadas apenas empresas legalizadas, regularizadas na Receita Federal (SOALHEIRO, 2008).

Apesar disso, dados mais recentes do INPE mostram que está ocorrendo verdadeiramente uma diminuição gradativa do desmatamento na Amazônia e, no ano de 2009, foi registrado o menor índice de desmatamento $\left(7.008 \mathrm{~km}^{2}\right)$ desde o início da utilização do PRODES ${ }^{6}$ (Projeto de Monitoramento de Desflorestamento na

\footnotetext{
${ }^{6}$ Desde 1988, o INPE utiliza o PRODES para estimar a taxa anual do desmatamento por corte raso, quando ocorre a retirada total da cobertura vegetal. Sendo que este sistema não registra as derrubadas parciais da floresta resultantes de queimadas e da extração seletiva de madeira. São utilizas imagens de satélite e sua margem de erro é de mais ou menos 10\%. Mais informações em http://www.obt.inpe.br/prodes/.
} 
Amazônia Legal) (PORTAL ECODEBATE, 2009). As Figuras 1 e 2 mostram a distribuição da intensidade do desmatamento nas cenas do satélite Landsat, utilizadas pelo PRODES, para o cálculo das taxas, em 2008 e 2009.

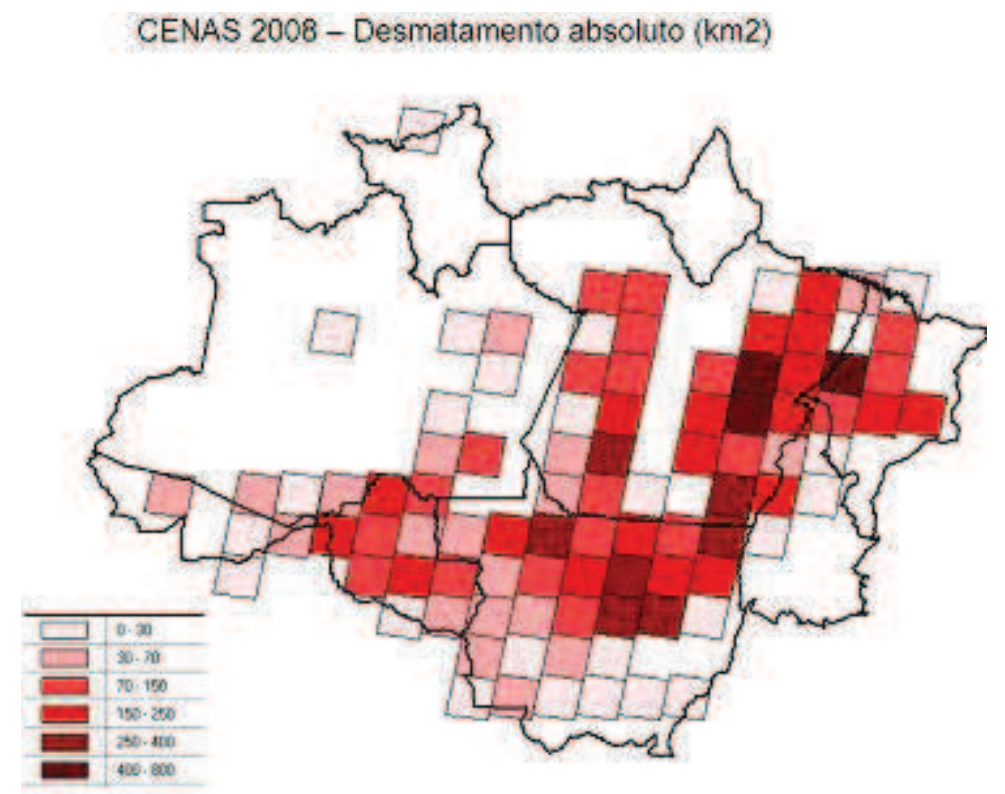

Figura 1 - Imagem de Satélite demonstrando a intensidade do desmatamento da Amazônia no ano de 2008. Fonte: PORTAL ECODEBATE (2009).

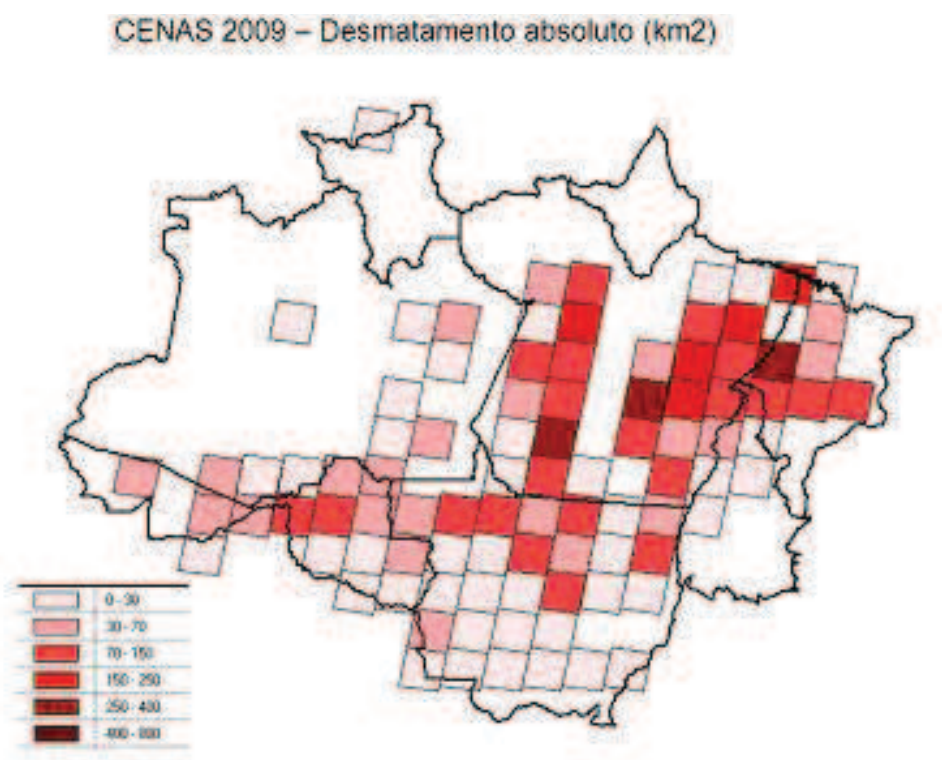

Figura 2 - Imagem de Satélite demonstrando a intensidade do desmatamento da Amazônia no ano de 2009. Fonte: PORTAL ECODEBATE (2009).

Dentre os estados que contemplam a Amazônia Legal e fazem parte da 
análise do PRODES, os estados do Pará, Mato Grosso e Maranhão respectivamente, possuem as maiores taxas de desmatamento em 2009. Na Tabela 5 é detalhada a evolução das áreas de desmatamento por estado de 2001 a 2009.

Tabela 5 - Desmatamento por estado na Amazônia Legal no período de 2001-2009. Fonte: INPE (2009).

\begin{tabular}{|c|c|c|c|c|c|c|c|c|c|}
\hline Estados\Ano & 2001 & 2002 & 2003 & 2004 & 2005 & 2006 & 2007 & 2008 & 2009 \\
\hline Acre & 419 & 883 & 1078 & 768 & 592 & 398 & 184 & 254 & 211 \\
\hline Amazonas & 634 & 885 & 1558 & 1232 & 775 & 788 & 610 & 604 & 406 \\
\hline Amapá & 7 & 0 & 25 & 46 & 33 & 30 & 39 & 100 & - \\
\hline Maranhão & 958 & 1014 & 993 & 755 & 922 & 651 & 613 & 1272 & 980 \\
\hline Mato Grossc & 7703 & 7892 & 10405 & 11814 & 7145 & 4333 & 2678 & 3258 & 1047 \\
\hline Pará & 5237 & 7324 & 6996 & 8521 & 5731 & 5505 & 5425 & 5606 & 3687 \\
\hline Rondônia & 2673 & 3099 & 3597 & 3858 & 3244 & 2049 & 1611 & 1136 & 505 \\
\hline Roraima & 345 & 84 & 439 & 311 & 133 & 231 & 309 & 574 & 116 \\
\hline Tocan & 189 & 212 & 156 & 158 & 271 & 124 & 63 & 107 & 56 \\
\hline Amazônia & 3165 & 30 & 22 & 463 & 18846 & 14109 & 037 & 12911 & 08 \\
\hline
\end{tabular}

Apesar da diminuição na taxa de desmatamento de 2009, que compreendeu dados do período entre agosto de 2008 a junho de 2009, foi verificado na soma dos meses de junho e julho de 2009 um aumento de 18,5\% no desmatamento em relação ao mesmo período de 2008, o que pode sinalizar uma inversão da curva de desmatamento. A maior parte do desmatamento foi detectada no Pará $(47 \%$ do total). Estes dados são do sistema DETER ${ }^{7}$ (Detecção de Desmatamento em Tempo Real), que também é utilizado pelo INPE (CPTEC, 2009).

Outros fatores preocupantes, descritos pelo Instituto de Pesquisa Ambiental da Amazônia (IPAM), é que parte da queda nas taxas de desmatamento é explicada pela baixa nos preços das commodities ${ }^{8}$ e pela crise econômica mundial, que deve perder força em 2010 (IPAM, 2009). Outra preocupação é que entre os principais

\footnotetext{
${ }^{7}$ Desde 2004, o INPE utiliza o sistema DETER para realizar um levantamento rápido mensal, com dados do sensor MODIS do satélite Terra/Aqua e do sensor WFI do satélite CBERS. O DETER foi desenvolvido como um sistema de alerta para suporte a fiscalização e controle de desmatamento. O mesmo utiliza imagens de baixa resolução e só identifica áreas desmatadas maiores que 25 hectares, além de possuir restrições com cobertura de nuvens. Mais informações em http://www.obt.inpe.br/deter/.

${ }^{8}$ Commodities é um termo utilizado nas bolsas de mercadorias para referenciar produtos de base (matériasprimas) ou com pequeno grau de industrialização. Estes produtos de base são importantes na economia por possuírem cotações globais, e suas oscilações de cotações tem impacto significativo nos fluxos financeiros mundiais.
} 
exportadores de madeira apenas a Indonésia e a Malásia, além do Brasil, possuem parte da sua produção baseada em florestas tropicais. Porém, devido à exploração predatória e não manejada nestes dois países os seus estoques de madeira estão rapidamente se esgotando. Desta forma, o Brasil tende a ser pressionado em um futuro próximo para aumentar suas exportações de madeira provenientes da Amazônia (LENTINI, 2009).

\subsection{RASTREABILIDADE}

Gryna (1992) define a rastreabilidade como a capacidade de preservar a identidade dos produtos e suas origens. Tendo como principais características:

- Garantir que somente materiais e componentes de qualidade estejam presentes no produto final.

- Melhor alocar as responsabilidades.

- Identificar produtos que são distintos, porém podem ser confundidos.

- Possibilitar o retorno de produtos com defeitos ou suspeitos.

- Localizar as causas de falhas e tomar medidas para repará-las ao menor custo possível.

Aplicada a uma cadeia de suprimentos, a rastreabilidade pode ser definida também como um processo de práticas sistemáticas de segregação física e troca de informações entre diferentes agentes da cadeia, responsáveis pela execução e cumprimento de uma meta específica, com a finalidade de preservar os atributos e a identidade de produtos transacionados de acordo com suas especificações (MACHADO, 2000).

A rastreabilidade de um produto pode ser realizada de duas formas, no sentido para frente (forward) e no sentido para trás (backward) (JANSEN-VULLERS; VAN DORP; BEULENS, 2003). A rastreabilidade forward indica o que aconteceu com determinado produto na sequência da sua cadeia produtiva, como por exemplo, quais produtos foram produzidos utilizando um determinado lote de matéria-prima. Já a rastreabilidade backward indica informações do passado de um produto, como por exemplo, qual a origem das matérias-primas que compõem determinado produto 
ou quais transformações este produto sofreu durante sua produção.

\subsubsection{APLICAÇÕES DE RASTREABILIDADE}

Devido à busca contínua de um maior controle dos processos produtivos e de uma maior qualidade dos produtos, pesquisas sobre a aplicação dos conceitos de rastreabilidade estão sendo realizadas em diversas áreas. Estes estudos buscam o desenvolvimento de modelos eficientes de rastreabilidade, que considerem as características específicas de cada um destes produtos. Bassani (2002) apresenta um modelo de rastreabilidade para produtos derivados de suínos, em Sobrinho (2008) é apresentado um sistema de informação para a rastreabilidade na indústria vinícola, no Ceruti (2007) um estudo sobre a aplicação dos conceitos de rastreabilidade na indústria de grãos e em Golan et al. (2004), produzido pelo Departamento de Agricultura dos Estados Unidos, são apresentadas considerações sobre a rastreabilidade no mercado alimentício norte-americano, principalmente em relação ao consumo de carne.

\subsection{RASTREABILIDADE DE PRODUTOS FLORESTAIS}

\subsubsection{SISTEMAS DE RASTREABILIDADE FLORESTAL NO BRASIL}

\subsubsection{DOF}

O Documento de Origem Florestal (DOF), instituído pela Portaria MMA nº. 253, de 18 de agosto de 2006, é um documento eletrônico de controle de produtos florestais, gerido por meio de um sistema informatizado com um banco de dados centralizado (IBAMA, 2006a).

Desde o dia $1^{\circ}$ de Setembro de 2006, o DOF passou a ser o novo sistema eletrônico do IBAMA para o controle de transporte e armazenamento de produtos e subprodutos florestais de origem nativa em substituição a Autorização de Transporte de Produtos Florestais (ATPF), que deixaram de ser emitidas por terem se transformado em um instrumento de fraudes e crimes ambientais (IBAMA, 2006a).

A lista de produtos e subprodutos florestais que necessitam da licença DOF 
para circular no país por via aérea, rodoviária, ferroviária, fluvial e marítima inclui madeira em tora, madeira serrada, estacas, moirões, toretes, postes não imunizados, lenha, carvão vegetal nativo, xaxim, palmito e carvão de resíduos da indústria madeireira, entre outros ambientais (IBAMA, 2006a) (BRASIL, 2006a).

O processo e as regras para a utilização deste sistema para o transporte de produtos florestais são detalhados nos documentos do IBAMA (2006b) e Fundação do Meio Ambiente (2006).

Este sistema é utilizado por grande parte dos estados brasileiros, com exceção do Pará, Mato Grosso e Rondônia, que utilizam o SISFLORA, do Ceará, que utiliza o DOF-CE, e de Minas Gerais, que não possui sistema para controle de transporte de produtos florestais (CHAVES, 2009).

\subsubsection{SISFLORA}

O Sistema de Cadastro, Comercialização e Transporte de Produtos Florestais (SISFLORA), do estado do Mato Grosso, foi elaborado por meio de análises de documentos e entrevistas com técnicos do SEMA e do IBAMA no Mato Grosso, com a empresa Tecnomapas e com o setor madeireiro do estado. O SISFLORA é um sistema eletrônico que controla a comercialização e o transporte de produtos e subprodutos florestais no Estado do Mato Grosso. Posteriormente, ele também foi adotado pelos estados do Pará, Rondônia e Maranhão. Este último, no ano de 2009, entrou em processo de substituição do seu sistema de controle pelo DOF, devido o grande número de fraudes descobertas desde 2007 (SEMA, 2009).

O processo e as regras para a utilização deste sistema para o transporte de produtos florestais são detalhados no documento SEMA (2008).

\subsubsection{SISTEMAS DE RASTREABILIDADE FLORESTAL NO MUNDO}

Neste tópico são apresentados dois sistemas internacionais de rastreabilidade e gerenciamento de cadeias de suprimentos da madeira. Estes sistemas utilizam conceitos e tecnologias relevantes a presente pesquisa, como o Global Positioning System (GPS) (GISDEVELOPMENT, 2009), o RFID (KORTEN; KAUL, 2008) e os códigos de barra, para o apoia a aquisição dos dados. Além disso, os sistemas 
foram testados e implantados em vários países exportadores de madeira. Por isso, seu estudo tem grande relevância para a presente pesquisa.

\subsubsection{CI WORLD $^{\mathrm{TM}}$ FOR TIMBER}

Este tópico utiliza como referência informações do produto $\mathrm{Cl}$ World $^{\mathrm{TM}}$, da empresa Helveta [http://corporate.helveta.com/ci-world-for-timber.html].

O $\mathrm{Cl}$ World $^{\mathrm{TM}}$ é uma plataforma de software, desenvolvido pela empresa Helveta [http://www.helveta.com], para a rastreabilidade e gerenciamento de cadeias de suprimentos nos setores florestais e alimentícios. Esta plataforma é composta pelos sistemas $\mathrm{Cl}$ Earth $^{\mathrm{TM}}, \mathrm{Cl}$ Audit $\mathrm{Cl}^{\mathrm{TM}}, \mathrm{Cl}^{\text {Control }^{\mathrm{TM}} \text { e } \mathrm{Cl} \text { Mobile }}{ }^{\mathrm{TM}}$.

$\mathrm{O} \mathrm{Cl}$ Earth $^{\mathrm{TM}}$ é uma aplicação cartográfica interativa utilizada para criar mapas de inventários florestais, em um ambiente on-line, acessível por todos os usuários registrados. Os dados são capturados utilizando-se o $\mathrm{Cl}$ Mobile $^{\mathrm{TM}}$, um Personal Digital Assistant (PDA) que utiliza um software de captura de dados, que combina as entradas manuais de dados com dados de GPS, RFID e leitores de código de barras. Devido à possibilidade de configuração das informações visíveis, os usuários desta aplicação podem variar de responsáveis pelo processo de exploração da madeira, passando por órgãos do governo ou ONGs.

$\mathrm{O} \mathrm{Cl}$ Audit $^{\mathrm{TM}}$ permite que usuários investiguem possíveis problemas com as madeiras controladas no $\mathrm{Cl}$ World $^{\mathrm{TM}}$. Estes problemas, quando percebidos, geram alertas de não conformidade no sistema, que oferece à administração e aos auditores uma ferramenta para validação on-line. Com base em uma especificação de regras e parâmetros, o sistema utiliza um motor de regras para analisar os dados recebidos pelo sistema e gerar alertas de possíveis problemas ou de dados inconsistentes.

Por último, o $\mathrm{Cl}$ Control $^{\mathrm{TM}}$ permite o controle automatizado do inventário, do gerenciamento da produção e da rastreabilidade, por toda a cadeia de suprimentos. Este sistema é o módulo de emissão de relatórios dentro do $\mathrm{Cl}$ World $^{\mathrm{TM}}$, e fornece a cada usuário sua própria visão, conforme as suas atividades atribuídas dentro do sistema. 


\subsubsection{TRACELITE - ALWAYS ON ${ }^{\mathrm{TM}}$}

O TracElite - Always $\mathrm{On}^{\mathrm{TM}}$ foi desenvolvido pela Helveta [http://www.helveta.com] em parceria com a Tropical Forest Trust (TFT) (TFT, 2009a). Neste produto, os componentes já existentes do $\mathrm{Cl}$ World $^{\mathrm{TM}}$ foram configurados para se adequarem a regras de negócio envolvendo comunidades locais, boas práticas para o rastreamento de madeira e possibilitar a produção legalizada e sustentável destes produtos.

A TFT foi fundada em 1999, e é uma organização internacional sem fins lucrativos focada na solução dos problemas de desmatamento, trabalhando com empresas e comunidades e ajudando-as a realizar uma atividade florestal responsável. A TFT trabalha em cadeias de suprimentos com o objetivo de criar um sistema de rastreabilidade que possa ajudar os produtores a realizarem uma gestão sustentável das florestas (TFT, 2009b).

\subsection{CERTIFICAÇÃO FLORESTAL}

A certificação florestal é um mecanismo de controle, não governamental e voluntário, pelo qual se atestam determinadas características do manejo praticado por uma operação florestal (IMAFLORA, 2009).

Várias são as iniciativas de sistemas de certificação florestal em nível nacional, como por exemplo, o Programa Brasileiro de Certificação Florestal (CERFLOR), do Brasil; o Sustainable Forest Management Program (CSA), do Canadá; e o American Tree Farm System (ATFS), dos Estados Unidos. Já em nível global destacam-se o Forest Stewardship Council (FSC) e o Program for the Endorsement of Forest Certification Schemes (PEFC) (REZENDE; AMARAL, 2006).

A presente pesquisa será focada na certificação FSC, que hoje é o selo verde mais reconhecido em todo o mundo, com presença em mais de 75 países e em todos os continentes (WORLD WILDLIFE FUND, 2009).

Em Rezende \& Amaral (2006) é apresentada uma avaliação comparativa dos principais sistemas de certificação florestal.

Os próximos tópicos sobre certificação florestal utilizarão como referência o Manual de Certificação de Cadeia de Custódia no Sistema Forest Stewardship 
Council - FSC (IMAFLORA, 2002).

\subsubsection{TIPOS DE CERTIFICAÇÃO FLORESTAL}

Existem duas modalidades de certificação implementadas pelos órgãos credenciados pela FSC: a certificação do manejo florestal, na qual certifica operações de manejo florestal que cumprem com os Princípios e Critérios do FSC, e a certificação de cadeia de custódia ( $\mathrm{CoC}$ ), na qual certifica as indústrias que processam e vendem produtos florestais, rastreando a matéria-prima desde a floresta até o consumidor.

\subsubsection{CERTIFICAÇÃO DE CADEIA DE CUSTÓDIA}

Para que produtos elaborados com matéria-prima florestal possam utilizar o selo da FSC, os mesmos devem ser rastreados em todo o seu processo produtivo, da extração madeireira e seu transporte até a venda para o consumidor final, passando por todas as etapas de confecção do produto. Este processo visa assegurar que os materiais certificados não se misturem com materiais não certificados. A verificação deste rastreamento é realizada de forma independente por um certificador credenciado pelo FSC e é conhecido como certificação de cadeia de custódia (CoC). Na Figura 3, é representada uma cadeia de custódia da madeira. 


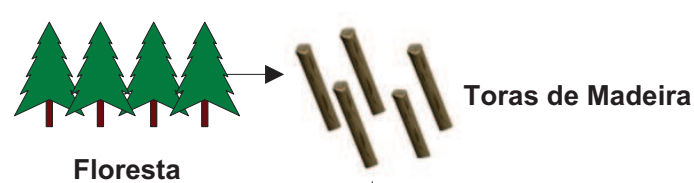

Floresta

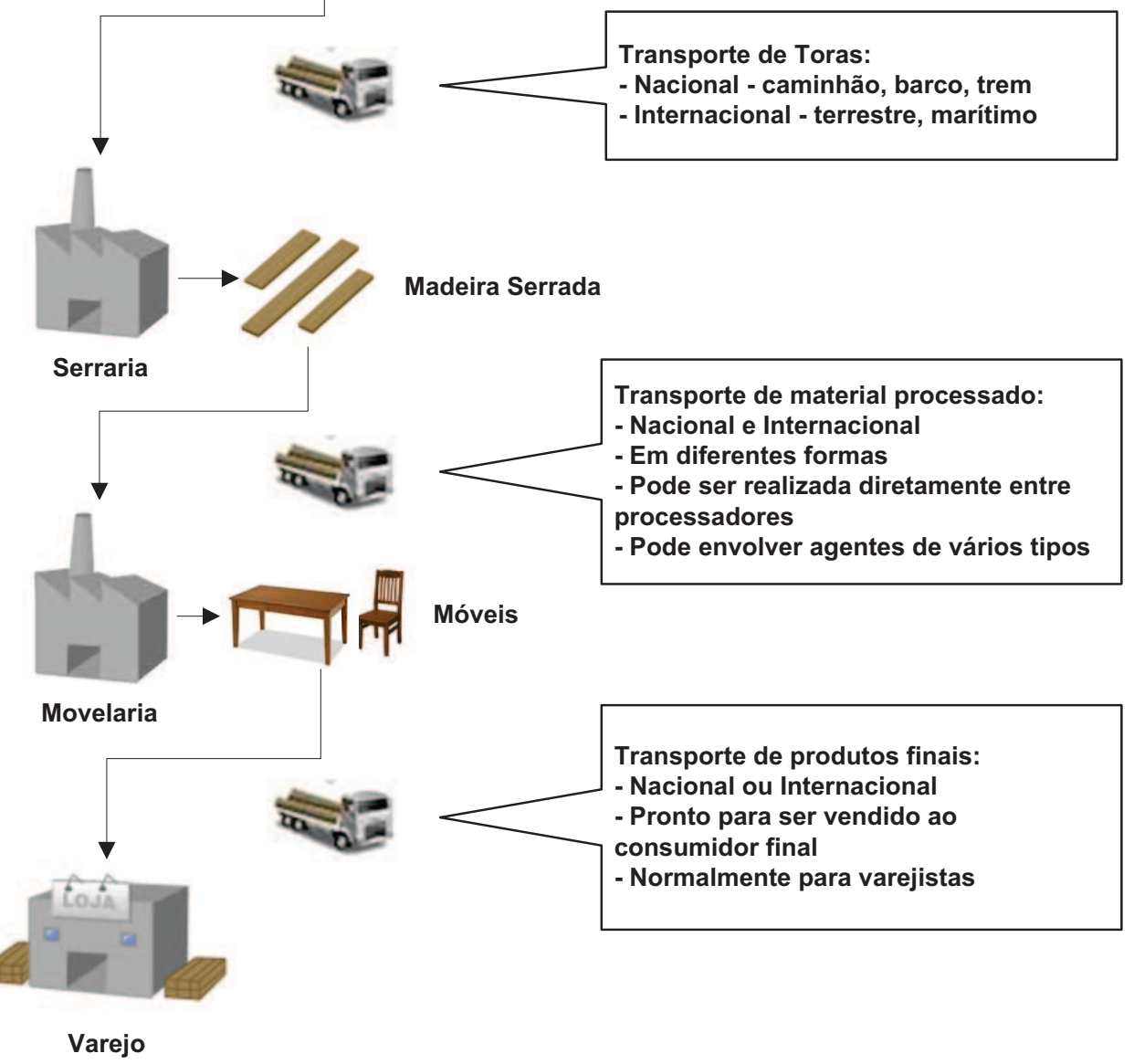

Figura 3 - Representação da cadeia de custódia da madeira, mostrando os estágios de um processo típico. As caixas à direita descrevem os movimentos dos materiais entre seus estágios de processamento. Fonte: Extraído e adaptado de Dykstra et al. (2002).

\subsection{PADRÕES PARA IDENTIFIÇÃO DE PRODUTOS}

\subsubsection{SISTEMA GS1}

O sistema GS1 oferece ferramentas de identificação e comunicação padronizadas e reconhecidas internacionalmente, que facilitam as operações automatizadas, são elas [http://gs1 brasil.org.br]:

1. Estruturas de dados padronizadas e reconhecidas internacionalmente, numerações exclusivas para identificação de itens comerciais denominados Números Globais de Itens Comerciais (GTINS) e podem ser de quatro tipos: GTIN-13, GTIN-8, GTIN-12 e GTIN-14. Há ainda identificadores de aplicação GS1, que identificam dados para a 
rastreabilidade de itens, como datas, números de série, número do lote.

2. Suporte a padrões para captura automática de dados (código de barras): EAN/UPC (GTIN-13, GTIN-8, UPC-A, UPC-E), ITF-14 e GS1-128. Estes padrões tratam da representação dos caracteres nos diferentes tipos de código de barras. Isto permite a interpretação das barras por equipamentos de leitura óticos.

3. Mensagens estruturadas para EDI (troca eletrônica de dados): UN/EDIFACT - EANCOM.

Mais informações sobre os padrões do sistema GS1 podem ser consultadas no GS1 (2009).

\subsubsection{SOLUÇÕES GS1}

Com a parceria entre a GS1 Brasil e empresas de diversos setores da indústria e comércio, foram criados guias de codificação com os padrões e melhores práticas para a automação destes processos.

Um destes guias é o Guia de codificação do setor moveleiro (GS1 BRASIL, 2009) que têm como objetivo demonstrar meios para a integração das operações de gestão de materiais e suprimentos das indústrias, tanto internamente, quanto com seus parceiros comerciais, por meio da implementação de código de barras e do comércio eletrônico, baseado em padrões internacionalmente aceitos.

\subsection{TECNOLOGIA PARA AQUISIÇÃO DE DADOS}

\subsubsection{ETIQUETAS DE CÓDIGO DE BARRAS}

Etiquetas são dispositivos físicos para armazenamento de informações. Vários padrões e protocolos foram definidos para o armazenamento de informações nestes formatos físicos, que possibilitam sua leitura eletronicamente. 


\subsubsection{CÓDIGO DE BARRAS UNIDIMENSIONAL}

Códigos de barra são padrões legíveis que são adicionadas aos produtos e armazenam informações em um formato eletrônico. Os códigos de barras utilizam a espessura das barras verticais desenhadas e o grau de separação entre elas para definir as suas informações armazenadas. Os códigos de barras lineares são utilizados em diversas aplicações, principalmente quando o uso de um código numérico ou alfanumérico pode fornecer a chave de um objeto no banco de dados. A principal limitação existente nestes dispositivos é a pequena quantidade de informações que pode ser armazenadas. Em situações onde o banco de dados está sempre acessível, esta limitação não é considerada um grande problema. Porém, em situações onde as etiquetas precisam ser lidas desconectadas (off-line), sem acesso direto ao banco de dados, seria interessante que este dispositivo pudesse armazenar uma quantidade maior de informações (DYKSTRA et al., 2002).

Mais de 250 simbologias para códigos de barra já foram criadas. As mais comuns são o UPC/EAN, Código 128, Código 39 e Código 93. As informações armazenadas variam entre 8 a 30 caracteres, onde alguns códigos de barras possuem restrições de números e letras. Na Figura 4, é mostrado um exemplo de um código de barras unidimensional (GS1, 2009).

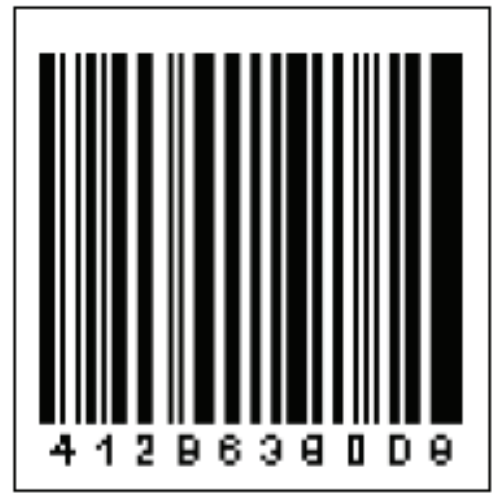

Figura 4- Exemplo de uma etiqueta com um código Universal Product Code (UPC). Fonte: Dykstra et al. (2002).

\subsubsection{CÓDIGO DE BARRAS BIDIMENSIONAL}

A nova área crescente na tecnologia de código de barras são os códigos de barra bidimensionais. Diversas variações de códigos de barras 2D são disponíveis, e 
eles não se limitam apenas a barras e espaços. Simbologias 2D fornecem um meio de armazenamento de grande quantidade de dados e um espaço relativamente pequeno. Etiquetas individuais disponíveis comercialmente podem armazenar em torno de 7000 caracteres numéricos e 4200 caracteres alfanuméricos (DYKSTRA et al., 2002). Na Figura 5 são mostrados exemplos de código de barras 2D.

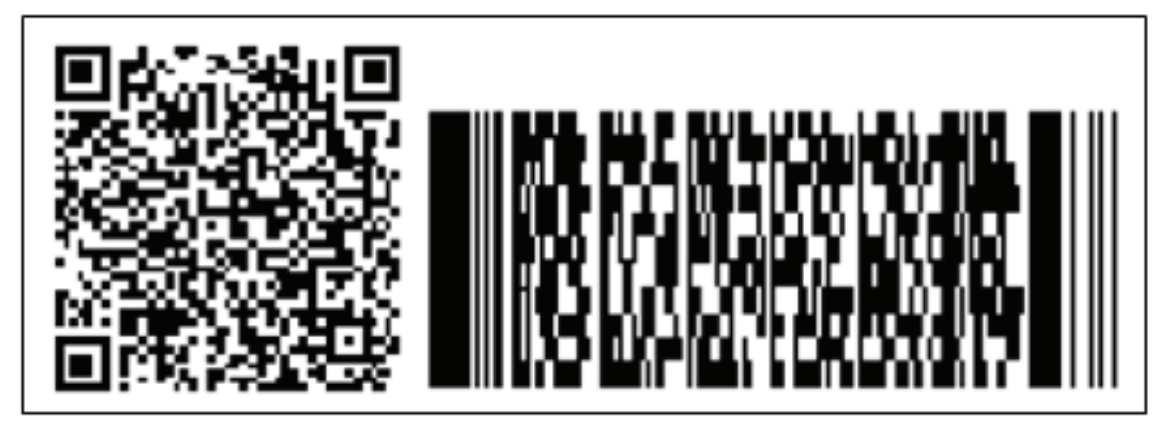

Figura 5 - Exemplos de Códigos de Barra 2D. Fonte: Dykstra et al. (2002).

\subsubsection{RADIO FREQUENCY IDENTIFICATION - RFID}

A tecnologia RFID tornou possível a troca de dados via rádio entre portadores de dados (transponder) e um leitor de dados. Um transponder é basicamente composto por um microchip para armazenar dados e uma bobina utilizada como antena. Se o transponder estiver no campo eletromagnético do leitor de dados, os dados podem ser lidos entre os dois dispositivos. No que diz respeito ao fornecimento de energia, há uma distinção entre os sistemas ativos e passivos. Transponders ativos são equipados com bateria. Esta bateria disponibiliza a energia necessária para o armazenamento dos dados, sua transmissão e para outros elementos integrados como os sensores. Já os transponders passivos utilizam memórias não voláteis, que não precisam de energia para seu armazenamento. Para a transferência das informações eles recebem a energia necessária por meio de um campo eletromagnético, gerado pela antena do dispositivo de leitura. Neste caso, as ondas de rádio são utilizadas tanto para o abastecimento, como para a transmissão dos dados (KORTEN; KAUL, 2008).

Mais informações sobre os conceitos de RFID, seus modelos e meios de utilização nas cadeias de suprimentos, podem ser encontrados em Dykstra et al. (2002), Voulodimos et al. (2009), Chen et al. (2007) e Wang et al. (2007). 


\subsubsection{A REDE EPCGLOBAL}

A rede EPCGlobal é um meio padronizado para a utilização da tecnologia RFID na cadeia logística, utilizando-se dos EPCs (códigos únicos de identificação) e da Internet para acessar grandes quantidades de informação associada ao produto, que pode ser compartilhada entre diversos usuários autorizados (QUENTAL, 2006).

O EPC é uma estrutura de numeração que identifica unicamente todos os objetos e é construído como parte da rede EPC Global. Cada EPC é a chave das informações relacionadas ao item na rede. Em cada país uma divisão da EPC Global gerencia o sistema EPC e as informações transportadas por ele (PMA, 2006).

Existem vários padrões para codificação EPC, dependendo do objetivo da sua utilização. Para a identificação de itens o padrão utilizado é o SGTIN. Assim como nos códigos de barra, o EPC (SGTIN) contém números que identificam a empresa e os itens, além de um número serial que identifica cada item unicamente. $O$ formato básico do EPC (SGTIN) é composto dos seguintes elementos (PMA, 2006):

- Cabeçalho - o número que identifica o tamanho, tipo, estrutura, versão e geração do EPC.

- Número Gerenciador EPC - identifica a empresa ou entidade relacionada ao item controlado.

- Classe do Objeto - é utilizado para identificar a classe dos objetos que estão sendo controlados.

- Número Serial - o número serial que torna cada EPC único.

$\mathrm{Na}$ Figura 6 é mostrado um exemplo de código UPC utilizado para identificação de produtos (SGTIN):

\begin{tabular}{|c|c|c|c|}
\hline 01. & 203D2A9. & 16E8B8. & 719BAE03C \\
\hline Header & $\begin{array}{c}\text { EPC Manager } \\
\text { Number }\end{array}$ & Object Class & $\begin{array}{c}\text { Serial } \\
\text { Number }\end{array}$ \\
\hline
\end{tabular}

Figura 6 - Exemplo de código EPC (SGTIN). Fonte: PMA (2006). 
Em Vican (2009) é apresentado um guia técnico para a implementação de soluções para gestão de ativos baseadas no sistema GS1 e nos padrões da EPCglobal.

\subsection{PADRÕES DE METADADOS PARA TROCA DE INFORMAÇÕES}

Padrões de metadados são definidos para facilitar o armazenamento e a troca de informações entre sistemas. A partir da definição de um padrão, sistemas podem enviar e receber informações de outros sistemas sem a necessidade de análise e ajuste das informações, tornando o processo mais transparente e eficiente.

$\mathrm{Na}$ agricultura, se destaca o AgroXML, apresentado em Schmitz (2008) e Kunisch (2009). Para a indústria de papel e celulose foi criado o PAPINET (PAPINET, 2003) e para a indústria florestal é apresentado o e-Forestry Industry Data Standards (eFIDS) em OASIS (2009).

\subsection{ARQUITETURA ORIENTADA A SERVIÇOS}

A Arquitetura Orientada a Serviços (SOA) (OASIS, 2006) é um paradigma para organização e utilização de competências distribuídas que estão sob controle de diferentes domínios proprietários. Esta definição demonstra uma das principais características deste paradigma. O SOA se baseia no fato de que a rede de sistemas distribuídos não é controlada por um único proprietário, havendo a necessidade de se considerar a heterogeneidade de plataformas, padrões e tecnologias.

Conforme Josuttis (2008), os principais conceitos técnicos de SOA que permitem lidar com as características destes sistemas são:

- Serviços

- Alta Interoperabilidade

- Acoplamento fraco

O objetivo de SOA é estruturar grandes sistemas distribuídos baseados em 
abstrações das regras e das funções de negócio. Um serviço é uma representação da TI de uma funcionalidade de negócio. A alta interoperabilidade é a capacidade da realização da conexão destes sistemas de uma forma facilitada. Por fim, o acoplamento baixo é o conceito de se minimizar as dependências entre os sistemas, para que modificações, problemas ou indisponibilidades de sistemas tenham seus efeitos minimizados nos demais sistemas. A diminuição das dependências contribui também para o aumento da tolerância a falhas, da flexibilidade e da escalabilidade destes sistemas.

Alguns dos benefícios que podem ser destacados deste paradigma são (ENDREl et al., 2004):

- Sobrevida aos recursos computacionais legados, quando transformados em serviços;

- Maior facilidade da integração e gerenciamento da complexidade proveniente da interoperabilidade;

- Maior capacidade de resposta e tempos de implementação menores;

- Menores custos e maiores possibilidades de reuso;

- Maior adequação às tendências futuras de desenvolvimento tecnológico.

Para a implementação de sistemas utilizando o paradigma do SOA, diversas tecnologias podem ser empregadas, sendo que a utilização de web services tem recebido grande aceitação (ENDREI et al., 2004). Isto ocorre devido esta tecnologia ser formada por um conjunto de padrões abertos que garante diversos benefícios, como a interoperabilidade.

\subsubsection{WEB SERVICES}

Os Web Services ou Serviços Web são aplicações auto descritivas e modulares acessadas por meio de interfaces programáveis e de protocolos de internet, com a finalidade de proporcionar formas de encontrar, assinar e invocar tais serviços (ENDREl et al, 2004). A especificação e padronização dos serviços web são de responsabilidade do World Wide Web Consortium (W3C ${ }^{\circledR}$ ) (W3C, 2007a). 
Estes serviços fornecem uma abordagem de computação distribuída para a integração de aplicações heterogêneas por meio da internet. Os serviços web são implementados baseando-se em cinco padrões fundamentais:

- XML (Extensible Markup Language);

- $\operatorname{HTTP}$ (Hypertext Transfer Protocol);

- WSDL (Web Services Description Language);

- $\operatorname{SOAP}($ Simple Object Acess Protocol);

- UDDI (Universal Description, Discovery and Integration).

O XML e o HTTP são padrões gerais que existiam antes e foram utilizados para a criação da abordagem de serviços web. O XML (W3C, 2007b) é usado como um formato geral para a descrição de modelos, formatos e tipos de dados. O HTTP (incluindo o HTTPS) é um protocolo de baixo nível usado pela internet. Por meio deste protocolo é possível o envio de serviços web pelas redes, utilizando-se tecnologias de Internet.

O WSDL, o SOAP e o UDDI são padrões específicos para os serviços web e foram os primeiros padrões especificados para tais serviços. Nos próximos tópicos serão apresentados estes três padrões com mais detalhes, baseando-se no trabalho apresentado em Cerami (2002).

\subsubsection{WSDL}

O WSDL é uma especificação que define como se descrever os serviços web utilizando XML. A padronização do WSDL fica a cargo do W3C (W3C, 2007c). Este padrão define quatro informações críticas:

- Informações das interfaces, descrevendo todas as funções públicas disponíveis;

- Informações sobre tipos de dados para todas as mensagens de requisição e de resposta;

- Informações de como as mensagens serão transmitidas na rede;

- Informações do endereço para a localização do serviço específico. 
O WSDL representa o contrato entre o solicitante do serviço e seu respectivo provedor de uma forma independente de linguagem de programação ou plataforma. Utilizando este padrão o cliente pode localizar o serviço web e invocar qualquer uma das suas funções públicas. Além disso, com ferramentas apropriadas é possível a automatização deste processo, possibilitando que as aplicações possam se integrar a novos serviços com pouco ou nenhum código escrito manualmente.

O WSDL, portanto representa um marco na arquitetura de serviços web, pois fornece uma linguagem comum para descrever os serviços e uma plataforma para integrá-los automaticamente.

Na Figura 7 é apresentada a estrutura resumida do WSDL:

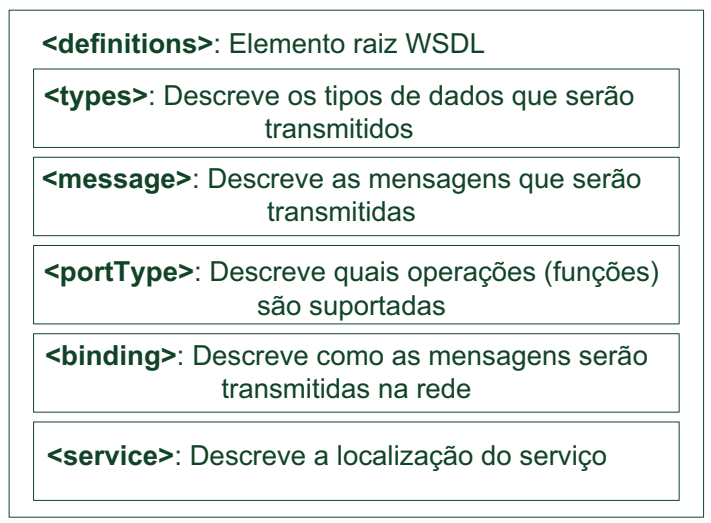

Figura 7- Especificação simplificada da WSDL. Fonte: Extraído e adaptado de Cerami (2002).

Com o acesso ao arquivo WSDL, o cliente do serviço obtém informações sobre os serviços web fornecidos, sua localização, quantidade e os tipos dos parâmetros de entrada e saída.

\subsubsection{SOAP}

O SOAP é um protocolo baseado em XML para o intercâmbio de informações entre sistemas computacionais. A sua padronização fica a cargo do W3C (W3C, 2007d). Apesar do SOAP ser utilizado em uma variedade de sistemas de mensagens e poder ser enviado por meio de diversos protocolos de transporte, a utilização principal do SOAP é o transporte das chamadas de procedimentos 
remotos via o protocolo HTTP. Este padrão possibilita que aplicações clientes se conectem facilmente a serviços remotos e invoquem seus métodos. Por isso, 0 SOAP representa o componente da arquitetura de serviços web que possibilita que diversas aplicações façam o intercâmbio de serviços e dados. Na Figura 8 é apresentado um exemplo de comunicação entre aplicações utilizando SOAP.

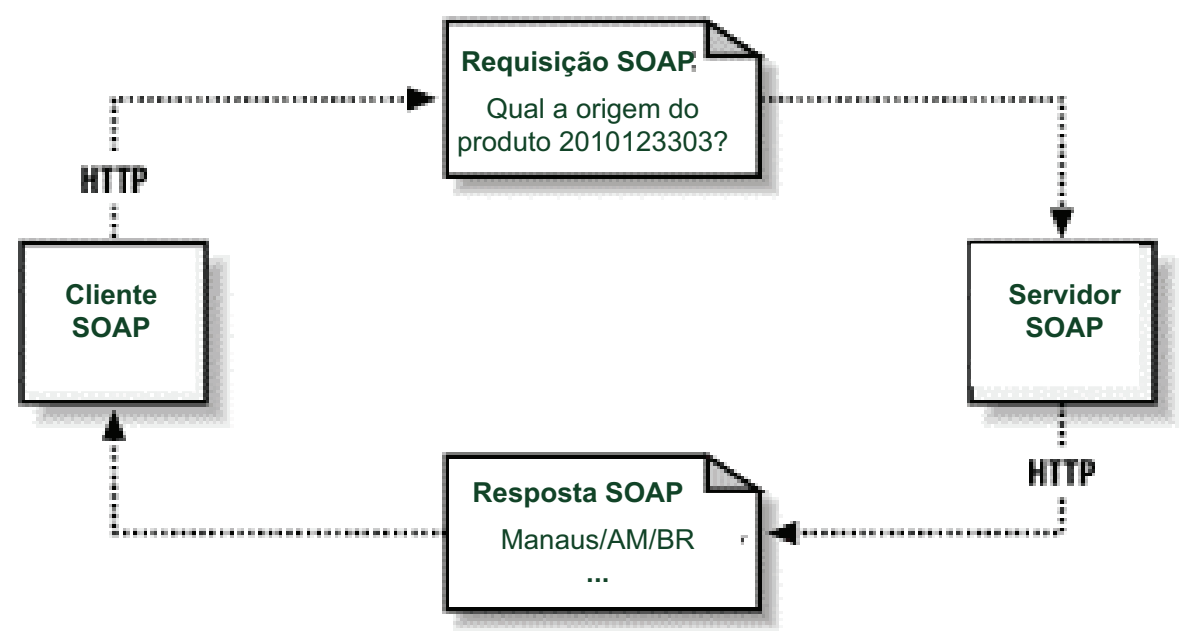

Figura 8 - Troca de mensagens utilizando o SOAP. Fonte: Extraído e adaptado de Cerami (2002).

\subsubsection{UDDI}

O UDDI é uma especificação técnica para descrever, descobrir e integrar serviços web. A ideia original do padrão era introduzir os três papéis do mercado em funcionamento: fornecedores que oferecem serviços, consumidores que precisam dos serviços e brokers ${ }^{9}$ que juntam os dois, divulgando e localizando os serviços. Isso resultaria no esquema apresentado na Figura 9.

\footnotetext{
9 Dentro da arquitetura SOA um broker pode ser utilizado para diferentes propósitos, como localizar serviços em tempo de modelagem e localizar o fornecedor correto em tempo de execução. Por isso, dois dos principais papéis que o broker pode desempenhar são como repositório de serviços e registro de serviços. Mais informações sobre a utilização de brokers na arquitetura SOA são apresentadas em Josuttis (2008).
} 


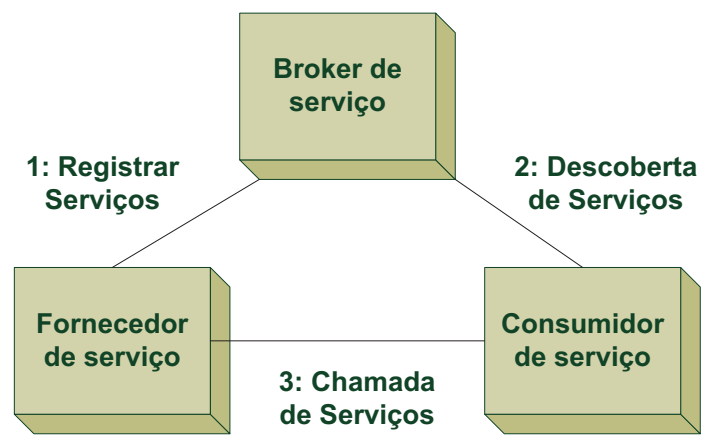

Figura 9 - Fornecedor, Consumidor e Broker. Fonte: Josuttis (2008).

A intenção do UDDI era que fosse o broker central para um mercado mundial de serviços web. Os fornecedores poderiam colocar qualquer serviço web no UDDI, e os consumidores poderiam procurar por UDDI para localizar qualquer serviço desejado.

Mostrou-se, no entanto, que o UDDI não funcionou e, em janeiro de 2006, foi descartado pelas empresas que mantinham o padrão (JOSUTTIS, 2008).

Mesmo assim, por motivos técnicos os serviços web normalmente precisam de um broker. Por serem inerentemente conexões ponto-a-ponto, alguns mecanismos e/ou processos são necessários para evitar que o endereçamento seja inserido diretamente no código dos consumidores de serviços web. Por isso, várias empresas procuram e implementam soluções alternativas para o UDDI, muitas vezes utilizando soluções de registro já existentes como LDAP, Java Naming and Directory Interface (JNDI), banco de dados relacionais ou CORBA Trader (JOSUTTIS, 2008). 


\section{PROCESSO PRODUTIVO FLORESTAL}

Neste capítulo é apresentada a cadeia de suprimentos dos produtos florestais e as suas principais etapas. Em seguida, são detalhados os problemas processuais e computacionais identificados neste processo e que possuem forte influência na correta operacionalização e fiscalização das etapas que compõem a cadeia produtiva.

\subsection{CADEIA DE SUPRIMENTOS DE PRODUTOS FLORESTAIS}

A cadeia de suprimentos de produtos florestais corresponde a todas as atividades do processo produtivo de um produto florestal, desde a extração da matéria-prima da floresta e seu transporte, até a sua venda ao consumidor final, passando por todas as etapas de transformação até o produto acabado (LUMMUS; VOKURKA, 2009).

$\mathrm{Na}$ Figura 10, é apresentada uma cadeia de suprimentos de móveis. A primeira etapa desta cadeia consiste na extração da madeira da floresta e seu transporte em toras para as serrarias. Nas serrarias as toras são serradas ou laminadas e transportadas para a fábrica de móveis. Na fábrica, os diversos modelos de móveis são montados, acabados e transportados para o varejo, que realiza a venda para os consumidores finais. Por se tratar de uma matéria-prima controlada por leis e normas ambientais, o Instituto Brasileiro do Meio Ambiente e dos Recursos Naturais Renováveis (IBAMA) e as Secretarias Estaduais do Meio Ambiente (SEMA) de cada estado, realizam o controle e a fiscalização das principais etapas desta cadeia de suprimentos. 


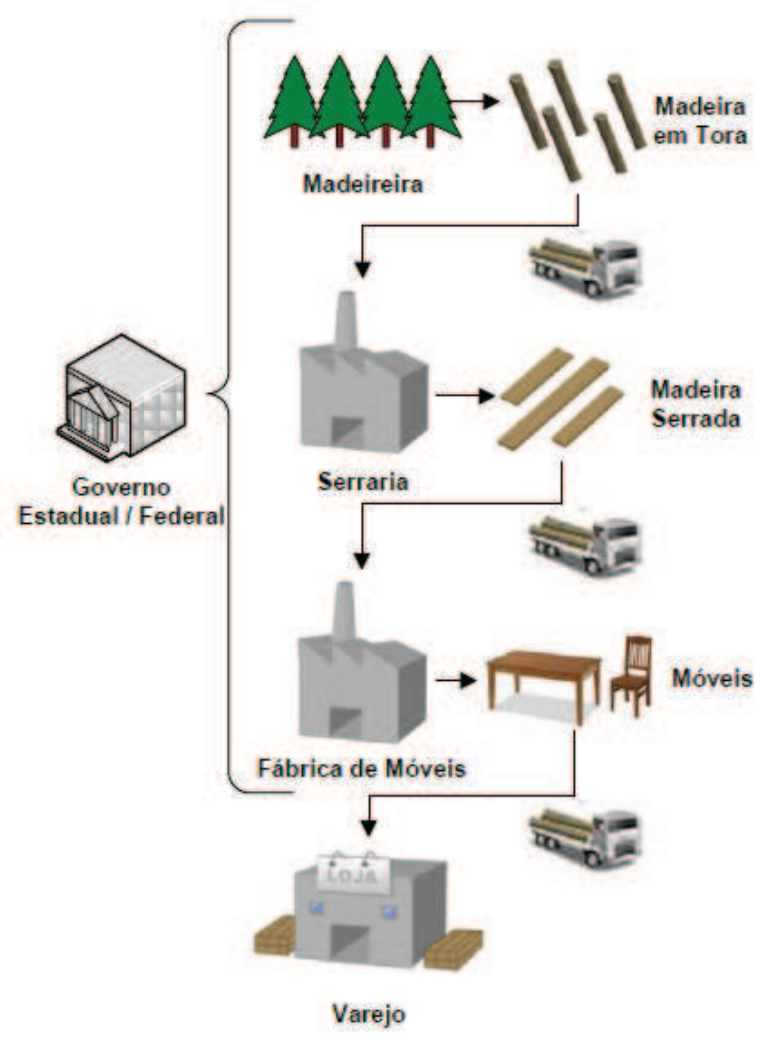

Figura 10 - Cadeia de suprimentos simplificada de produtos florestais. Fonte: Extraído e adaptado de Dykstra et al. (2002).

\subsubsection{PLANO DE MANEJO FLORESTAL SUSTENTÁVEL (PMFS) E AUTORIZAÇÃO DE DESMATAMENTO}

Os PMFSs e as autorizações para desmatamento florestal são as únicas modalidades legais de exploração da madeira proveniente de florestas tropicais brasileiras.

O PMFS é um projeto produzido com base em normas técnicas de manejo de baixo impacto ambiental, no qual são definidos os critérios para exploração da área desejada. Esta atividade é regulamentada por leis, decretos e instruções normativas.

As autorizações para desmatamento florestal são liberadas pelos órgãos ambientais em áreas destinadas a instalação de cultivos ou pastos, e em áreas fora da reserva legal da propriedade, que corresponde a $80 \%$ da sua área total.

O plano de manejo é executado normalmente em três etapas. Na primeira, faz-se o zoneamento ou divisão da propriedade florestal em áreas exploráveis, áreas de preservação permanente e áreas inacessíveis à exploração. A segunda etapa consiste no planejamento das estradas secundárias que conectam a área de 
exploração às estradas primárias. Na terceira etapa, divide-se a área alocada para exploração em blocos ou talhões de exploração anual.

Também fazem parte destas atividades os inventários florestais, onde são identificadas e registradas todas as árvores de valor comercial, existentes na área de exploração. Estas informações são validadas pelos órgãos governamentais e utilizadas para a geração da Autorização de Colheita Florestal (ACOF), da Autorização de Exploração (AUTEX) ou da Autorização de Exploração Florestal (AUTEF), dependendo da operação realizada e do estado onde se localiza a empresa solicitante.

Estas autorizações serão responsáveis pela geração do saldo virtual inicial das empresas (estoque) dentro dos sistemas de monitoramento de transporte da madeira. Nestes sistemas, apenas as espécies de árvores ou produtos florestais com quantidades disponíveis no estoque da empresa poderão ser comercializadas e transportadas legalmente, durante o período de tempo pré-determinado pela autorização.

Em Amaral et al. (1998) são detalhados todos os passos para a elaboração e execução do plano de manejo florestal.

Na Portaria N¹86 (BRASIL, 2006c), da Secretaria de Estado do Desenvolvimento Ambiental de Rondônia, de 25 de Outubro de 2006, são definidos os roteiros mínimos necessários para a apresentação dos documentos para aprovação do PMFS, do Plano Operacional Anual (POA), dos relatórios de atividades Pós-Exploratórias do PMFS, além de definir as especificidades técnicas dos mapas e imagens digitais que compõem estes documentos.

\subsubsection{CENSO FLORESTAL}

O inventário florestal ou censo florestal é realizado de um a dois anos antes da exploração de uma área florestal e envolve a demarcação dos talhões ou Unidades de Produção Anual (UPA), a abertura de trilhas para orientação e a identificação, localização e avaliação das árvores de valor comercial. Além disso, outras informações úteis ao planejamento da exploração e às práticas silvicultoras, como presença de cursos d'água, áreas cipoálicas e variações topográficas também 
são registradas durante este levantamento (AMARAL et al., 1998).

Inicialmente a área a ser manejada é dividida em talhões, conforme a Figura 11. O censo considera as árvores de valor comercial, árvores matrizes (importantes para regeneração da floresta) e as árvores com potencial para cortes futuros. Os dados são anotados em uma ficha de campo e usados na elaboração do mapa do censo. Posteriormente, essas informações são utilizadas para o planejamento da infraestrutura da exploração.

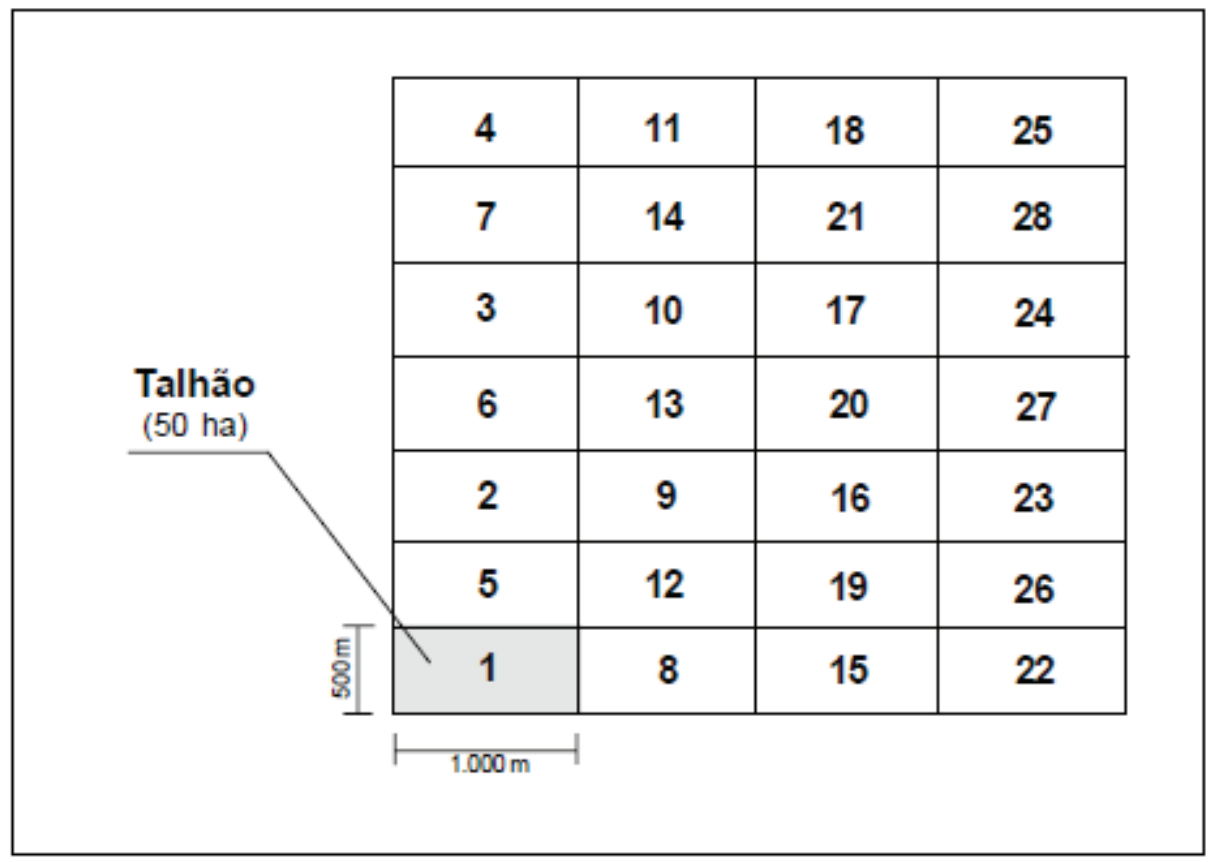

Figura 11 - Divisão da área de manejo florestal em talhões. Fonte: Amaral et al. (1998).

A identificação e o registro das árvores, no censo florestal, seguem as seguintes fases:

- Medição das árvores - Mede-se a circunferência ou o diâmetro da árvore para estimar o volume e ajudar na seleção das árvores a serem exploradas;

- Numeração das árvores - Cada árvore a ser explorada deve ser identificada com uma numeração única. Normalmente os números são impressos em plaquetas de alumínio. A Figura 12 apresenta um modelo de plaqueta utilizada na identificação de árvores. 


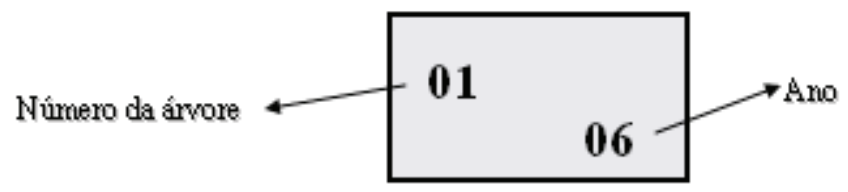

Figura 12 - Modelo de plaqueta de identificação de árvores para exploração comercial. Fonte: Amaral et al. (1998).

- Mapeamento das árvores - Identificação da posição da árvore, em sistemas de coordenadas $\mathrm{x}$ e $\mathrm{y}$, que pode ser baseada nas delimitações dos talhões ou utilizando-se coordenadas georreferenciadas via GPS (Sistema de posicionamento Global).

- Estimativa da altura comercial - Verificação da estimativa da altura do tronco, que corresponde ao ponto de corte na base da árvore até a primeira bifurcação dos seus galhos.

- Avaliação da qualidade do tronco - Identificação da qualidade comercial dos troncos, conforme suas características.

- Detecção da presença de ocos - Identificação das árvores ocas. Estas árvores, que são consideradas sem valor comercial, devem ser preservadas, pois são importantes como produtoras de sementes, fontes de alimentos e abrigo de animais.

- Seleção das árvores matrizes - Esta seleção é realizada conforme características das árvores. Para cada espécie, selecionam-se três a cinco árvores matrizes por hectare. Caso este número não exista, regras de manejo são aplicadas para se determinar a possibilidade da extração desta espécie.

As informações contidas na ficha de campo (Figura 13) são a base para a elaboração do mapa do censo (Figura 14). Esse mapa é utilizado para a localização das árvores a serem extraídas, das árvores remanescentes (exploração futura), das árvores matrizes e da topografia do relevo. 


\begin{tabular}{|c|c|c|c|c|c|c|c|c|}
\hline Faixa & $\mathrm{N}^{\circ}$ da árvore & Coord. X & Coord. Y & Nome comum da árvore & DAP(cm) & Altura com.(m) & Qualid. Tronco & Qualid. Copa \\
\hline 2 & 26 & 166 & 110 & Macaranduba & 128,9 & 19,7 & 1 & 1 \\
\hline 2 & 27 & 122 & 430 & Macaranduba & 107,6 & 23,1 & 1 & 3 \\
\hline 2 & 28 & 112 & 200 & Amapa amargoso & 105,7 & 20,4 & 1 & 2 \\
\hline 2 & 29 & 200 & 60 & Amapá doce & 103,8 & 23,0 & 2 & 1 \\
\hline 2 & 30 & 345 & 320 & Anani & 99,0 & 28,9 & 1 & 1 \\
\hline 3 & 45 & 400 & 145 & Angelim amargoso & 98,7 & 29,1 & 2 & 1 \\
\hline 3 & 46 & 340 & 290 & Angelim vermelho & 95,5 & 31,0 & 1 & 2 \\
\hline 3 & 47 & 120 & 150 & Angelim rajado & 93,7 & 20,7 & 1 & 1 \\
\hline 3 & 48 & 70 & 90 & Angelim vermelho & 93,6 & 25,9 & 1 & 1 \\
\hline 3 & 49 & 50 & 30 & Angelim vermelho & 93,5 & 14,0 & 2 & 1 \\
\hline
\end{tabular}

Figura 13 - Ficha de campo preenchida. Fonte: Extraído e adaptado de Amaral et al. (1998).

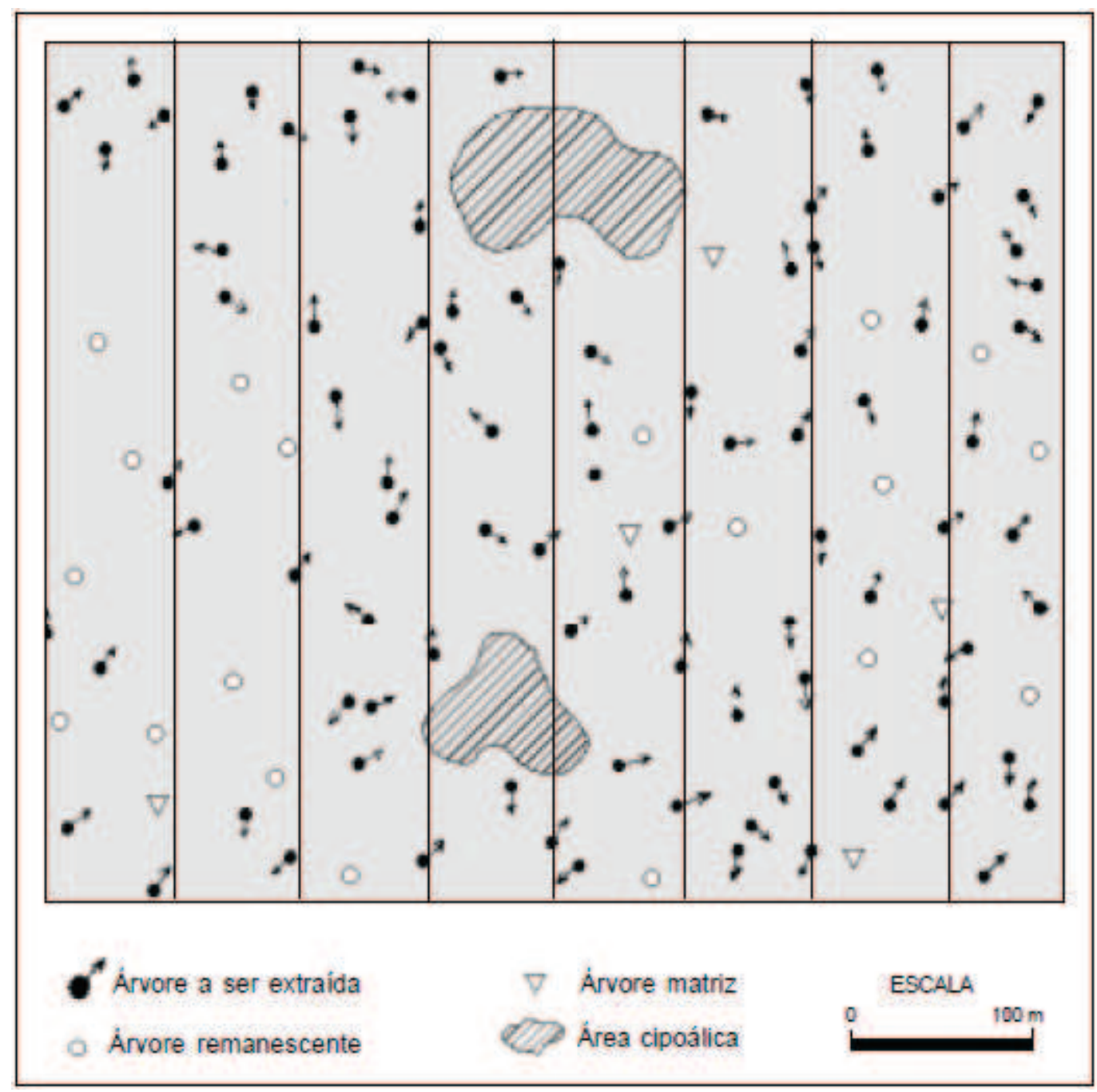

Figura 14 - Mapa do censo florestal. Fonte: Amaral et al. (1998).

O mapa do censo florestal também pode incluir os códigos de identificação de cada uma das árvores, tornando-o mais rico de informações e possibilitando a identificação exata de cada uma das árvores descritas no mapa.

O censo é fundamental para elaboração do plano operacional de manejo. As 
informações registradas no censo permitem os cálculos do volume a ser explorado e a são a base para a produção da versão final do mapa de exploração. Este mapa é o instrumento básico para orientar a operacionalização das próximas atividades, como o corte de cipós, o planejamento, a demarcação e a construção de estradas e pátios de estocagem, o corte e as atividades pós-exploratórias.

\subsubsection{EXTRAÇÃO FLORESTAL}

A extração florestal consiste no corte das árvores, utilizando-se técnicas de exploração madeireira que buscam evitar os desperdícios excessivos de madeira, os danos desnecessários às florestas e uma maior incidência de acidentes de trabalho. Estas atividades também se baseiam no plano de exploração florestal, construído a partir da análise do censo florestal das áreas de exploração anual e das informações da autorização para exploração.

Nesta etapa também são identificadas as atividades pré-corte e pós-corte, que são realizadas para garantir o bom funcionamento do processo e para cumprir as normas legais estabelecidas.

As atividades pré-corte são compostas por verificações da qualidade da árvore e pela análise de melhores práticas para a extração e arraste da tora. Dentre estas atividades a manutenção e a documentação da identidade das árvores são destacadas. Nestas atividades, a plaqueta de identificação, pregada na árvore durante o censo florestal, é transferida do seu tronco para a sua base, situada abaixo da linha do corte. A manutenção da plaqueta na base da árvore é necessária para a realização da validação e registro das árvores efetivamente extraídas. Estas informações serão detalhadas nos relatórios pós-exploratórios.

As atividades pós-corte são compostas pela preparação das toras e seu arraste para os pátios de estocagem.

A identificação das toras cortadas, antes do seu arraste, mantendo a mesma numeração da plaqueta fixada na base da árvore é uma boa prática sugerida pelas certificadoras, pois garante a manutenção da identidade destas árvores, mesmo depois de armazenadas nos pátios de estocagem. Estas informações são fundamentais para um sistema de rastreabilidade deste processo, pois possibilita que, ao associar estes identificadores a um lote de venda, as origens destas árvores 
possam ser identificadas no restante da cadeia de suprimentos. Na Figura 15, é mostrado um lote de toras identificadas em um pátio de estocagem.

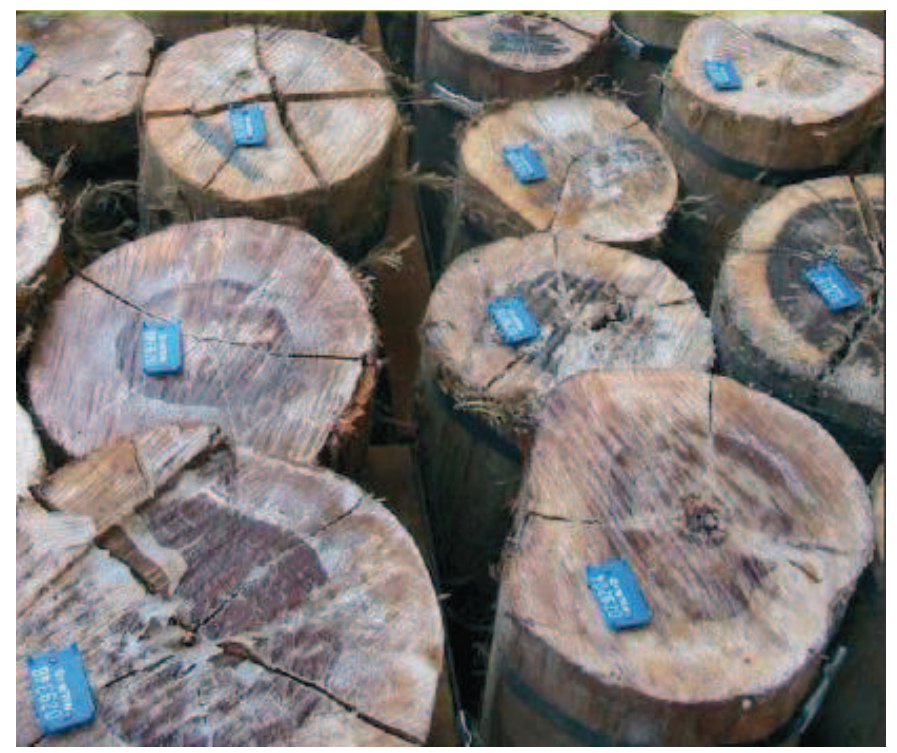

Figura 15 - Identificação de toras no pátio de estocagem de uma madeireira. Fonte: Conselho Brasileiro de Manejo Florestal (2010).

\subsubsection{LICENCIAMENTO AMBIENTAL PARA BENEFICIAMENTO}

O licenciamento ambiental é o procedimento no qual o poder público, representado por órgãos ambientais, autoriza e acompanha a implantação e a operação de atividades que utilizam recursos naturais ou que sejam consideradas efetivas ou potencialmente poluidoras. É obrigação do empreendedor, prevista em lei, buscar o licenciamento ambiental junto ao órgão competente, desde as etapas iniciais de seu planejamento e instalação até a sua efetiva operação.

Desde 1981, de acordo com a Lei Federal 6.938/1981 (BRASIL, 1981), o licenciamento ambiental é obrigatório. As indústrias da madeira tais como as serrarias, as dedicadas ao desdobramento de madeira, as fabricantes de estruturas de madeira e as moveleiras, devem possuir a licença ambiental.

O licenciamento ambiental consiste no cadastramento (nos níveis federais e estaduais) da pessoa jurídica que vai exercer a atividade e no seu licenciamento. Estas duas etapas (cadastramento e licenciamento) podem ser realizadas simultaneamente. Em caso de um novo empreendimento é necessário a solicitação da Licença Prévia (LP), da Licença de Instalação (LI) e da Licença de Operação 
(LO). Já no caso de um estabelecimento existente, que possui apenas a intenção de regularizar sua operação, é necessária apenas a solicitação da LO.

\subsubsection{TRANSFORMAÇÃO E PRODUÇÃO}

As transformações ocorrem normalmente em várias empresas participantes da cadeia de suprimentos e consiste no processamento da madeira, em seus vários níveis de subprodutos, até a montagem final do produto. Estas empresas utilizam técnicas para controlar as entradas de matérias-primas, a sua transformação e a saída dos produtos gerados. Estas transformações devem ser registradas nos sistemas governamentais de transporte de produtos florestais, que realizam a conversão sistêmica do saldo em estoque destas matérias-primas em seus produtos derivados, consumindo o saldo das matérias-primas e gerando saldo de novos produtos no estoque da empresa. Esta transformação é baseada nos índices de conversão cadastrados nestes sistemas, estipulados previamente pelo governo, mas que podem ser reajustados conforme solicitação das empresas beneficiadoras de madeira.

\subsubsection{SISTEMAS COMPUTACIONAIS NO PROCESSO PRODUTIVO FLORESTAL BRASILEIRO}

Atualmente no Brasil existem sistemas computacionais que realizam o controle do Plano de Manejo Florestal Sustentável (PMFS), do licenciamento para desmate florestal e do transporte dos produtos e subprodutos florestais (ALIANÇA DA TERRA et al., 2007). Na Tabela 6, são listados os sistemas utilizados em cada um dos estados da Amazônia Brasileira.

Tabela 6 - Estados do Amazonas e seus respectivos sistemas de controle florestal em utilização. Fonte: Aliança da Terra et al. (2007).

\begin{tabular}{|l|l|l|l|}
\hline \multicolumn{4}{|c|}{ Estados na Amazônia Brasileira } \\
\hline Estado & PMFS & Desmate & Transporte \\
\hline $\begin{array}{l}\text { Mato } \\
\text { Grosso }\end{array}$ & CEPROF & CEPROF & SISFLORA \\
\hline Acre & SISPROF & $\begin{array}{l}\text { Sistema } \\
\text { Próprio }\end{array}$ & DOF \\
\hline Amapá & SISPROF & SISPROF & DOF \\
\hline
\end{tabular}




\begin{tabular}{|l|l|l|l|} 
Amazonas & - & - & DOF \\
\hline Maranhão & - & - & SISFLORA \\
\hline Pará & CEPROF & CEPROF & SISFLORA \\
\hline Rondônia & CEPROF & CEPROF & SISFLORA \\
\hline Roraima & SISPROF & SISPROF & DOF \\
\hline Tocantins & $\begin{array}{l}\text { Sistema } \\
\text { Próprio }\end{array}$ & $\begin{array}{l}\text { Sistema } \\
\text { Próprio }\end{array}$ & DOF \\
\hline
\end{tabular}

O Sistema Integrado de Monitoramento e Controle dos Recursos e Produtos Florestais (SISPROF) e o Sistema de Cadastro de Consumidores de Produtos Florestais (CEPROF) são responsáveis pelo cadastramento das propriedades, dos projetos florestais e das licenças para liberação dos planos de manejo florestal e das autorizações de desmatamento.

O Documento de Origem Florestal (DOF) (IBAMA, 2006a) e o Sistema de Cadastro, Comercialização e Transporte de Produtos Florestais (SISFLORA) (SEMA, 2008) são os sistemas que realizam o monitoramento do transporte de madeira e seus derivados. Obrigatoriamente, qualquer produto florestal que seja controlado pelas normas ambientes do país precisa ter seu transporte controlado por estes sistemas. A transformação de madeira em seus derivados e o estoque de produtos florestais nos pátios das empresas também é controlada por estes sistemas.

A criação dos sistemas DOF e SISFLORA foi considerada uma grande evolução em relação ao antigo sistema de exploração e transporte de produtos florestais que deixou de ser utilizado em 2006, chamado de Autorização para Transporte de Produtos Florestais (ATPF). Diferente dos sistemas DOF e SISFLORA que são baseados em documentos eletrônicos, este sistema era baseado em papel e seu preenchimento manual, tornando-se bastante vulnerável a fraudes, corrupção e falsificação (IBAMA, 2006a).

Entretanto, ainda existem problemas a serem solucionados também nestes novos sistemas, para possibilitar um real controle destas atividades.

\subsubsection{ANÁLISE DO PROCESSO PRODUTIVO FLORESTAL}

Com o levantamento das atividades do processo produtivo florestal pode-se 
visualizar as principais etapas que o compõe e seus objetivos. Abaixo será descrito um resumo deste processo, juntamente com a utilização dos sistemas computacionais, para facilitar a visualização do processo como um todo.

A cadeia de suprimentos legalizada da madeira amazônica é iniciada com a aprovação de um PMFS ou de uma autorização para desmatamento florestal em uma determinada área. Junto com esta autorização se obtém o AUTEX/ACOF/AUTEF, que informa o que poderá ser extraído da floresta.

Para a utilização dos sistemas de transporte as empresas também devem estar devidamente cadastradas e legalizadas nos orgãos governamentais responsáveis de cada estado.

A partir desta etapa, todos os transportes de madeiras e seus derivados, provenientes das relações entre as empresas participantes da cadeia, deverão ser registrados pelos sistemas de transporte.

O processo de venda destes produtos se inicia com uma negociação on-line entre a empresa vendedora e a compradora, até a aprovação do negócio no sistema. Com a negociação aprovada é possível a geração do documento de autorização de transporte, chamado de Documento de Origem Florestal (DOF) no sistema DOF e da Guia Florestal (GF) no sistema SISFLORA. Estes documentos acompanham a mercadoria no trajeto entre as duas empresas, e contém as informações sobre os produtos transportados, a nota fiscal da operação realizada, o meio de transporte utilizado e o trajeto da sua origem ao seu destino.

$\mathrm{Na}$ chegada da mercadoria ao seu destino, a empresa compradora realiza o registro de chegada da mercadoria no sistema de transporte, que realiza a transferência do saldo virtual do estoque do vendedor para o estoque do comprador.

Nos casos em que as empresas realizam transformações e beneficiamentos nas matérias-primas, como por exemplo, nas serrarias que transformam toras de madeira em madeira serrada ou laminada, o sistema de transporte possibilita a conversão do saldo da matéria-prima utilizada para o novo produto gerado, possibilitando assim que este produto seja comercializado.

Após o término da produção, estes produtos são destinados normalmente para varejistas que realizam a venda para o consumidor final. Esta operação é registrada nos sistemas de transporte, que realizam o consumo deste saldo do 
estoque das fábricas e registra a destinação correta destes produtos para posterior consulta.

\subsection{PROBLEMAS DO PROCESSO}

No processo produtivo apresentado, existem etapas nas quais problemas e fraudes são identificadas com frequência, devido sua fragilidade e precários meios de controle e fiscalização. Estas etapas são descritas abaixo.

- Na concepção dos projetos para aprovação do PMFS ou das licenças para desmate florestal. São utilizados dados fraudulentos para se obter a liberação da exploração em áreas proibidas ou para a disponibilização de saldos virtuais inexistentes para a comercialização legal de madeiras extraídas ilegalmente de outras áreas proibidas (IBAMA, 2009), (GLOBO AMAZÔNIA, 2009a), (FÓRUM BRASILEIRO DE SEGURANÇA PÚBLICA, 2009).

- No transporte de madeiras e seus derivados. Nesta etapa ocorre o maior número de fraudes. A criação de documentos de autorização de transporte com dados fraudulentos, falsificação dos documentos, reutilização da mesma nota fiscal para diversos transportes de cargas diferentes, são algumas das fraudes adotadas.

- Na realização de processos de transformações de madeira em seus derivados. Devido os coeficientes de transformação serem muitas vezes desatualizados e genéricos, as empresas se beneficiam destas falhas para a geração de saldos maiores no sistema, possibilitando "esquentar" madeira proveniente de origens ilegais (GLOBO AMAZÔNIA, 2009a), (CHAVES, 2007).

- Durante o processo de fiscalização em campo. Os orgãos governamentais de fiscalização possuem poucos fiscais e fraca infraestrutura para realizar as fiscalizações nas empresas e nos diversos canais por onde são transportadas a madeira, facilitando assim, as ações criminosas (CHAVES, 2007), (FLORESTA VIVA AMAZONAS, 2007). 
- Na comercialização dos produtos florestais no mercado. Devido à falta de meios para o consumidor consultar a origem real dos produtos oferecidos no mercado, os mesmos acabam comprando produtos provenientes de atividades ilegais, que normalmente possuem preços mais baratos (GLOBO AMAZÔNIA, 2009b).

\subsection{PROBLEMAS COMPUTACIONAIS}

Em relação aos sistemas computacionais utilizados para o controle e monitoramento da cadeia de suprimentos da madeira, foram identificados os principais problemas que afetam o funcionamento do processo.

- Falta de integração e padronização dos cadastros, regras e coeficientes considerados nos sistemas de monitoramento do transporte da madeira. Devido à falta de integrações e padronizações entre os sistemas de transportes, produtos que são vendidos para outros estados, que possuem um sistema de transporte diferente do estado de origem, não são fiscalizados, pois os sistemas não compartilham seus dados (GLOBO AMAZÔNIA, 2009a).

- Inexistência da integração dos sistemas de transporte com os sistemas fiscais estaduais e do departamento de trânsito nacional. Devido à falta de integrações com os sistemas governamentais, fraudes geradas pelo preenchimento incorreto dos documentos de autorização de transporte não podem ser descobertas no momento da entrada destas informações, ficando a cargo das fiscalizações em campo a sua descoberta (FLORESTA VIVA AMAZONAS, 2007).

- Inexistência de padrões de identificação eletrônica (Códigos de Barras, Radio Frequency Identification - RFID, etc.) para a madeira e seus derivados durante a cadeia. Devido à falta destes padrões, a identificação destes produtos, em cada uma das etapas produtivas, é realizada de forma manual, dificultando a validação dos dados virtuais com os produtos físicos (GREENPEACE, 2009).

- Problemas de segurança da informação. De acordo com um 
relatório publicado sobre o sistema SISFLORA, o mesmo não é considerado um sistema seguro de acordo com as normas ISO/IEC 15408:2005, ISO/IEC 17799:2005 e ISO/ 27001:2005 (GREENPEACE, 2009). Já o sistema DOF, possui registros de invasões realizadas por hackers, que alteraram os saldos virtuais de 107 madeireiras para possibilitar a comercialização de madeira ilegal por estas empresas (GREENPEACE, 2008b). 


\section{MODELAGEM DO SISTEMA PROPOSTO}

Este capítulo traz considerações sobre a modelagem do sistema computacional proposto.

\subsection{ANÁLISE DE REQUISITOS}

Com base no processo produtivo florestal e nos problemas identificados durante a pesquisa, faz-se inicialmente uma descrição dos requisitos considerados essenciais para que o sistema de rastreabilidade proposto possa alcançar os objetivos desejados.

\subsubsection{AQUISIÇÃO EFICIENTE DOS DADOS}

Os dados registrados nos sistemas devem ser validados automaticamente, no momento de sua entrada no sistema, evitando assim o armazenamento de dados inválidos, que serão manipulados em diferentes pontos da cadeia de suprimentos, por diferentes sistemas de informação, podendo gerar inconsistências e possibilidade de fraudes no processo.

\subsubsection{IDENTIFICAÇÃO ELETRÔNICA DE PRODUTOS}

As matérias-primas e produtos devem possibilitar a identificação e o registro de suas informações durante todo o seu ciclo de vida. A estratégia proposta é que sejam definidos padrões de codificação para identificá-los durante todas as etapas produtivas. Padrões como os definidos pelo sistema GS1 (GS1, 2009), reconhecidos internacionalmente, garantem a identificação única dos produtos em qualquer lugar do mundo. Estes identificadores podem ser associados aos produtos por meio da utilização de tecnologias como RFID e códigos de barras (DYKSTRA et al., 2002), (CHEN, 2007).

\subsubsection{INTEROPERABILIDADE ENTRE OS SISTEMAS}

Para possibilitar a manutenção das informações durante todo o ciclo de vida 
do produto e a eficiência no monitoramento deste processo produtivo, é necessário o compartilhamento de informações, em tempo real, dos diversos sistemas participantes desta cadeia de suprimentos, sejam eles produtivos, de transporte ou de fiscalização. Devido à natureza heterogênea destes sistemas, uma solução para a interoperabilidade entre eles deve ser desenvolvida. A estratégia proposta é a modelagem de uma arquitetura orientada a serviços (SOA) (OASIS, 2006) (ENDREI et al., 2004), baseada em padrões abertos, que possibilite a integração destes sistemas por meio da utilização de padrões de metadados, como o e-Forestry Industry Data Standards (eFIDS) (OASIS, 2009), para o intercâmbio destas informações. A representação da arquitetura proposta é apresentada na Figura 16, onde os sistemas participantes do processo são integrados, possibilitando a troca de informações entre eles, durante todo o ciclo de vida do produto.

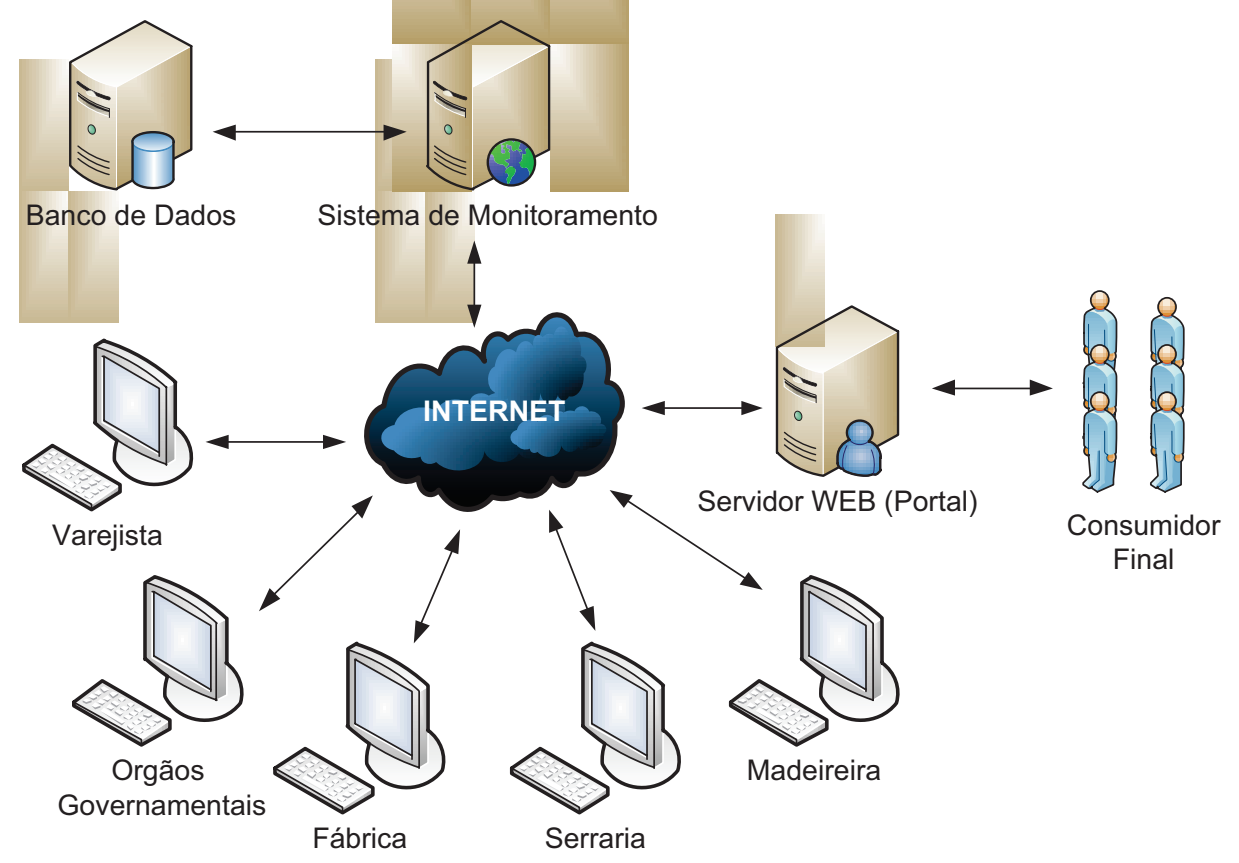

Figura 16 - Arquitetura simplificada do sistema.

\subsubsection{DISPONIBILIZAÇÃO DAS INFORMAÇÕES DO PRODUTO NA CADEIA DE SUPRIMENTOS}

Disponibilizar informações seguras sobre a rastreabilidade dos produtos e matérias-primas em toda a cadeia de suprimentos, inclusive para os consumidores finais poderem comprovar a origem do produto antes de sua compra. A estratégia 
proposta é a disponibilização de serviços web para a consulta da origem dos produtos florestais. Os serviços utilizam a base de dados do sistema de monitoramento e são acessados diretamente pelos sistemas dos participantes da cadeia de suprimentos ou pelos consumidores finais, por meio de aplicações disponibilizadas em Portais Web ou embarcadas em dispositivos como celulares e palm tops. O produto florestal, vendido no varejo, pode ser rastreado e ter sua origem consultada por meio de um identificador único ou pelo lote de fabricação associado ao produto.

\subsubsection{UTILIZAÇÃO DE DISPOSITIVOS MÓVEIS PARA A FISCALIZAÇÃO DO PROCESSO}

Utilizar dispositivos móveis para possibilitar a validação das informações dos documentos de autorização e transporte de produtos florestais. A estratégia proposta considera a utilização de dispositivos móveis com aplicações embarcadas que podem ser executadas em modo on-line e off-line. No caso de acesso on-line, o software embarcado realizará a consulta do documento através da Internet, mas caso não exista este recurso no local da fiscalização, o sistema poderá realizar a consulta em sua base de dados local, que é sincronizada com a base de dados do sistema de rastreabilidade na existência de uma conexão de Internet.

\subsubsection{FACILITAR O PROCESSO DE CERTIFICAÇÃO DA CADEIA DE CUSTÓDIA}

Disponibilizar no sistema computacional as ferramentas de controle que apoiem a certificação do processo produtivo destas empresas. A estratégia proposta é realizar um estudo dos requisitos das certificações florestais existentes no mercado e adequá-los aos requisitos do sistema proposto. Com isso, as empresas que utilizarem este sistema terão maior facilidade e menores custos para se adequarem as exigências das certificadoras, já que os controles e as informações requeridas na certificação estão presentes no sistema de rastreabilidade. 


\subsection{ARQUITETURA PROPOSTA}

Baseado nos requisitos descritos é apresentada a modelagem do sistema proposto, que utiliza o paradigma da arquitetura orientada a serviços (SOA), com o objetivo de garantir a rastreabilidade e a origem dos produtos e matérias-primas florestais durante toda a sua cadeia de suprimentos.

O processo utilizado na modelagem do sistema é baseado no método apresentado em Endrei et al. (2004), que define boas práticas para a implementação de soluções usando este paradigma.

Este método consiste em sete passos principais, apresentados na Figura 17. A aplicação prática destes padrões varia conforme o sistema a ser desenvolvido e a equipe de trabalho, sendo possível inclusive a realização de atividades em paralelo, a inclusão, exclusão ou adaptação de atividades, conforme a necessidade.

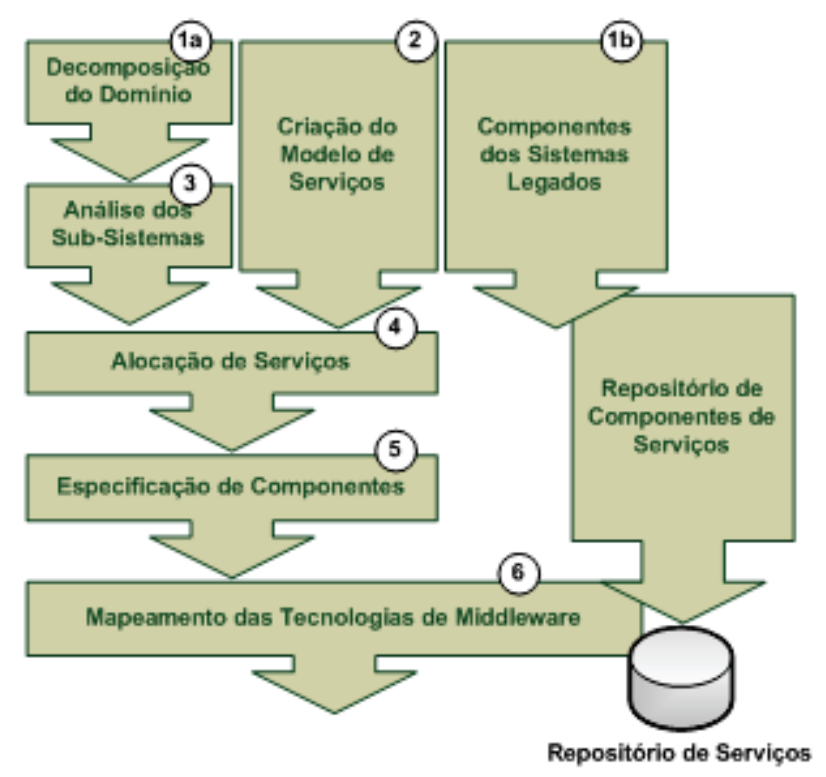

Figura 17 - Principais etapas do método de modelagem SOA. Fonte: Extraído e adaptado de Corrêa (2007).

\subsubsection{DECOMPOSIÇÃO DO DOMÍNIO}

Na primeira etapa do método é decomposto o domínio do problema, sendo identificadas as suas respectivas áreas funcionais. Após esta definição, as áreas funcionais são decompostas em processos, subprocessos e casos de uso de negócio. 
A Figura 18 apresenta a decomposição do domínio da cadeia de suprimentos da madeira.

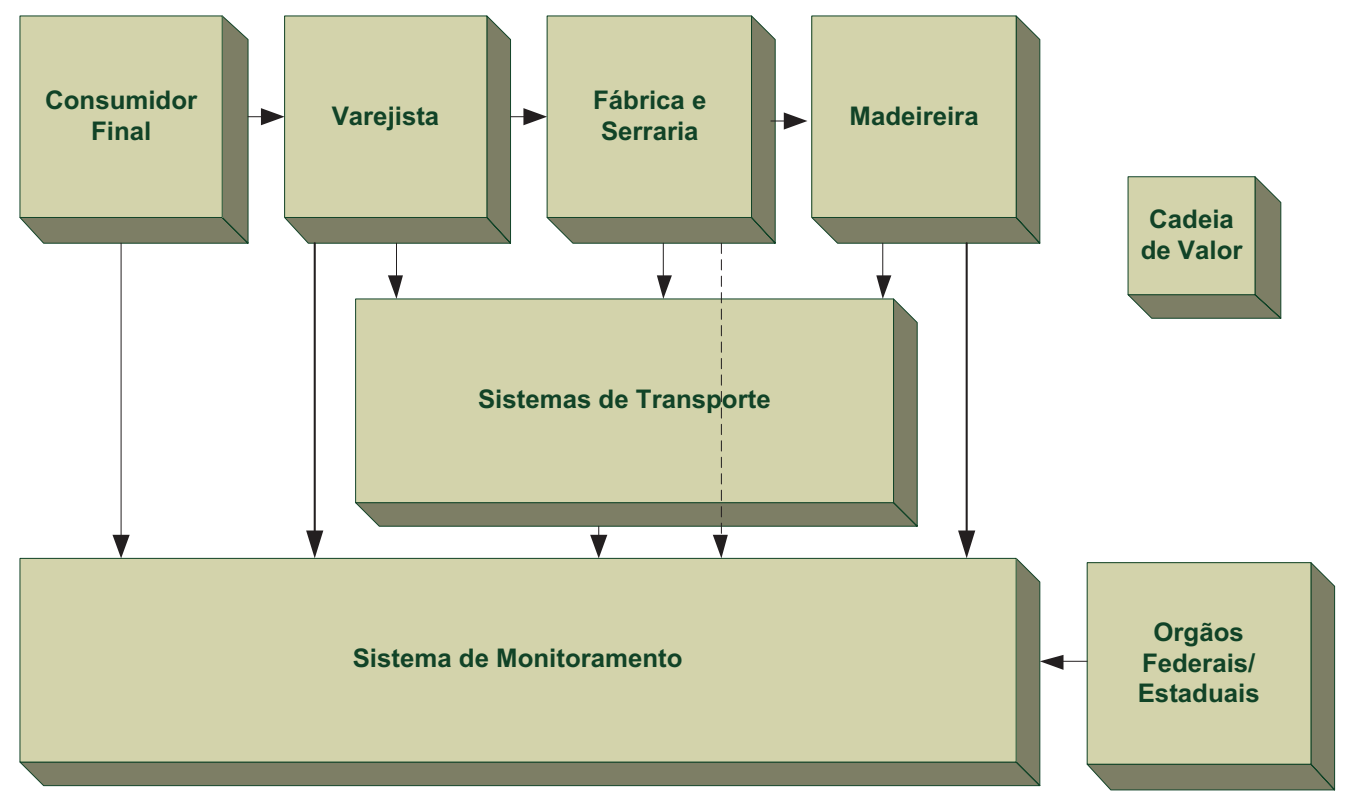

Figura 18 - Decomposição do Domínio da Cadeia de Valor em áreas funcionais.

Esta decomposição em áreas funcionais identifica a relação entre os participantes da cadeia de valor e o Sistema de Monitoramento, que têm por objetivo gerenciar e registrar todas as informações que envolvem as relações entre os participantes do processo, possibilitando com isso, a manutenção e a validação destas informações durante todo o ciclo de vida do produto. As áreas funcionais identificadas foram as seguintes:

- Consumidor Final. Representa a pessoa ou empresa que compra produtos florestais no varejo e em lojas especializadas para consumo próprio ou para a utilização na construção civil. Esta área funcional não possui participação direta no processo produtivo, mas é responsável pela geração da demanda de produtos na cadeia de suprimentos.

- Varejista. Empresa que realiza a compra de produtos florestais das empresas de beneficiamento para disponibilizá-lo ao mercado consumidor.

- Fábrica e Serraria. Empresas de beneficiamento que compram matérias primas das madeireiras e realizam os beneficiamentos 
necessários para a geração de produtos ou subprodutos florestais.

- Madeireira. Empresa extrativista que realiza a colheita/extração da matéria prima em florestas tropicais nativas. Ela é responsável pela elaboração dos projetos de manejo e de exploração que, após aprovados, possibilitam a exploração e comercialização destes produtos.

- Sistemas de Transporte. Sistema governamental responsável pelo gerenciamento das atividades comerciais que envolvem os produtos florestais controlados por lei. O DOF e o SISFLORA são os principais representantes destes sistemas no Brasil.

- Órgãos Federais e Estaduais. Órgãos governamentais responsáveis pelas autorizações das atividades de exploração, beneficiamento e comercialização de produtos florestais e pela supervisão de toda a cadeia de suprimento destes produtos. São representados por diversas entidades estaduais e federais, entre elas destacam-se o IBAMA, as SEMAs e o Instituto de Proteção Ambiental do Estado do Amazonas (IPAAM).

- Sistema de Monitoramento. Sistema proposto responsável pelo monitoramento e integração dos sistemas participantes do processo produtivo, realizando também o registro das informações necessárias para a rastreabilidade do processo e dos produtos.

\subsubsection{CASOS DE USO}

Após a identificação das áreas funcionais e suas relações, são identificados os respectivos casos de uso de negócio relevantes para a manutenção das informações do processo produtivo florestal. Na definição dos casos de uso, são utilizadas as duas abordagens sugeridas pelo método de modelagem: A Top-Down e a Bottom-Up.

A abordagem Top-Down é utilizada para identificar os serviços baseados no domínio da aplicação e a abordagem Bottom-Up identifica os serviços considerando os sistemas legados, banco de dados e pacotes de software existentes no processo. 
Nos próximos tópicos são detalhados os principais processos da cadeia de suprimentos de produtos florestais e as atividades que irão interagir com o sistema de monitoramento. Estas atividades registram ou consomem informações essenciais para o gerenciamento e a manutenção das informações da cadeia de suprimentos.

Com a finalidade de simplificar os diagramas de casos de uso apresentados a seguir, será utilizado o conceito de Sistemas Corporativos para representar os sistemas computacionais utilizados pelas Empresas Extrativistas (Madeireiras), pelas Empresas de Beneficiamento (Fábricas e Serrarias) e pelas empresas Varejistas. Esta generalização é possível devido estas empresas possuírem atividades em comum dentro do processo produtivo florestal.

\subsubsection{PROCESSO DE PLANEJAMENTO E AUTORIZAÇÃO DE EXPLORAÇÃO}

Este processo consiste nas atividades necessárias para a obtenção das autorizações e licenças para a exploração da área florestal. Dentre estas atividades, o inventário florestal se destaca, pois é nesta atividade onde podem ser atribuídas identificações únicas às árvores, que possibilitarão sua rastreabilidade durante todo seu ciclo de vida.

O levantamento dos dados da propriedade florestal e o inventário das árvores, realizados pelas grandes empresas extrativistas, utilizam sistemas de informação próprios, GPS entre outras ferramentas tecnológicas que podem ser integrados ao sistema de rastreabilidade, facilitando assim o registro destas informações. Sendo que muitas empresas, principalmente as de pequeno porte, ainda executam estas atividades de forma primitiva, por meio de levantamento de campo, medições e registros manuais.

Para garantir uma padronização destas informações na base de dados do Sistema de Monitoramento, independente das condições e do nível de informatização da empresa extrativista, no item 4.2.2.8 é apresentado um Portal Web que pode ser utilizado como alternativa para o registro e consulta de informações no sistema de rastreabilidade.

Diversos órgãos e sistemas governamentais também são envolvidos nestas 
atividades. Com a integração destes sistemas, uma maior agilidade, melhor controle e rastreabilidade serão possíveis.

Na Figura 19 é apresentado o fluxo deste processo.

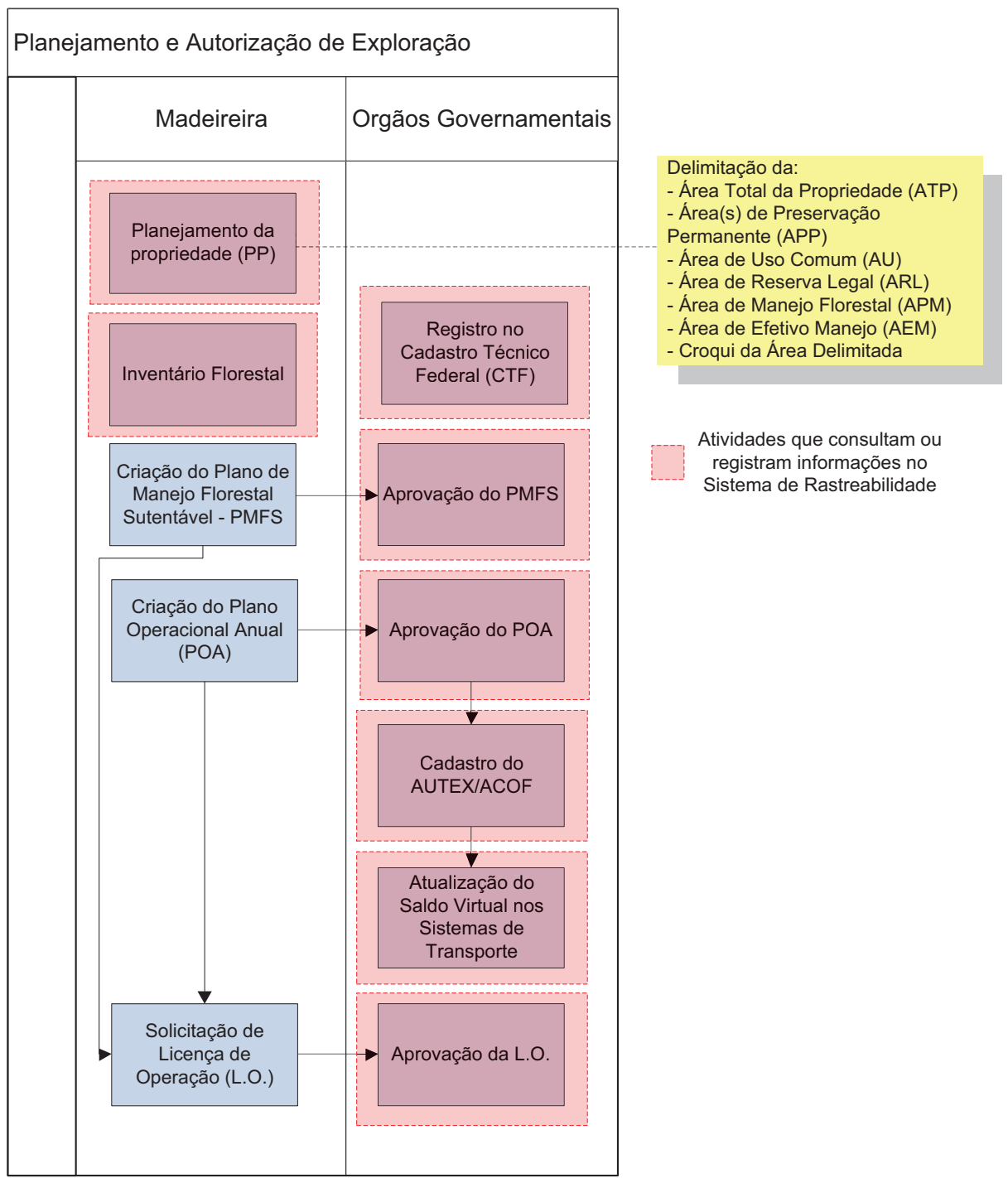

Figura 19 - Fluxo resumido de atividades do processo de planejamento e autorização de exploração florestal.

Com a realização da integração destes sistemas, a aprovação de uma autorização para exploração refletirá automaticamente nos demais sistemas envolvidos, como os Sistemas de Transporte (DOF e SISFLORA), que disponibilizarão o saldo florestal nos estoques virtuais para comercialização. Já em situações onde são verificadas irregularidades em uma empresa, o bloqueio da sua Licença de Operação (LO) no Sistema de Fiscalização bloqueará automaticamente o 
saldo virtual nos Sistemas de Transporte, impossibilitando que novas transações comerciais sejam realizadas. Na Figura 20 são apresentados os casos de uso deste processo.

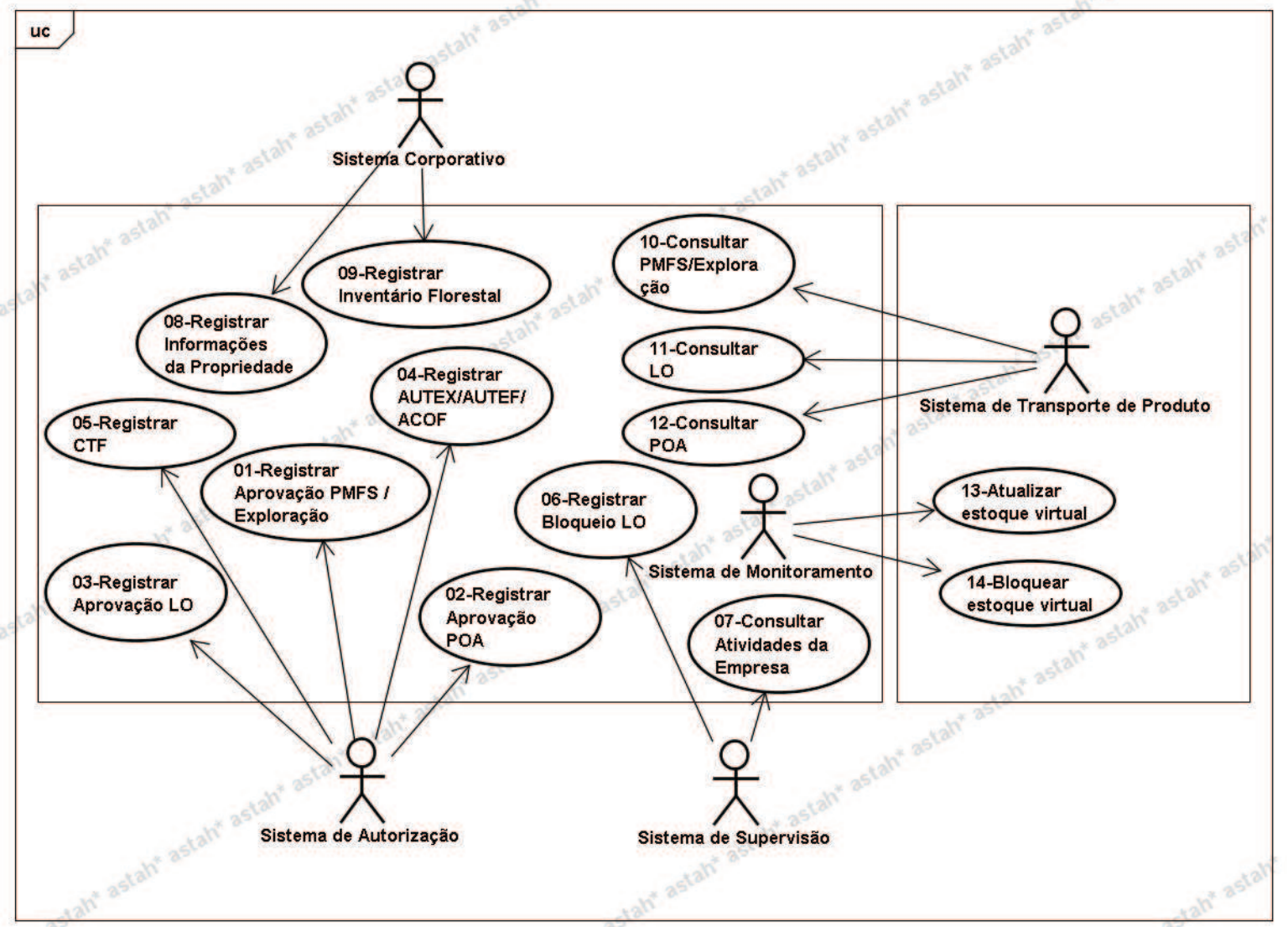

Figura 20 - Diagrama de caso de uso do processo de planejamento e autorização de exploração florestal.

Na Tabela 7, os casos de uso apresentados no diagrama são detalhados.

Tabela 7- Casos de Uso do processo de planejamento e autorização de exploração.

\begin{tabular}{|l|l|c|c|}
\hline \multicolumn{1}{|c|}{ Caso de Uso } & \multicolumn{1}{|c|}{ Descrição } & Fornecedor & Consumidor \\
\hline $\begin{array}{l}\text { UC01-Registrar } \\
\text { aprovação de } \\
\text { PMFS/Exploração }\end{array}$ & $\begin{array}{l}\text { Registra o projeto de PMFS } \\
\text { e/ou a autorização para } \\
\text { exploração florestal aprovada. }\end{array}$ & $\begin{array}{c}\text { Sistema de } \\
\text { Monitoramento }\end{array}$ & $\begin{array}{c}\text { Sistema de } \\
\text { Autorização }\end{array}$ \\
\hline $\begin{array}{l}\text { UC02 - Registrar } \\
\text { aprovação de POA }\end{array}$ & $\begin{array}{l}\text { Registra o POA (Plano } \\
\text { Operacional Anual) aprovado. }\end{array}$ & $\begin{array}{l}\text { Sistema de } \\
\text { Monitoramento }\end{array}$ & $\begin{array}{l}\text { Sistema de } \\
\text { Autorização }\end{array}$ \\
\hline
\end{tabular}




\begin{tabular}{|c|c|c|c|}
\hline $\begin{array}{l}\text { UC03 - Registrar } \\
\text { aprovação de LO }\end{array}$ & $\begin{array}{l}\text { Registrar a LO (licença de } \\
\text { operação) aprovada. }\end{array}$ & $\begin{array}{c}\text { Sistema de } \\
\text { Monitoramento }\end{array}$ & $\begin{array}{l}\text { Sistema de } \\
\text { Autorização }\end{array}$ \\
\hline $\begin{array}{l}\text { UC04 - Registrar } \\
\text { AUTEX/AUTEF/ACOF }\end{array}$ & $\begin{array}{l}\text { Registrar as autorizações para } \\
\text { exploração aprovadas, com } \\
\text { suas respectivas espécies, } \\
\text { volumes, números de } \\
\text { identificação unitários e } \\
\text { quantidades. }\end{array}$ & $\begin{array}{c}\text { Sistema de } \\
\text { Monitoramento }\end{array}$ & $\begin{array}{l}\text { Sistema de } \\
\text { Autorização }\end{array}$ \\
\hline UC05 - Registrar CTF & $\begin{array}{l}\text { Registrar o registro do CTF } \\
\text { (Cadastro Técnico Federal) de } \\
\text { uma empresa. }\end{array}$ & $\begin{array}{c}\text { Sistema de } \\
\text { Monitoramento }\end{array}$ & $\begin{array}{l}\text { Sistema de } \\
\text { Autorização }\end{array}$ \\
\hline $\begin{array}{l}\text { UC06 - Registrar } \\
\text { Bloqueio L.O. }\end{array}$ & $\begin{array}{l}\text { Registrar o bloqueio da L.O de } \\
\text { uma empresa devido } \\
\text { irregularidades na exploração } \\
\text { e/ou comercialização de } \\
\text { produtos florestais. }\end{array}$ & $\begin{array}{c}\text { Sistema de } \\
\text { Monitoramento }\end{array}$ & $\begin{array}{l}\text { Sistema de } \\
\text { Fiscalização }\end{array}$ \\
\hline $\begin{array}{l}\text { UC07 - Consultar } \\
\text { atividades da empresa }\end{array}$ & $\begin{array}{l}\text { Consultar as atividades de } \\
\text { extração, transformação e/ou } \\
\text { comercialização de uma } \\
\text { empresa. }\end{array}$ & $\begin{array}{c}\text { Sistema de } \\
\text { Monitoramento }\end{array}$ & $\begin{array}{l}\text { Sistema de } \\
\text { Fiscalização }\end{array}$ \\
\hline $\begin{array}{l}\text { UC08 - Registrar } \\
\text { informações da } \\
\text { propriedade }\end{array}$ & $\begin{array}{l}\text { Registrar informações da } \\
\text { propriedade onde será } \\
\text { realizado o PMFS ou a } \\
\text { Exploração Florestal. }\end{array}$ & $\begin{array}{c}\text { Sistema de } \\
\text { Monitoramento }\end{array}$ & $\begin{array}{c}\text { Sistema } \\
\text { Corporativo }\end{array}$ \\
\hline $\begin{array}{l}\text { UC09 - Registrar } \\
\text { Inventário Florestal }\end{array}$ & $\begin{array}{l}\text { Registrar as informações } \\
\text { geradas pelo inventário } \\
\text { florestal da propriedade. }\end{array}$ & $\begin{array}{c}\text { Sistema de } \\
\text { Monitoramento }\end{array}$ & $\begin{array}{c}\text { Sistema } \\
\text { Corporativo }\end{array}$ \\
\hline $\begin{array}{l}\text { UC10 - Consultar } \\
\text { PMFS / Autorização de } \\
\text { Exploração. }\end{array}$ & $\begin{array}{l}\text { Consultar informações sobre o } \\
\text { PMFS ou a Autorização para } \\
\text { Exploração de uma empresa. }\end{array}$ & $\begin{array}{c}\text { Sistema de } \\
\text { Monitoramento }\end{array}$ & $\begin{array}{l}\text { Sistema de } \\
\text { Transporte }\end{array}$ \\
\hline UC11 - Consultar LO & $\begin{array}{l}\text { Consultar informações sobre a } \\
\text { L.O. de uma empresa }\end{array}$ & $\begin{array}{c}\text { Sistema de } \\
\text { Monitoramento }\end{array}$ & $\begin{array}{l}\text { Sistema de } \\
\text { Transporte }\end{array}$ \\
\hline UC12 - Consultar POA & $\begin{array}{l}\text { Consultar informações sobre o } \\
\text { POA de uma empresa. }\end{array}$ & $\begin{array}{c}\text { Sistema de } \\
\text { Monitoramento }\end{array}$ & $\begin{array}{l}\text { Sistema de } \\
\text { Transporte }\end{array}$ \\
\hline $\begin{array}{l}\text { UC13-Atualizar } \\
\text { Estoque Virtual }\end{array}$ & $\begin{array}{l}\text { Atualizar saldo em estoque no } \\
\text { sistema de transporte }\end{array}$ & Sistema de Transporte & $\begin{array}{c}\text { Sistema de } \\
\text { Monitoramento }\end{array}$ \\
\hline
\end{tabular}




\begin{tabular}{|l|l|l|l|}
\hline & $\begin{array}{l}\text { correspondente (DOF ou } \\
\text { SISFLORA), conforme os } \\
\text { dados do AUTEX, ATEF ou } \\
\text { ACOF aprovado. Também é } \\
\text { utilizado na venda de produtos } \\
\text { florestais. }\end{array}$ & & \\
\hline $\begin{array}{l}\text { ES14 - Bloquear } \\
\text { Estoque Virtual }\end{array}$ & $\begin{array}{l}\text { Bloquear o saldo em estoque } \\
\text { no sistema de transporte } \\
\text { correspondente (DOF ou } \\
\text { SISFLORA), conforme } \\
\text { bloqueio realizado pelos } \\
\text { sistemas de fiscalização. }\end{array}$ & & Sistema de Transporte \\
\hline
\end{tabular}

\subsubsection{PROCESSO DE EXTRAÇÃO DA MADEIRA}

Neste processo as informações relevantes para o Sistema de Rastreabilidade são os registros das árvores extraídas, associadas à autorização que possibilitou a sua extração legal. Este registro é possível por meio do identificador único associado às árvores durante o processo de inventário florestal. Com o registro destas informações, uma fiscalização mais efetiva das atividades exploratórias pode ser realizada.

O inventário pós-corte e os relatórios pós-exploratórios, atividades obrigatórias no processo, também poderão ser automatizados, possibilitando uma validação do processo pela combinação das informações destes relatórios com as registradas durante a exploração. Além disso, a análise destes dados juntamente com os dados disponibilizados pelos sistemas de fiscalização facilita a descoberta de fraudes nas atividades de extração. Na Figura 21 é apresentado o fluxo deste processo. 


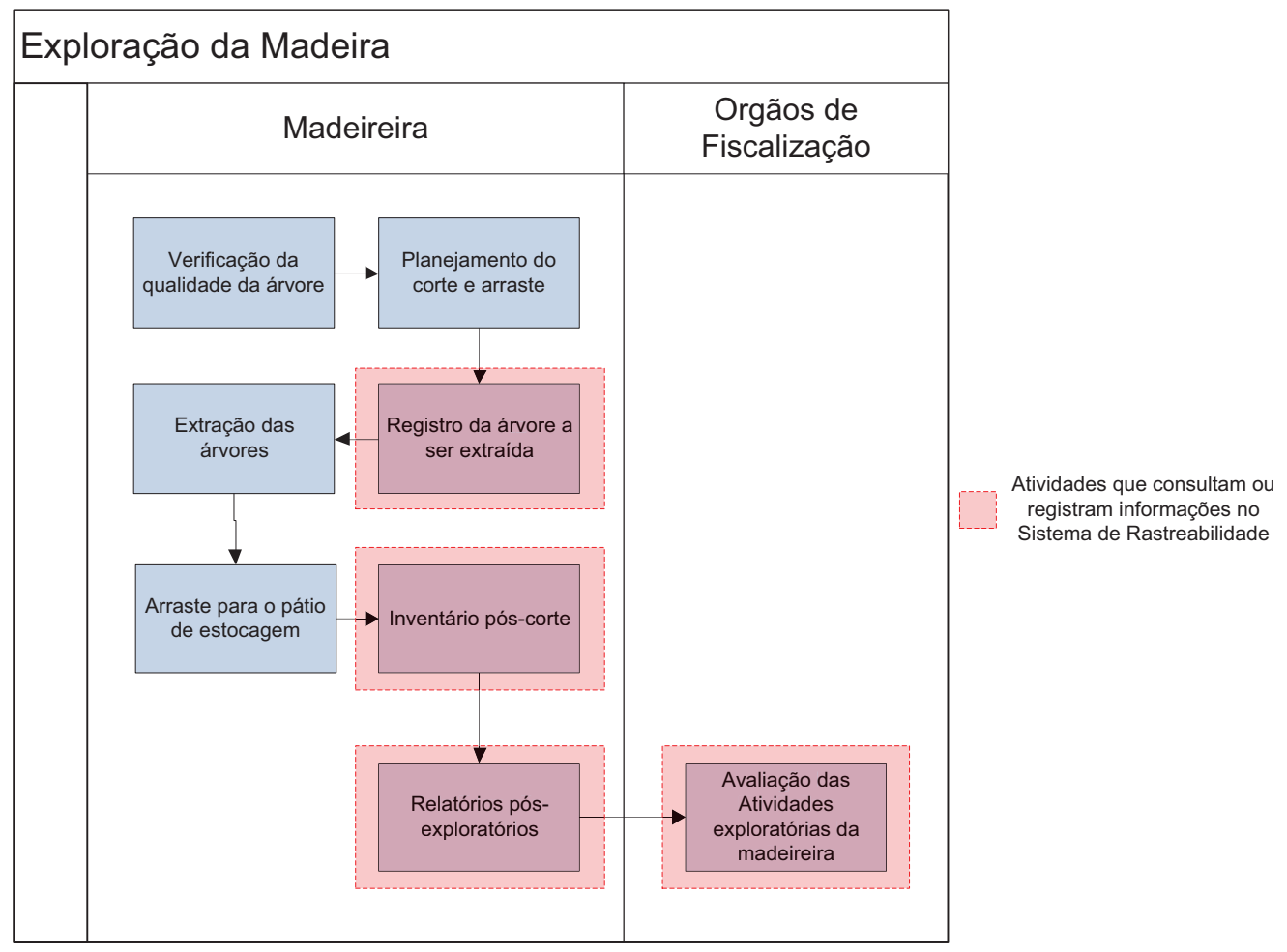

Figura 21 - Fluxo resumido do processo de exploração da madeira.

Na Figura 22 são apresentados os casos de uso deste processo.

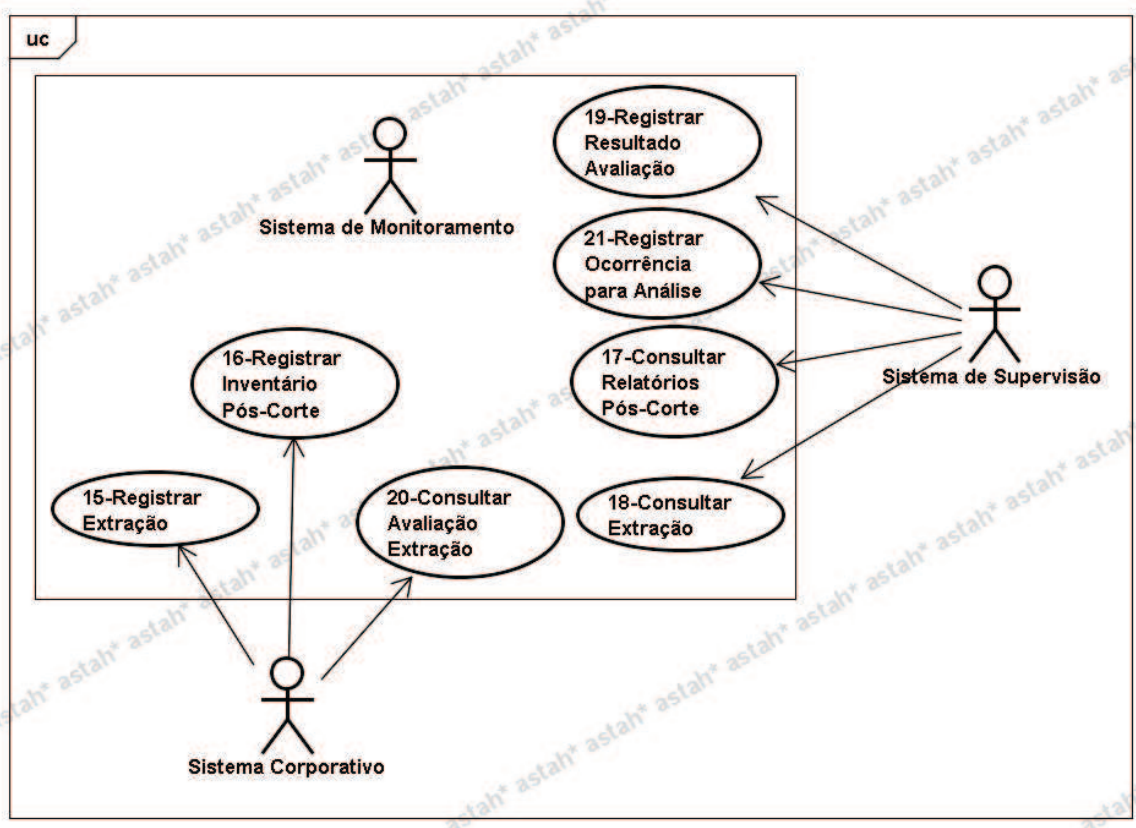

Figura 22 - Diagrama de caso de uso do processo de exploração de madeira.

Na Tabela 8, os casos de uso apresentados no diagrama são descritos: 
Tabela 8 - Casos de uso do processo de extração da madeira.

\begin{tabular}{|c|c|c|c|}
\hline Caso de Uso & Descrição & Fornecedor & Consumidor \\
\hline $\begin{array}{l}\text { UC15 - Registrar } \\
\text { Extração }\end{array}$ & $\begin{array}{l}\text { Registrar as árvores } \\
\text { extraídas e a respectiva } \\
\text { autorização que permitiu a } \\
\text { realização desta atividade. }\end{array}$ & $\begin{array}{c}\text { Sistema de } \\
\text { Monitoramento }\end{array}$ & Sistema Corporativo \\
\hline $\begin{array}{l}\text { UC16 - Registrar } \\
\text { Inventário Pós-Corte }\end{array}$ & $\begin{array}{l}\text { Registrar a totalização das } \\
\text { árvores extraídas, para } \\
\text { possibilitar a confirmação dos } \\
\text { dados registrados durante a } \\
\text { extração. }\end{array}$ & $\begin{array}{c}\text { Sistema de } \\
\text { Monitoramento }\end{array}$ & Sistema Corporativo \\
\hline $\begin{array}{l}\text { UC17 - Consultar } \\
\text { Relatório Pós-Corte }\end{array}$ & $\begin{array}{l}\text { Consultar as informações } \\
\text { registradas no relatório pós- } \\
\text { exploratório. }\end{array}$ & $\begin{array}{c}\text { Sistema de } \\
\text { Monitoramento }\end{array}$ & $\begin{array}{l}\text { Sistema de } \\
\text { Supervisão }\end{array}$ \\
\hline $\begin{array}{l}\text { UC18 - Consultar } \\
\text { Extração }\end{array}$ & $\begin{array}{lcr}\text { Consultar } & \text { informações da } \\
\text { atividade } & \text { de extração } \\
\text { realizada. } & & \end{array}$ & $\begin{array}{c}\text { Sistema de } \\
\text { Monitoramento }\end{array}$ & $\begin{array}{c}\text { Sistema de } \\
\text { Supervisão, Sistema } \\
\text { Corporativo }\end{array}$ \\
\hline $\begin{array}{l}\text { UC19 - Registrar } \\
\text { resultado avaliação }\end{array}$ & $\begin{array}{l}\text { Registrar a aprovação do } \\
\text { relatório pós-exploratório } \\
\text { enviado por determinada } \\
\text { empresa, possibilitando a } \\
\text { continuidade das atividades } \\
\text { de extração. }\end{array}$ & $\begin{array}{c}\text { Sistema de } \\
\text { Monitoramento }\end{array}$ & $\begin{array}{l}\text { Sistema de } \\
\text { Supervisão }\end{array}$ \\
\hline $\begin{array}{l}\text { UC20 - Consultar } \\
\text { Avaliação Extração }\end{array}$ & $\begin{array}{l}\text { Consultar a avaliação do } \\
\text { relatório pós-corte, realizado } \\
\text { pelo sistema de fiscalização. }\end{array}$ & $\begin{array}{c}\text { Sistema de } \\
\text { Monitoramento }\end{array}$ & $\begin{array}{l}\text { Sistema Corporativo, } \\
\text { Sistema de } \\
\text { Supervisão }\end{array}$ \\
\hline $\begin{array}{l}\text { UC21 - Registrar } \\
\text { Ocorrência para } \\
\text { Análise }\end{array}$ & $\begin{array}{l}\text { Registrar a suspeita de } \\
\text { possíveis irregularidades em } \\
\text { uma empresa. }\end{array}$ & $\begin{array}{c}\text { Sistema de } \\
\text { Monitoramento }\end{array}$ & $\begin{array}{l}\text { Sistema de } \\
\text { Fiscalização }\end{array}$ \\
\hline
\end{tabular}

\subsubsection{PROCESSO DE LICENCIAMENTO AMBIENTAL PARA BENEFICIAMENTO}

O licenciamento ambiental é um pré-requisito para que as empresas de beneficiamento e as indústrias de produtos florestais possam operar legalmente. $\mathrm{Na}$ Figura 23 é apresentado este processo. 


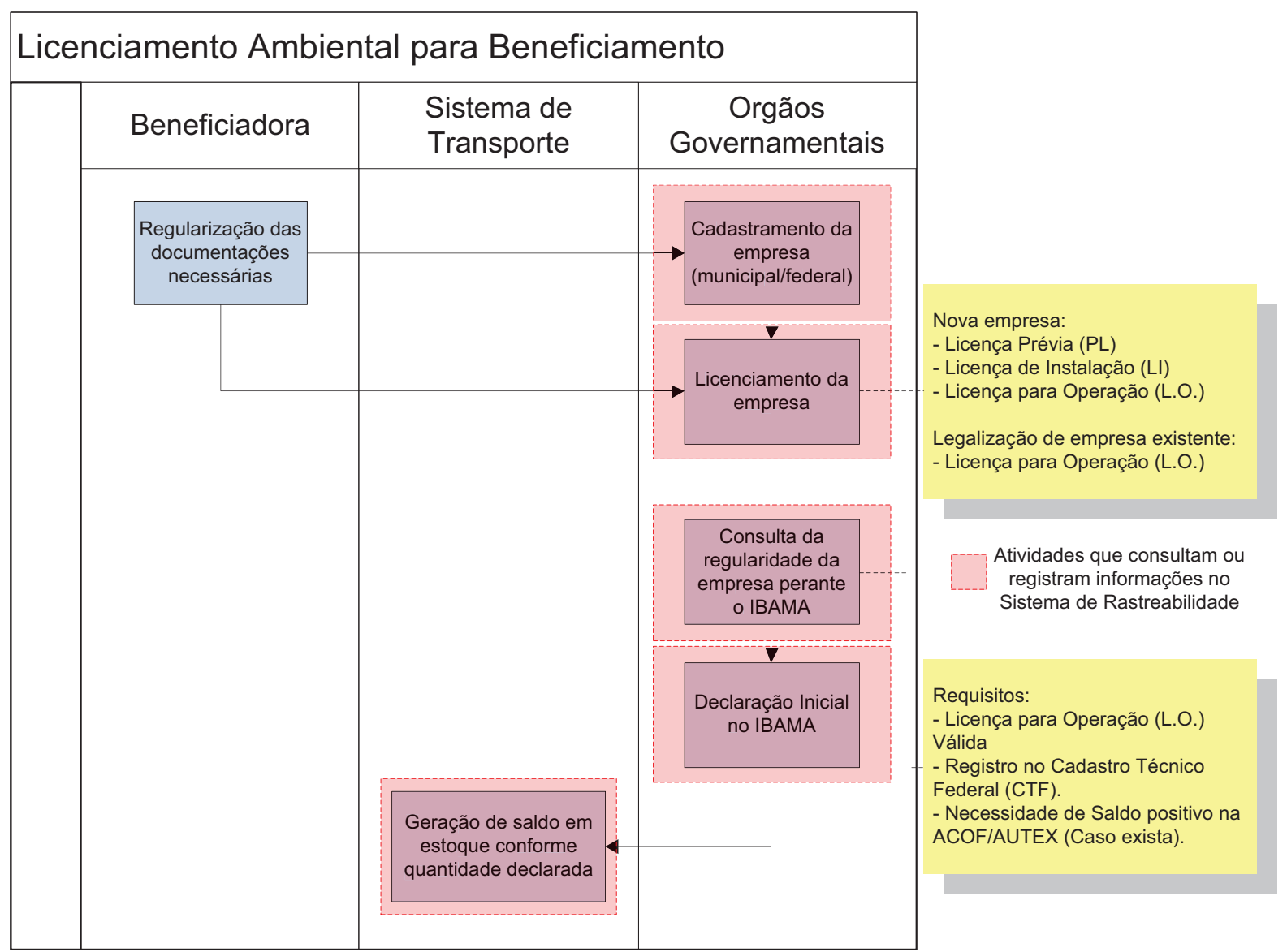

Figura 23 - Fluxo resumido de atividades do processo de licenciamento ambiental para beneficiamento.

Conforme apresentado no fluxo, as atividades de cadastro e licenciamento das empresas de beneficiamento poderão ser integradas por meio do sistema de rastreabilidade. Esta integração possibilitará que durante os cadastros, todos os prérequisitos sejam validados de forma on-line. Já na conclusão do processo, será gerado automaticamente o saldo virtual nos sistemas de transporte, referente aos produtos florestais declarados nos estoques das empresas. Na Figura 24, são apresentados os casos de uso deste processo. 


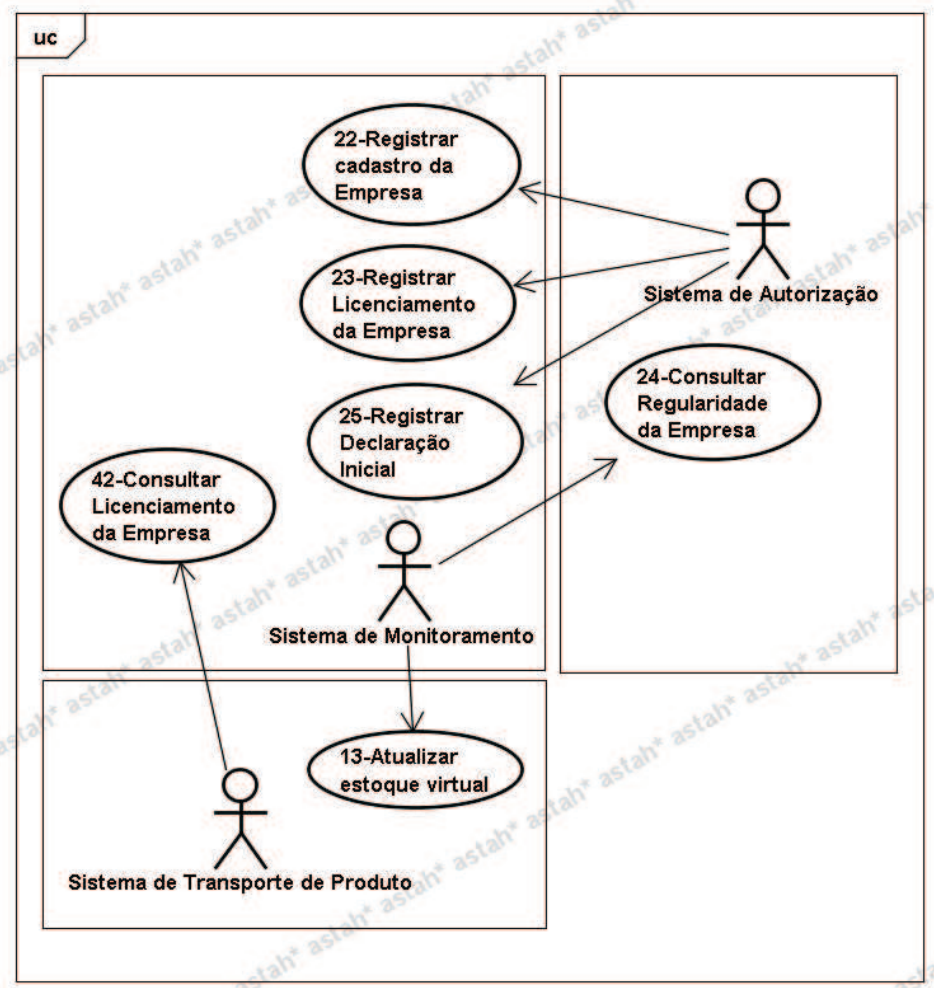

Figura 24 - Diagrama de casos de uso do processo de licenciamento ambiental para beneficiamento.

Na Tabela 9, os casos de uso apresentados no diagrama são descritos.

Tabela 9 - Casos de uso do processo de licenciamento ambiental para beneficiamento.

\begin{tabular}{|l|l|c|c|}
\hline \multicolumn{1}{|c|}{ Caso de Uso } & \multicolumn{1}{|c|}{ Descrição } & Fornecedor & Consumidor \\
\hline $\begin{array}{l}\text { UC22 - Registrar } \\
\text { Empresa }\end{array}$ & $\begin{array}{l}\text { Registrar o cadastro da } \\
\text { empresa de beneficiamento que } \\
\text { deseja realizar atividades } \\
\text { envolvendo insumos/produtos } \\
\text { florestais. }\end{array}$ & $\begin{array}{c}\text { Sistema de } \\
\text { Monitoramento }\end{array}$ & $\begin{array}{c}\text { Sistema de } \\
\text { Autorização }\end{array}$ \\
\hline $\begin{array}{l}\text { UC23 - Registrar } \\
\text { Licenciamento da }\end{array}$ & $\begin{array}{l}\text { Registrar o licenciamento da } \\
\text { empresa de beneficiamento que } \\
\text { deseja realizar atividades } \\
\text { envolvendo insumos/produtos } \\
\text { florestais. Sistema de }\end{array}$ & $\begin{array}{l}\text { Sonitoramento } \\
\text { Autorização }\end{array}$ \\
\hline $\begin{array}{l}\text { UC24 - Consultar } \\
\text { Regularidade da } \\
\text { Empresa }\end{array}$ & $\begin{array}{l}\text { Consultar situação da empresa } \\
\text { perante os Orgãos de } \\
\text { Autorização. }\end{array}$ & $\begin{array}{l}\text { Sistema de } \\
\text { Autorização }\end{array}$ & $\begin{array}{r}\text { Sistema de } \\
\text { Monitoramento }\end{array}$ \\
\hline UC25 - Registrar & $\begin{array}{l}\text { Registrar a declaração inicial } \\
\text { Sistema de }\end{array}$ & Sistema de \\
\hline
\end{tabular}




\begin{tabular}{|l|l|c|c|}
\hline Declaração Inicial & $\begin{array}{l}\text { requerida pelo IBAMA para que } \\
\text { a empresa possa iniciar sua } \\
\text { operação. }\end{array}$ & Monitoramento & Autorização \\
\hline $\begin{array}{l}\text { UC42 - Consultar } \\
\text { Licenciamento da } \\
\text { Empresa }\end{array}$ & $\begin{array}{l}\text { Consultar informações sobre o } \\
\text { licenciamento de uma empresa } \\
\text { de beneficiamento. }\end{array}$ & $\begin{array}{c}\text { Sistema de } \\
\text { Monitoramento }\end{array}$ & $\begin{array}{r}\text { Sistema de } \\
\text { Transporte }\end{array}$ \\
\hline
\end{tabular}

\subsubsection{PROCESSO DE TRANSFORMAÇÃO/FABRICAÇÃO DE PRODUTOS FLORESTAIS}

Neste processo são controladas as etapas produtivas dos produtos florestais, desde o gerenciamento dos insumos até a finalização do produto acabado. Os produtos florestais possuem uma quantidade de etapas produtivas (transformações) variadas, dependendo da complexidade do produto fabricado. Nestas transformações os insumos são desmembrados e agrupados, dificultando a manutenção da sua rastreabilidade. Na Figura 25 é apresentada a sequência de transformações existentes na fabricação de uma moldura para quadros de madeira.

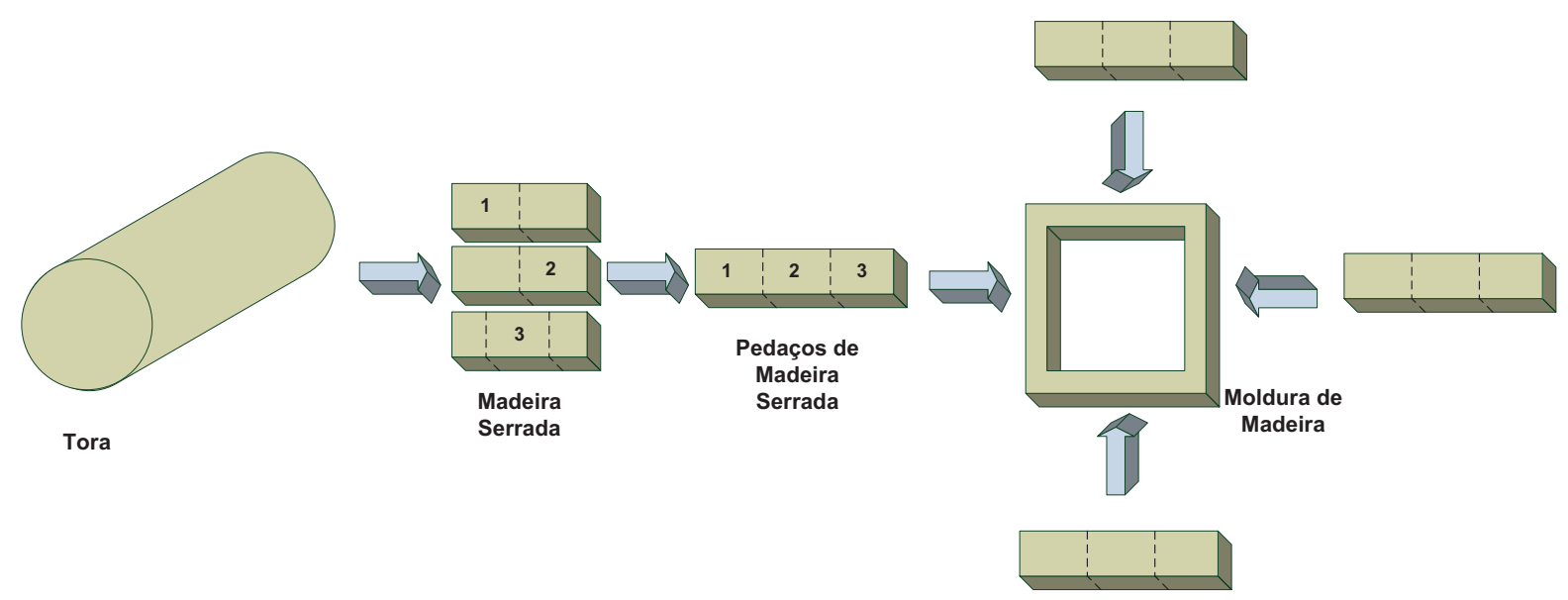

Figura 25 - Processo de transformação de madeira em produto final. Fonte: Extraído e adaptado de Sirkka (2008).

O principal objetivo do sistema de rastreabilidade neste processo é garantir as conexões entre as etapas produtivas e as empresas participantes, possibilitando assim, a rastreabilidade da origem do produto independente do número de 
transformações que o mesmo sofreu.

Para garantir a rastreabilidade neste cenário é necessário o registro de todos os insumos utilizados como matéria-prima, e realizar sua associação aos respectivos produtos fabricados, possibilitando desta maneira a manutenção da origem do produto, mesmo após a passagem por diversas etapas produtivas. Na Figura 26 é apresentado este processo.

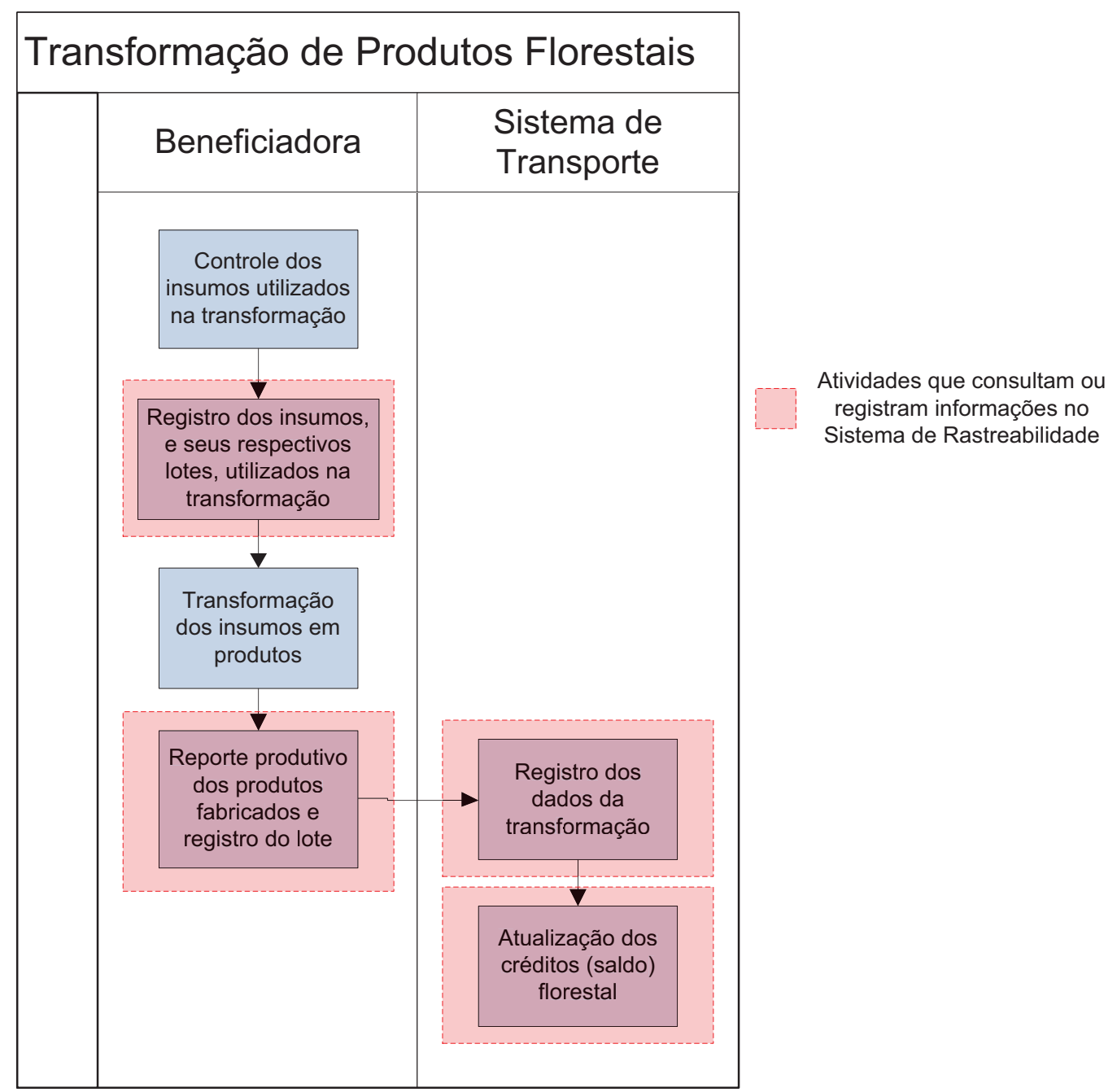

Figura 26 - Processo resumido de transformação de produtos florestais.

Uma das principais necessidades neste processo é o gerenciamento dos lotes de produtos. Toda matéria-prima comprada deve possuir um número de lote definido pelo seu fabricante. Este lote, além de facilitar o armazenamento e a utilização destas mercadorias na empresa compradora, possibilitará a ligação entre as diversas etapas produtivas no Sistema de Monitoramento. Após o processo de 
transformação, este lote de insumo será associado ao novo lote de produto acabado fabricado.

$\mathrm{Na}$ Figura 27 são apresentados os casos de uso do processo de transformação de produtos florestais.

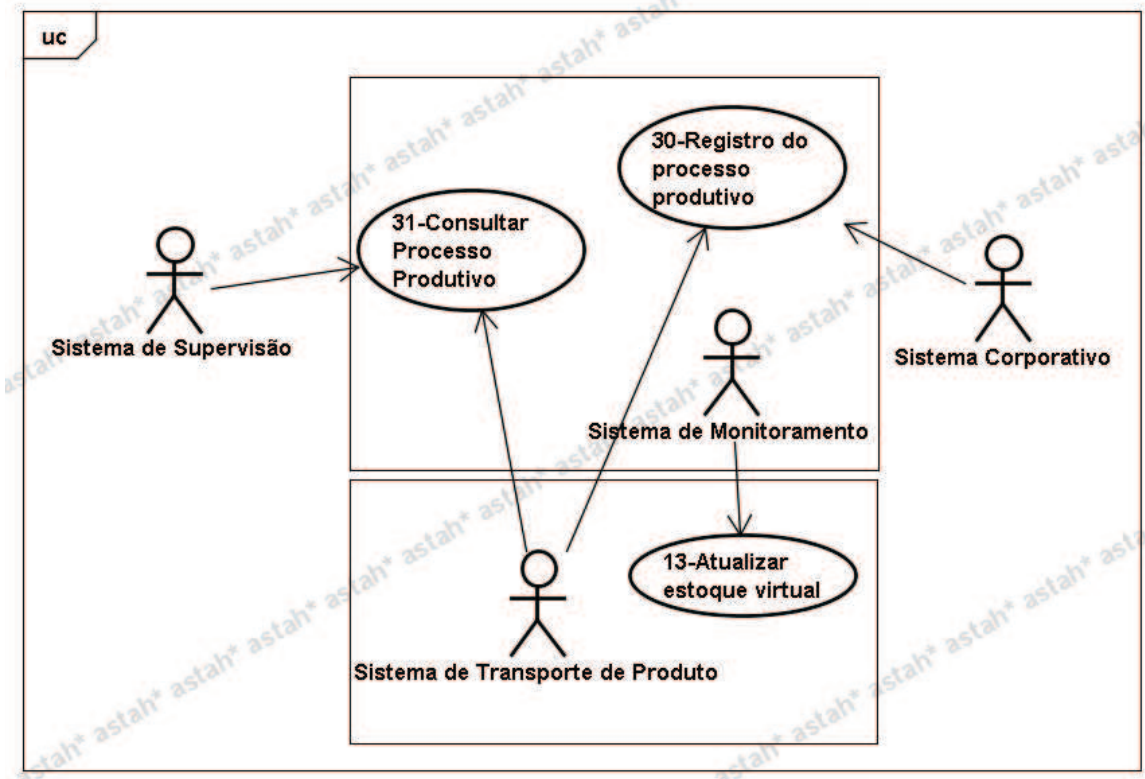

Figura 27 - Diagrama de casos de uso do processo de transformação de produtos florestais.

Na Tabela 10, os casos de uso apresentados no diagrama são descritos.

Tabela 10 - Casos de uso do processo de transformação de produtos florestais.

\begin{tabular}{|c|c|c|c|}
\hline Caso de Uso & Descrição & Fornecedor & Consumidor \\
\hline $\begin{array}{l}\text { UC30 - Registrar } \\
\text { Processo Produtivo }\end{array}$ & $\begin{array}{l}\text { Registrar os insumos de entrada } \\
\text { e seu lote, os produtos fabricados } \\
\text { e seu lote, além do registro dos } \\
\text { resíduos gerados. }\end{array}$ & $\begin{array}{c}\text { Sistema de } \\
\text { Monitoramento }\end{array}$ & $\begin{array}{l}\text { Sistema } \\
\text { Corporativo, } \\
\text { Sistema de } \\
\text { Transporte }\end{array}$ \\
\hline $\begin{array}{l}\text { UC31 - Consultar } \\
\text { Processo Produtivo }\end{array}$ & $\begin{array}{l}\text { Consultar as informações } \\
\text { referentes a um processo } \\
\text { produtivo de uma empresa. }\end{array}$ & $\begin{array}{c}\text { Sistema de } \\
\text { Monitoramento }\end{array}$ & $\begin{array}{l}\text { Sistema de } \\
\text { Transporte, } \\
\text { Sistema de } \\
\text { Supervisão }\end{array}$ \\
\hline
\end{tabular}




\subsubsection{PROCESSO DE NEGOCIAÇÃO/VENDA DE PRODUTOS}

FLORESTAIS

O processo de negociação e venda dos produtos florestais é realizado pelos sistemas de transporte. Devido à falta de integrações entre o DOF, o SISFLORA e os demais sistemas envolvidos no processo, vários problemas ainda são verificados, conforme detalhado no item 3.3 deste trabalho. Para cumprir os requisitos definidos para o sistema proposto, é necessária a real integração entre os sistemas, que possibilitará a validação, em tempo real, das informações registradas pelas empresas. Além disso, o gerenciamento destas informações possibilitará o rastreamento dos produtos, facilitando a supervisão do processo. Na Figura 28 é apresentada as atividades deste processo. 


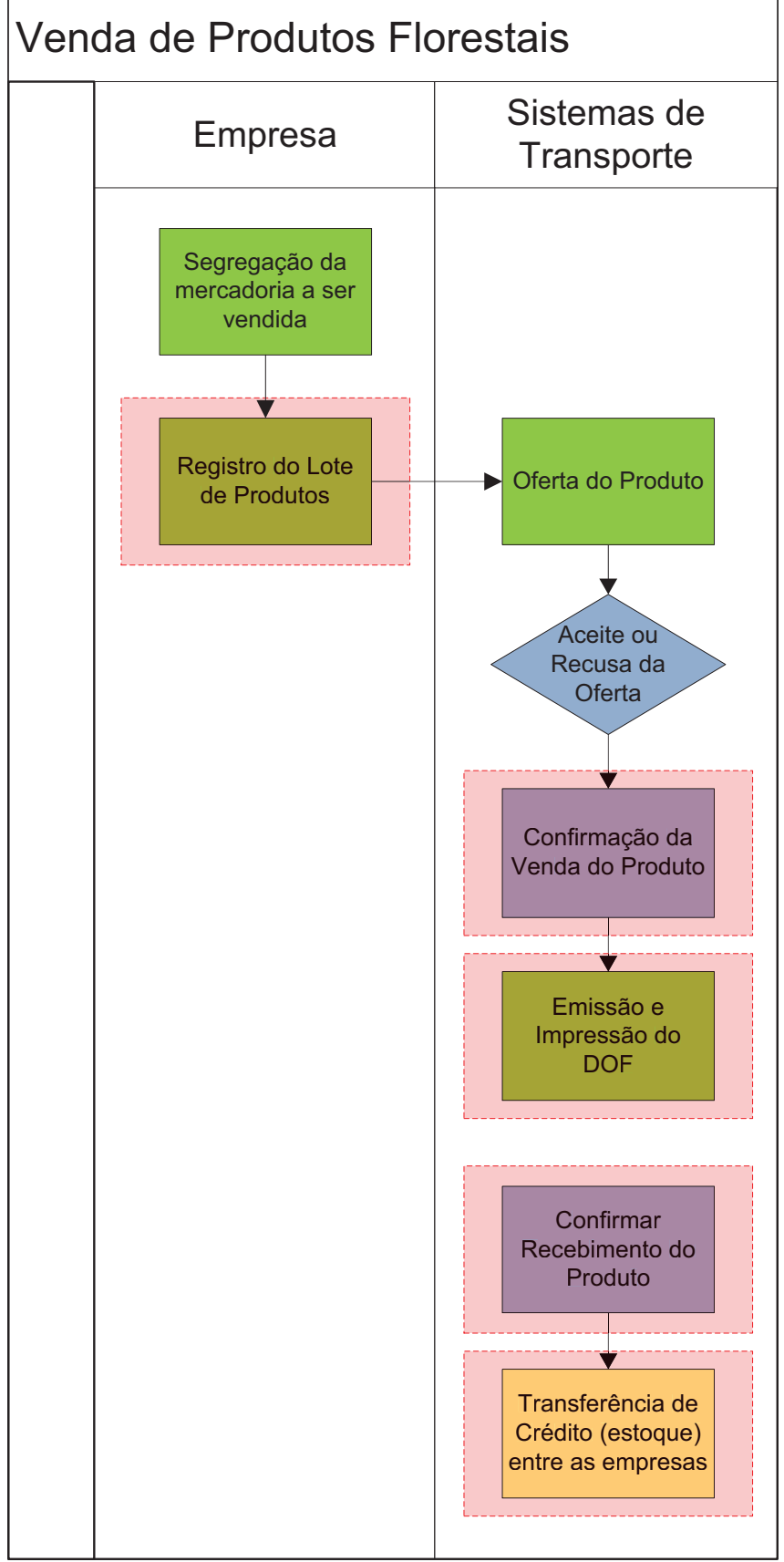

Realizador do Processo

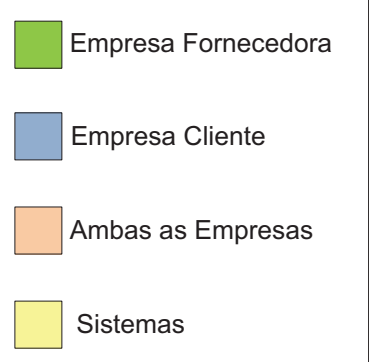

Atividades que consultam ou

registram informações no

Sistema de Rastreabilidade

Figura 28 - Processo de negociação/venda de produtos florestais.

Na Figura 29 são apresentados os casos de uso do processo. 


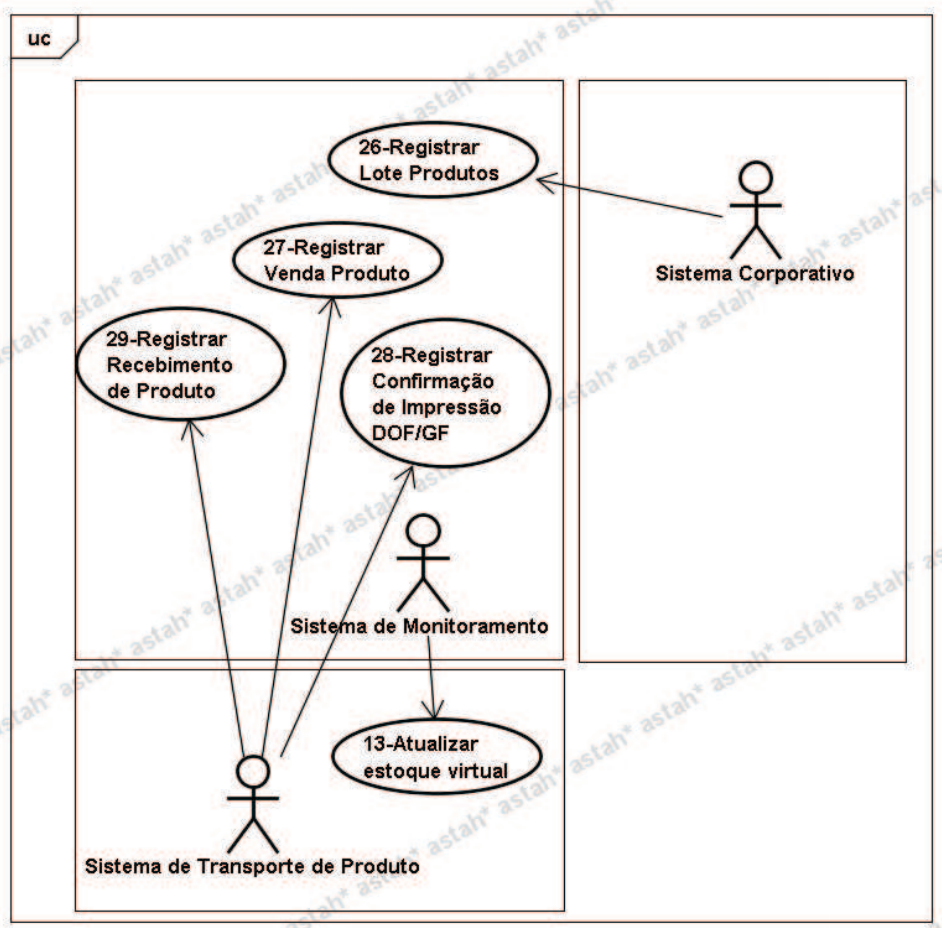

Figura 29 - Diagrama de casos de uso do processo de negociação/venda de produtos florestais.

Conforme verificado no diagrama, a utilização de lotes na venda de produtos florestais é uma novidade dentro do processo, que antes se preocupava apenas com as espécies e quantidades vendidas.

A venda de produtos em lotes possibilitará que os compradores possam realizar um melhor gerenciamento durante a armazenagem e a utilização da matéria prima na produção, além de possibilitar que o sistema de rastreabilidade utilize esta informação como um elo entre as diversas etapas da cadeia de suprimentos. $\mathrm{Na}$ Tabela 11 os casos de uso do diagrama são descritos.

Tabela 11 - Casos de uso do processo de negociação/venda de produtos florestais.

\begin{tabular}{|l|l|c|c|}
\hline \multicolumn{1}{|c|}{ Caso de Uso } & \multicolumn{1}{|c|}{ Descrição } & Fornecedor & Consumidor \\
\hline $\begin{array}{l}\text { UC26 - Registrar } \\
\text { Lote Produto }\end{array}$ & $\begin{array}{l}\text { Registrar o lote de produto } \\
\text { que será negociado pelo } \\
\text { sistema de transporte. }\end{array}$ & $\begin{array}{l}\text { Sistema de } \\
\text { Monitoramento }\end{array}$ & Sistema Corporativo \\
\hline $\begin{array}{l}\text { UC27 - Registrar } \\
\text { Venda Produto }\end{array}$ & $\begin{array}{l}\text { Registrar uma negociação } \\
\text { concretizada entre duas } \\
\text { empresas. }\end{array}$ & $\begin{array}{l}\text { Sistema de } \\
\text { Monitoramento }\end{array}$ & $\begin{array}{l}\text { Sistema de } \\
\text { Transporte }\end{array}$ \\
\hline
\end{tabular}




\begin{tabular}{|l|l|c|c|}
\hline $\begin{array}{l}\text { UC28 - Registrar } \\
\text { confirmação de } \\
\text { impressão de }\end{array}$ & $\begin{array}{l}\text { Registrar o momento que a } \\
\text { empresa realizou a } \\
\text { DOF/GF }\end{array}$ & $\begin{array}{l}\text { Sistema de } \\
\text { Monitoramento } \\
\text { do documento para } \\
\text { transporte de mercadorias } \\
\text { (DOF ou GF) }\end{array}$ & $\begin{array}{r}\text { Sistema de } \\
\text { Transporte }\end{array}$ \\
\\
$\begin{array}{l}\text { UC29-Registrar } \\
\text { Recebimento de }\end{array}$ & $\begin{array}{l}\text { Registrar a chegada do } \\
\text { produto comprado no pátio } \\
\text { de estocagem da empresa } \\
\text { compradora. }\end{array}$ & $\begin{array}{l}\text { Sistema de } \\
\text { Monitoramento }\end{array}$ & $\begin{array}{l}\text { Sistema de } \\
\text { Transporte }\end{array}$ \\
\hline
\end{tabular}

\subsubsection{PROCESSO DE DESTINAÇÃO DE PRODUTOS FLORESTAIS}

O processo de destinação é semelhante ao processo de venda de produtos, com a diferença de que o cliente, neste caso, não é uma empresa cadastrada nos órgãos governamentais, e sim, um varejista ou consumidor final. Na Figura 30 é apresentado este processo.

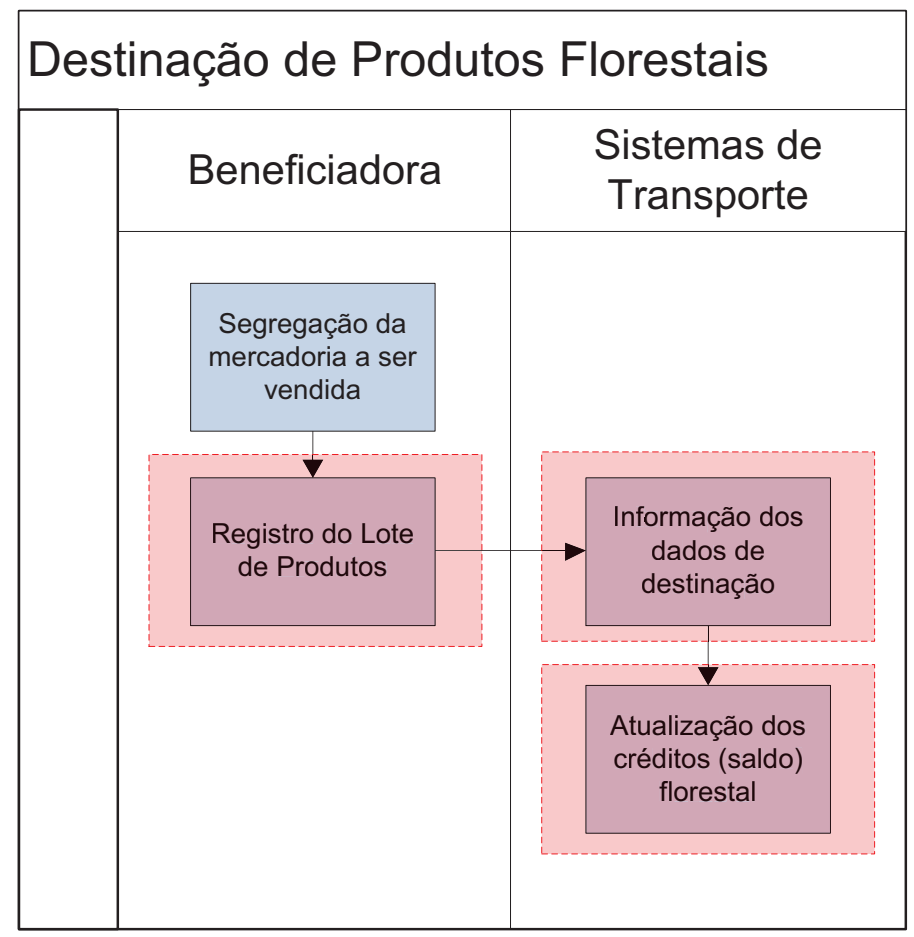

Atividades que consultam ou

registram informações no

Sistema de Rastreabilidade

Figura 30 - Processo de destinação de produtos florestais.

A principal necessidade neste processo para o sistema de rastreabilidade é 
que, antes da sua venda, os produtos acabados sejam identificados com um código de produto ou um código de lote, que possibilite o rastreamento da sua origem por meio desta identificação. Na Figura 31 são apresentados os casos de uso do processo e na Tabela 12 os casos de uso do diagrama são descritos.

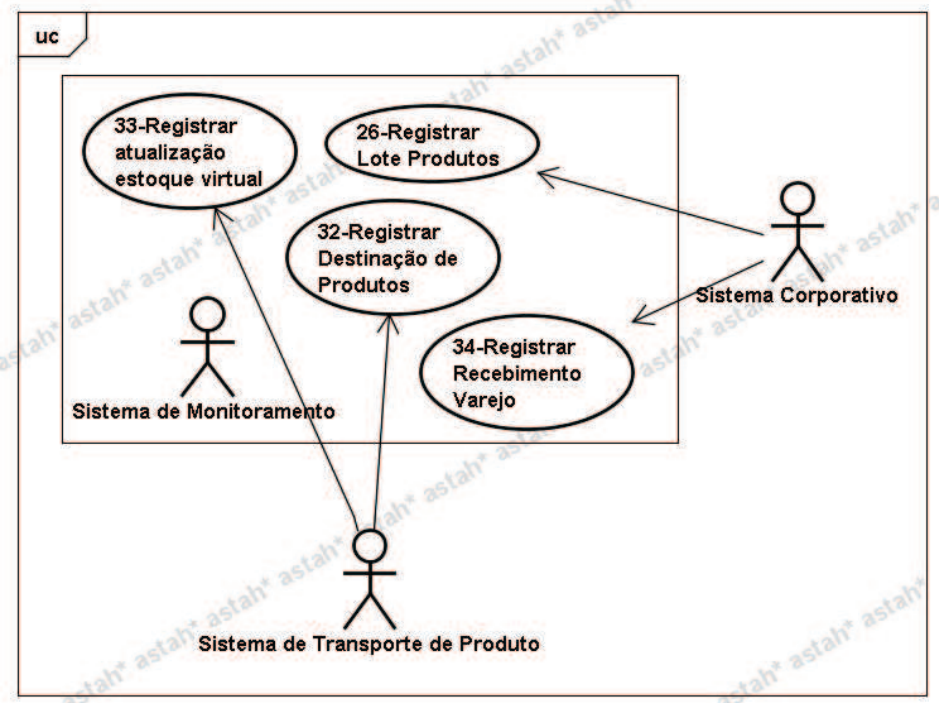

Figura 31 - Diagrama de casos de uso do processo de destinação de produtos florestais.

Tabela 12 - Casos de uso do processo de destinação de produtos florestais.

\begin{tabular}{|l|l|c|c|}
\hline \multicolumn{1}{|c|}{ Caso de Uso } & \multicolumn{1}{|c|}{ Descrição } & Fornecedor & Consumidor \\
\hline UC32 - Registrar & $\begin{array}{l}\text { Registrar a venda de produtos } \\
\text { para empresas que não de Produtos } \\
\text { possuem acesso ao sistema } \\
\text { DOF. }\end{array}$ & $\begin{array}{c}\text { Sistema de } \\
\text { Monitoramento }\end{array}$ & $\begin{array}{r}\text { Sistema de } \\
\text { Transporte }\end{array}$ \\
\hline $\begin{array}{l}\text { UC33 - Registrar } \\
\text { Atualização Estoque } \\
\text { Virtual }\end{array}$ & $\begin{array}{l}\text { Registrar alterações dos } \\
\text { estoques virtuais gerados pela } \\
\text { comercialização de produtos } \\
\text { florestais nos sistemas de } \\
\text { transporte. }\end{array}$ & $\begin{array}{l}\text { Sistema de } \\
\text { Monitoramento }\end{array}$ & $\begin{array}{l}\text { Sistema de } \\
\text { Transporte }\end{array}$ \\
\hline $\begin{array}{l}\text { UC34 - Registrar } \\
\text { Recebimento Varejo }\end{array}$ & $\begin{array}{l}\text { Registrar o recebimento real } \\
\text { dos produtos comprados pelo } \\
\text { varejo, para confrontar com as } \\
\text { informações registradas no } \\
\text { DOF/SISFLORA. }\end{array}$ & Sistema de \\
\end{tabular}




\subsubsection{ANÁLISE DOS SISTEMAS DE APOIO}

Após a identificação dos casos de uso pela análise dos processos de negócio, são analisados dois novos sistemas que podem contribuir com o gerenciamento da cadeia de suprimentos dos produtos florestais. O sistema da Secretaria da Fazenda (SEFAZ) e o sistema do Departamento Nacional de Trânsito (DENATRAN), integrados ao sistema de rastreabilidade, possibilitam a validação de informações que hoje são alvos de fraudes e irregularidades, devido a dificuldade de sua validação. Além disso, estes órgãos poderão consultar no sistema informações de grande importância, como dados tributários das empresas e a situação dos veículos utilizados no transporte dos produtos florestais.

O sistema da SEFAZ é responsável pela validação das notas fiscais emitidas nas vendas de insumos e produtos e na verificação da situação fiscal das empresas envolvidas. A validação on-line destas informações, no momento da emissão dos documentos de transporte florestal, pode evitar fraudes, como a utilização de uma mesma nota fiscal em vários documentos de transporte diferentes.

O sistema do DENATRAN é responsável pelo gerenciamento das informações de todos os veículos registrados no país. A validação on-line destas informações evita que veículos irregulares, tanto de documentação quanto de capacidade de carga, sejam utilizados para o transporte dos produtos florestais. Na Figura 32 são apresentados os casos de uso da interação destes sistemas com o Sistema de Monitoramento. 


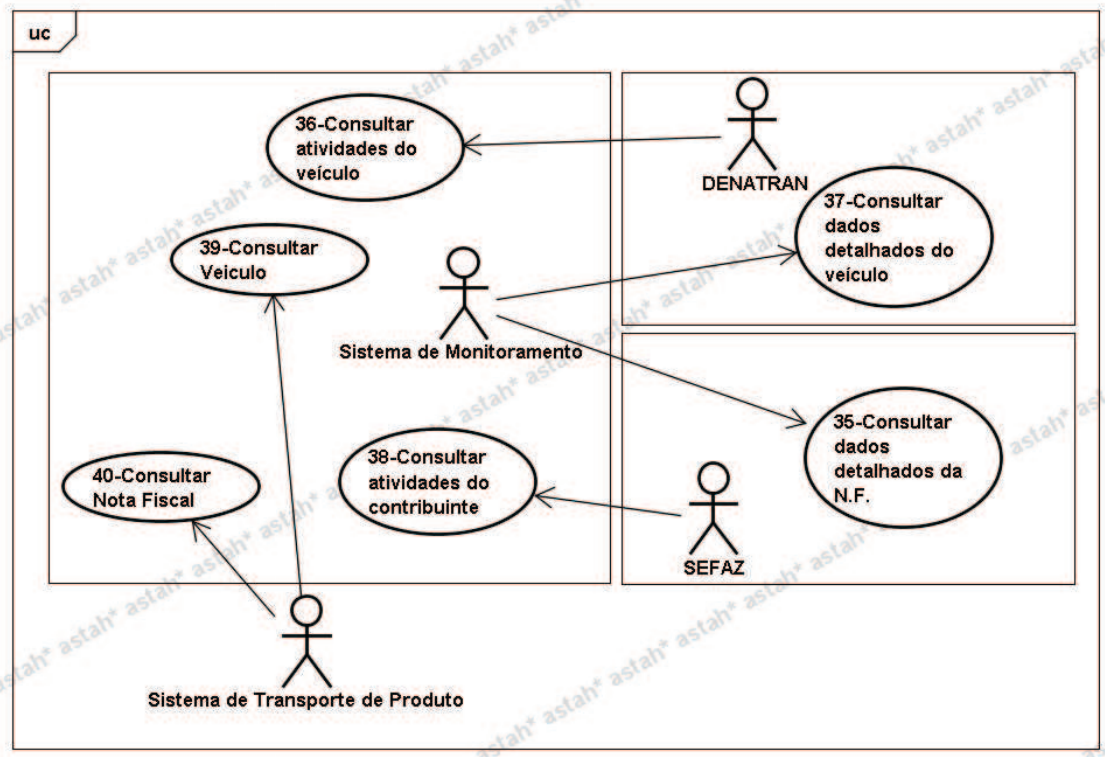

Figura 32 - Diagrama de casos de uso da integração entre o sistema de monitoramento e os sistemas de apoio.

Na Tabela 13, os casos de uso do diagrama são descritos.

Tabela 13 - Casos de uso da integração entre o sistema de rastreabilidade e os sistemas de apoio.

\begin{tabular}{|l|l|c|c|}
\hline \multicolumn{1}{|c|}{ Caso de Uso } & \multicolumn{1}{|c|}{ Descrição } & Fornecedor & Consumidor \\
\hline $\begin{array}{l}\text { UC35 - Consultar } \\
\text { dados detalhados } \\
\text { de NF }\end{array}$ & $\begin{array}{l}\text { Consultar todas as } \\
\text { informações sobre uma } \\
\text { determinada nota fiscal. }\end{array}$ & SEFAZ & $\begin{array}{c}\text { Sistema de } \\
\text { Monitoramento }\end{array}$ \\
\hline $\begin{array}{l}\text { UC36 - Consultar } \\
\text { atividades do } \\
\text { veículo }\end{array}$ & $\begin{array}{l}\text { Consultar todas as atividades } \\
\text { de transporte de produtos } \\
\text { florestais de um veículo ou de } \\
\text { uma empresa, em } \\
\text { determinado período. }\end{array}$ & $\begin{array}{c}\text { Sistema de } \\
\text { Monitoramento }\end{array}$ & DENATRAN \\
\hline $\begin{array}{l}\text { UC37 - Consultar } \\
\text { dados detalhados } \\
\text { do veículo }\end{array}$ & $\begin{array}{l}\text { Consultar todas as } \\
\text { informações sobre um } \\
\text { determinado veículo. }\end{array}$ & DENATRAN & $\begin{array}{c}\text { Sistema de } \\
\text { Monitoramento }\end{array}$ \\
\hline $\begin{array}{l}\text { UC38 - Consultar } \\
\text { atividades do } \\
\text { contribuinte }\end{array}$ & $\begin{array}{l}\text { Consultar todas as atividades } \\
\text { comerciais da empresa que } \\
\text { envolva produtos florestais, } \\
\text { em um determinado período. }\end{array}$ & Sistema de \\
\hline
\end{tabular}




\begin{tabular}{|l|l|c|c|}
\hline $\begin{array}{l}\text { UC39 - Consultar } \\
\text { veículo }\end{array}$ & $\begin{array}{l}\text { Consultar as informações } \\
\text { sobre o veículo relacionado a } \\
\text { um documento de transporte } \\
\text { florestal. }\end{array}$ & $\begin{array}{r}\text { Sistema de } \\
\text { Monitoramento }\end{array}$ & $\begin{array}{r}\text { Sistema de } \\
\text { Transporte }\end{array}$ \\
\hline $\begin{array}{l}\text { UC40 - Consultar } \\
\text { Nota Fiscal }\end{array}$ & $\begin{array}{l}\text { Consultar as informações } \\
\text { sobre a nota fiscal } \\
\text { relacionada a um documento } \\
\text { de transporte florestal. }\end{array}$ & $\begin{array}{l}\text { Sistema de } \\
\text { Monitoramento }\end{array}$ & $\begin{array}{l}\text { Sistema de } \\
\text { Transporte }\end{array}$ \\
\hline
\end{tabular}

\subsubsection{FUNCIONALIDADES DO PORTAL WEB}

A integração do sistema de rastreabilidade aos sistemas corporativos das empresas madeireiras e de beneficiamento é um dos objetivos do sistema proposto. Com esta integração, diversas informações podem ser validadas e consultadas automaticamente. Sendo que, devido os custos com estas integrações, várias empresas acabam não possuindo condições de investir nessa adequação. Muitas vezes também, as empresas não possuem sistemas corporativos, e realizam seu controle totalmente em papéis ou em simples planilhas de cálculo.

Para possibilitar que todas as empresas, inclusive as menores, utilizem o sistema de rastreabilidade, é disponibilizado como alternativa um Portal Web, que disponibiliza as principais funções do sistema de rastreabilidade e onde a empresa que não possui sistema computacional poderá registrar e consultar as informações do seu processo produtivo.

Este portal possui duas áreas distintas. A primeira é pública, e voltada para a consulta da origem dos produtos florestais, e a segunda área, restrita as empresas cadastradas, possibilitará o acesso as funcionalidades que apoiam as atividades relacionadas ao processo produtivo da empresa. Na Figura 33 são apresentados os casos de uso do Portal Web. 


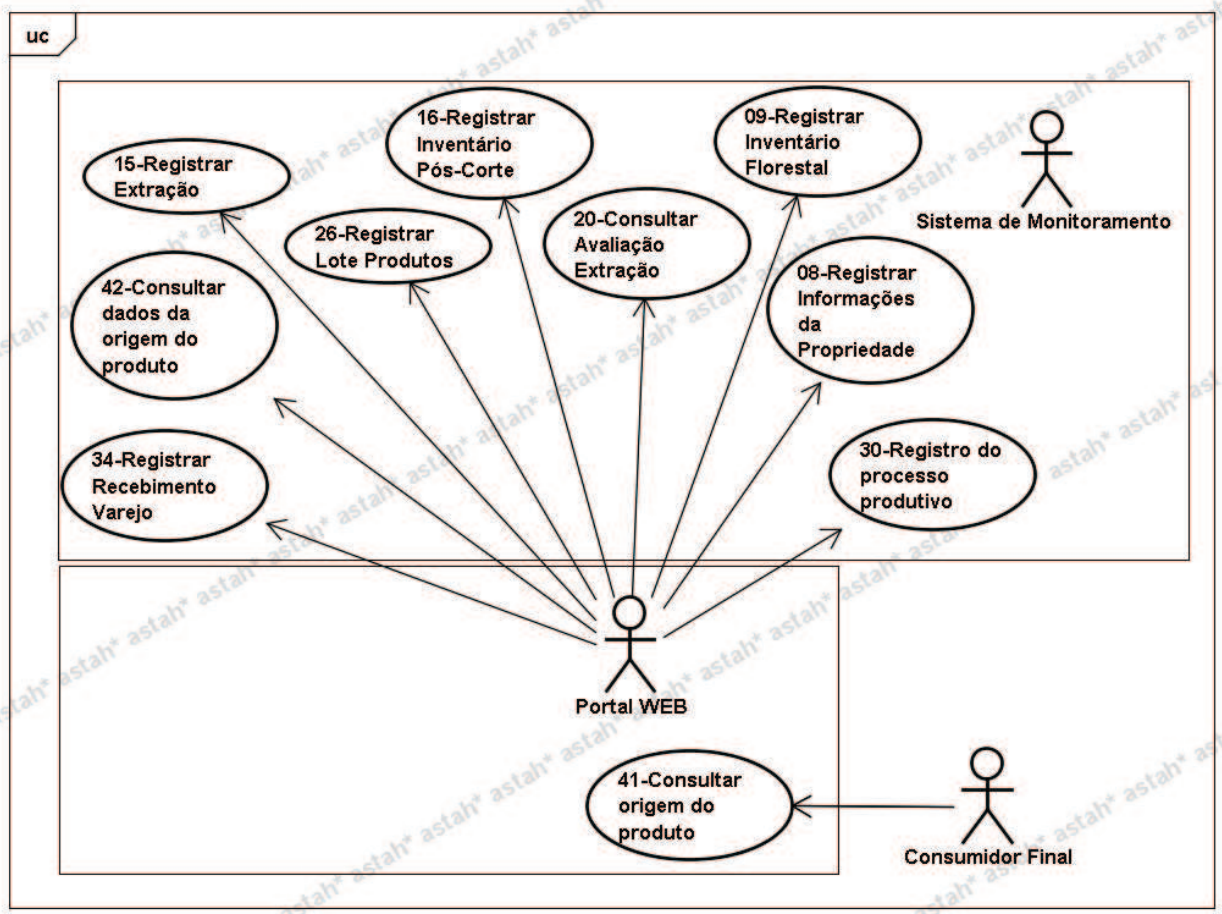

Figura 33 - Diagrama de casos de uso do Portal WEB.

Na Tabela 14 os casos de uso do diagrama são descritos.

Tabela 14- Casos de Uso relacionados ao Portal Web proposto.

\begin{tabular}{|c|l|c|c|}
\hline \multicolumn{1}{|c|}{ Caso de Uso } & \multicolumn{1}{|c|}{ Descrição } & Fornecedor & Consumidor \\
\hline $\begin{array}{l}\text { UC41 - Consultar } \\
\text { origem de produto }\end{array}$ & $\begin{array}{l}\text { Consultar as informações } \\
\text { referentes a origem florestal } \\
\text { de um produto. }\end{array}$ & Portal Web & Consumidor Final \\
\hline
\end{tabular}

\subsubsection{CONSIDERAÇÕES FINAIS}

Com o detalhamento e a análise dos principais processos da cadeia de suprimentos dos produtos florestais foi possível a identificação dos casos de uso de cada uma destas etapas. Também foram realizados os ajustes necessários no processo para possibilitar o cumprimento dos requisitos do sistema proposto. $\mathrm{Na}$ Figura 34 são apresentados todos os casos de uso do sistema de rastreabilidade, agrupados em cada uma das áreas funcionais do domínio da aplicação. 


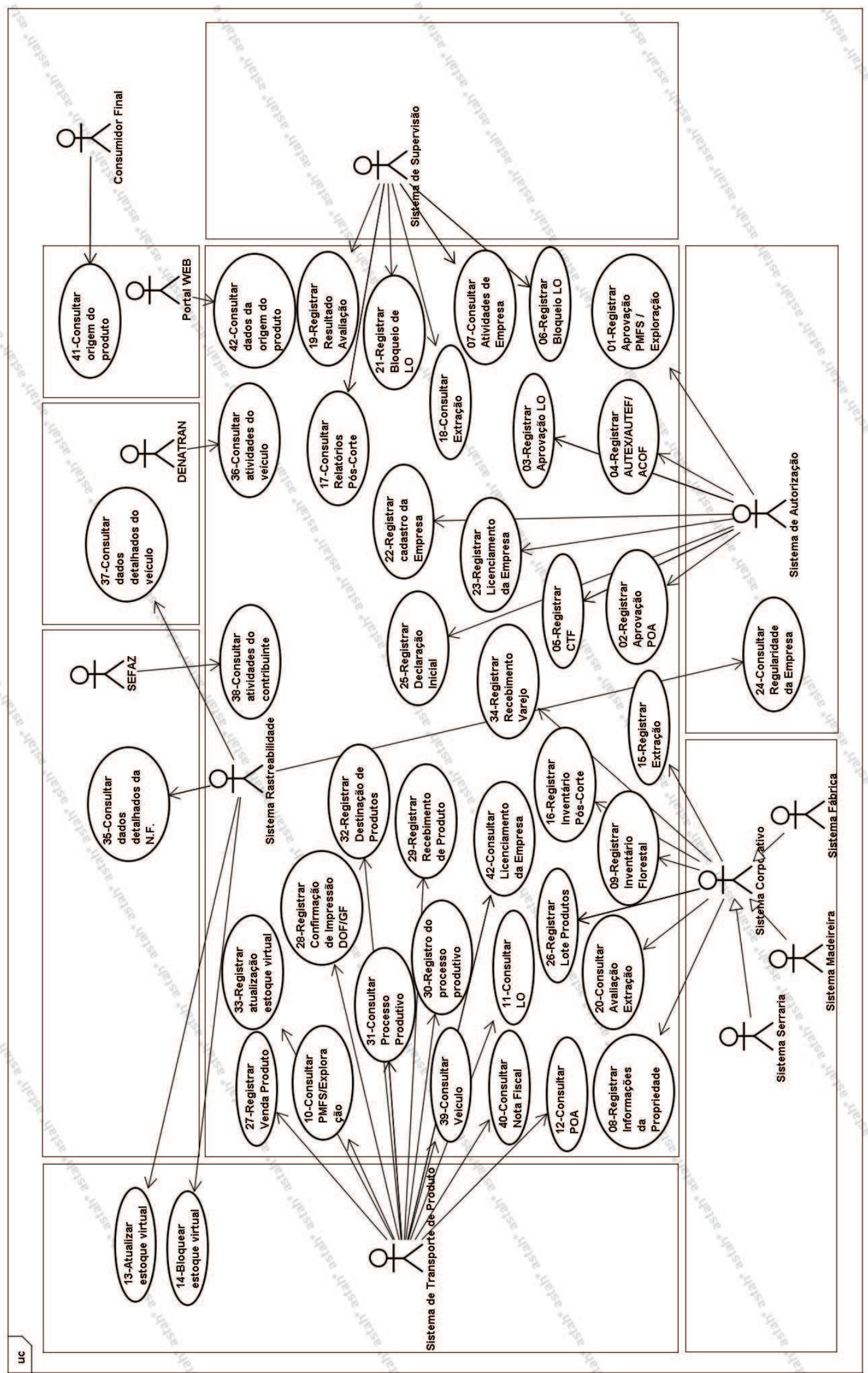

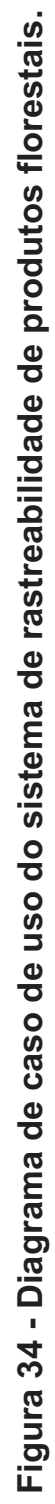




\subsubsection{MODELO DE INFORMAÇÃO DO SISTEMA DE MONITORAMENTO}

O Modelo de Informação apresenta o modelo de dados do Sistema de Monitoramento e o padrão de metadados utilizado no intercâmbio de informações entre os sistemas que formam o sistema de rastreabilidade.

A modelagem dos dados iniciou-se com a análise de uma estrutura de dados adequada para o registro das informações deste processo produtivo. $O$ trabalho de Sirkka (2008) apresenta um modelo de dados para representar a rastreabilidade de insumos e produtos florestais. Este conceito serviu como base para o presente trabalho.

A principal característica do modelo de dados proposto é a capacidade de registrar e relacionar as diversas etapas produtivas do produto florestal, possibilitando a rastreabilidade de todo o processo a partir de um produto ou lote.

O lote é um agrupamento de produtos de uma determinada empresa. Este produto pode ser desde uma tora de árvore de espécie definida até um produto final originado de diversas variedades de madeira. Cada elemento de um lote pode estar associado a um identificar único. Na Figura 35 são representadas estas relações:

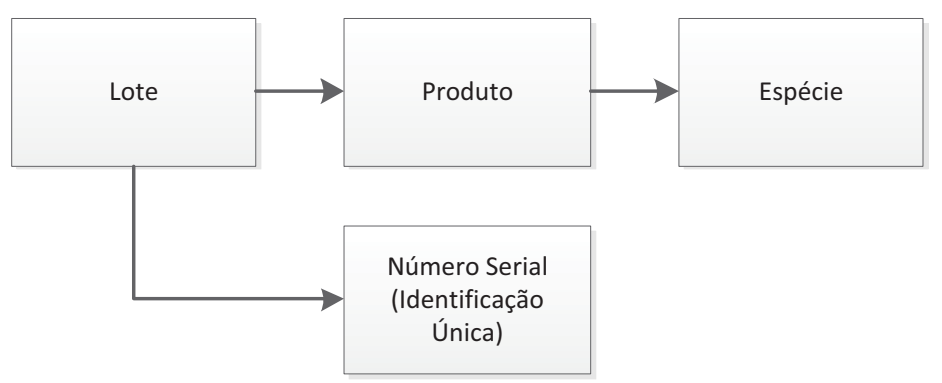

Figura 35 - Representação das relações da entidade Lote do modelo de dados.

No modelo, cada atividade na cadeia é considerada um processo. O processo pode ser representado por uma extração, transformação ou venda de produtos florestais. O processo também é associado a uma empresa de origem e uma de destino, utilizadas nas atividades de venda, e a lotes de insumo e lotes de produto, utilizados nas atividades de transformação.

Para representar um processo de transformação, na Figura 36 são 
representadas as relações existentes nesta atividade.

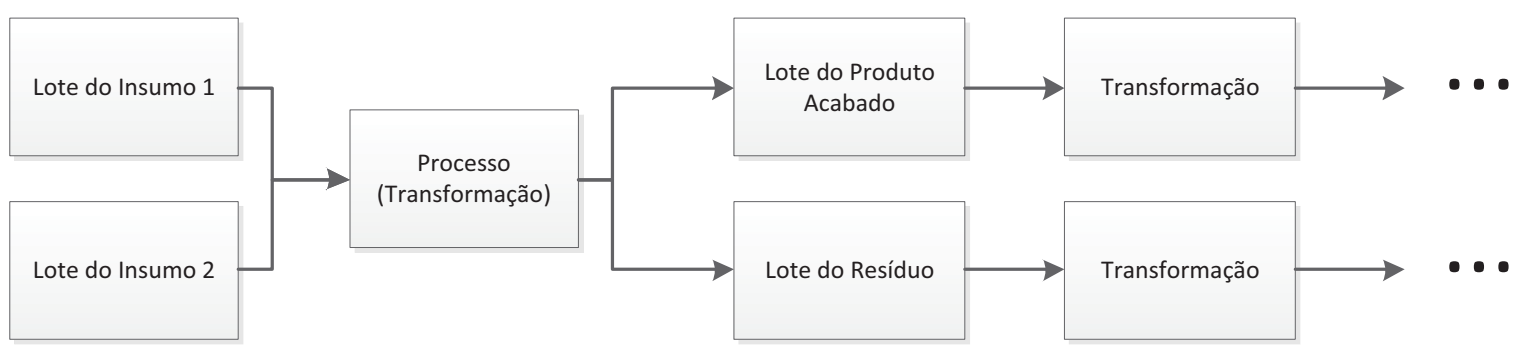

Figura 36 - Representação das relações da entidade Processo em uma atividade de transformação.

Conforme representado na Figura 36, devido a quantidade de transformações exigidas no processo produtivo de um produtivo florestal, o lote de produto acabado, gerado a partir de uma transformação, pode se tornar um lote de insumo em uma próxima etapa produtiva. Em cada uma destas atividades, também são gerados os lotes de resíduos, que são registrados e sua destinação acompanhada. Os índices de conversão dos produtos, definidos nos sistemas de transporte, são registrados e definem as quantidades que são movimentadas no estoque virtual da empresa após cada transformação. Na Figura 37 são representadas estas relações.

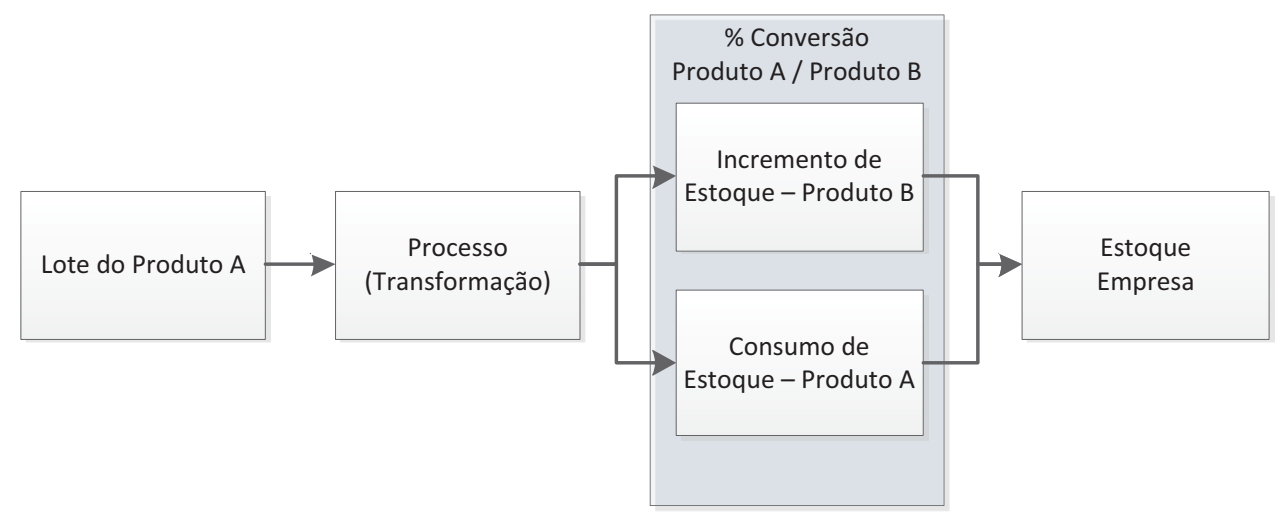

Figura 37 - Relação das entidades Processo e Estoque na atividade de transformação.

Nas atividades de venda, o modelo de dados registra as movimentações existentes nos estoques virtuais das empresas de origem (vendedor) e de destino (comprador). Devido a necessidade de confirmação do recebimento do produto 
florestal comprado, o saldo movimentado permanece empenhado no estoque, sem possibilidade de utilização, até a confirmação de recebimento por parte do comprador. Na Figura 38 são representadas as relações desta atividade.

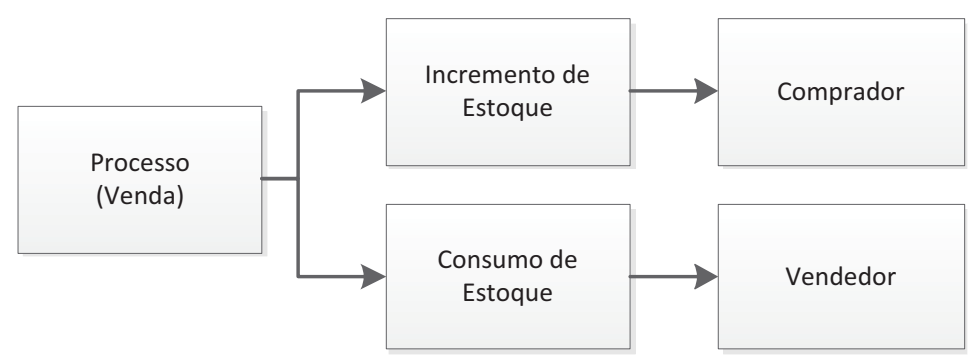

Figura 38 - Relações da entidade Processo em uma atividade de venda.

A partir das características do processo e dos objetivos da pesquisa apresenta-se na Figura 39 o modelo físico da base de dados do sistema de rastreabilidade proposto, com suas entidades, propriedades, tipos e relações. A seguir, são descritas as principais entidades do modelo:

- Autorização. Cada autorização ou licença expedida pelos órgãos governamentais para as empresas que fazem parte do processo produtivo.

- Produto. Caracteriza o insumo, subproduto ou produto florestal, gerenciados pelo sistema.

- Lote. Realiza o agrupamento de produtos florestais e possibilita sua identificação e rastreabilidade no restante da cadeia de suprimentos. Todos os processos gerenciados pelo sistema utilizam lotes existentes ou criam novos lotes.

- Empresa. Participantes do processo produtivo florestal, com exceção do consumidor final, que não possui registro cadastral no sistema, e utiliza o sistema apenas para consultar a origem florestal de um produto.

- Estoque. Registra os saldos virtuais de produtos florestais das empresas. $\mathrm{Na}$ identificação de irregularidades nas atividades de uma empresa, o mesmo é bloqueado para evitar a transformação e 
comercialização de mercadorias.

- Movimentação Estoque. Registra as movimentações de produtos nos estoques das empresas, associado ao processo que gerou a movimentação.

- Processo. Qualquer atividade de extração, venda ou transformação de produtos florestais em sua cadeia produtiva. Dependendo do produto florestal o mesmo pode possuir uma quantidade diferente de etapas produtivas. $O$ gerenciamento destas atividades possibilita $\mathrm{O}$ rastreamento histórico da cadeia de suprimentos, obtendo-se a origem de um produto.

- Ocorrências. Cada irregularidade identificada nas atividades de uma empresa de produtos florestais. Estas ocorrências podem gerar um alerta para os órgãos de fiscalização realizarem investigações sobre uma determinada empresa, como também pode bloquear totalmente as atividades da empresa por tempo indeterminado.

- Documento. Registra os documentos de autorização de transporte (DOF ou GF) gerados e informações de sua rastreabilidade, possibilitando a análise dos mesmos.

- Certificação. Registra as certificações conquistadas pelas empresas de extração e beneficiamento de produtos florestais. Estas informações serão visíveis as demais empresas da cadeia de suprimentos e aos consumidores finais, no momento da consulta da origem de um produto ou insumo. 







\subsubsection{METADADOS PARA INTEROPERABILIDADE DE DADOS ENTRE OS SISTEMAS}

O padrão de metadados escolhido para a interoperabilidade entre os sistemas foi o eFIDS, por ser um padrão projetado para controlar transações eletrônicas na indústria florestal. $\mathrm{O}$ esquema deste metadados fornece uma estrutura que permite representar uma grande variedade de documentos comerciais para serem utilizados entre as empresas participantes do processo produtivo. Com o objetivo de se tornar genérico, o esquema do eFIDS não define como devem ser os documentos, mas apenas fornece estruturas para os diversos campos destes documentos. Desta forma, não existe um elemento XML chamado "Nota Fiscal", mas há um elemento cuja função é identificar que o documento se trata de uma nota fiscal. (OASIS, 2008).

Os demais padrões pesquisados, o AgroXML e o PAPINET não foram considerados adequados para o sistema proposto por serem específicos para as áreas agrícolas e de celulose respectivamente, havendo a necessidade de uma grande adequação para sua utilização.

O padrão eFIDS possibilita que um arquivo possua diversas estruturas Document. Cada uma destas estruturas possui três seções: o Header, o Details e o Trailer. No Header são armazenados os dados gerais do processo e as informações que definem como será estruturado o restante do documento. O Details, que possui a capacidade de múltiplas linhas, armazena informações detalhadas sobre os produtos florestais. Finalizando a estrutura, o Trailer possui o controle de erros, os campos de totalização dos valores da seção Details e informações adicionais de parametrização.

Considerando os atributos do esquema definido pelo eFIDS, o mapeamento destas informações com a base de dados do Sistema de Monitoramento podem ser observados na Tabela 15.

Conforme observado na tabela, todas as informações da estrutura básica do eFIDS estão presentes na base de dados do Sistema de Monitoramento. Além disso, com estruturas adicionais existentes no padrão, podem-se representar as demais informações necessárias para o mapeamento dos principais processos do sistema: extração, comercialização e transformação dos produtos florestais. 
Com a estrutura definida pelo eFIDS, também é possível o agrupamento dos produtos em lotes, o que garante a adequação do metadado ao modelo criado para a rastreabilidade das informações no Sistema de Monitoramento.

Tabela 15- Mapeamento do padrão eFIDS com a base de dados do sistema de monitoramento.

\begin{tabular}{|c|c|c|c|}
\hline $\begin{array}{l}\text { Estrutura do } \\
\text { e-Forestry }\end{array}$ & $\begin{array}{l}\text { Descrição da } \\
\text { Estrutura }\end{array}$ & $\begin{array}{l}\text { Tabelas do BD de } \\
\text { Rastreabilidade }\end{array}$ & Campo da Tabela \\
\hline \multicolumn{4}{|c|}{ Header (TRADING) } \\
\hline DOCUMENT & Tipo do Documento & Processo & pro_id_tipo_processo \\
\hline S.UNB.InterchangeHeader & $\begin{array}{c}\text { Dados do Remetente } \\
\text { e do Destinatário }\end{array}$ & Processo (FK), Empresa (PK) & $\begin{array}{c}\text { pro_id_empresa_fornecedor } \\
\text { pro_id_empresa_cliente }\end{array}$ \\
\hline S.DTM.DateTimePeriod & $\begin{array}{c}\text { Data/Hora da } \\
\text { Mensagem }\end{array}$ & Processo & pro_dt_atualizacao \\
\hline S.FTXText, S.SG01 & $\begin{array}{c}\text { Dados sobre o } \\
\text { processo registrado }\end{array}$ & $\begin{array}{l}\text { Nota_Fiscal, Documento, } \\
\text { Tipo_processo }\end{array}$ & vários \\
\hline S.SG04 & $\begin{array}{c}\text { Termos de } \\
\text { Pagamento, se existir }\end{array}$ & Processo (FK), Nota Fiscal (PK) & vários \\
\hline S.SG08 & $\begin{array}{c}\text { Dados das empresas } \\
\text { e endereços }\end{array}$ & Empresa, Endereco & vários \\
\hline S.SG10 & $\begin{array}{l}\text { Detalhes do } \\
\text { Transporte }\end{array}$ & Processo, Documento & vários \\
\hline \multicolumn{4}{|c|}{ Details (S.SG50) } \\
\hline $\begin{array}{l}\text { S.PIA.AdditionalProductldentification, } \\
\text { S.IMD.ItemDescription }\end{array}$ & Descrição do Produto & Produto, Categoria, Especie & vários \\
\hline S.MEA.Measurement, S.QTY.Quantity & $\begin{array}{c}\text { Dados de Tamanho e } \\
\text { Quantidade }\end{array}$ & $\begin{array}{l}\text { Lote, Produto, } \\
\text { Detalhe_lote_produto }\end{array}$ & vários \\
\hline S.MOA.MonetaryAmount & $\begin{array}{c}\text { Detalhes monetários, } \\
\text { taxas e descontos }\end{array}$ & Nota_Fiscal & vários \\
\hline S.ALI.AdditionalInformation & $\begin{array}{c}\text { Informações } \\
\text { Adicionais }\end{array}$ & - & - \\
\hline S.GIN.GoodsIdentityNumber & Números Seriais & Detalhe_lote_produto & dlp_numero_serial \\
\hline S.DTM.DateTimePeriod & Data/Hora & Processo & pro_dt_atualizacao \\
\hline S.FTX.Text & Campo de Texto & Lote & lot_codigo \\
\hline S.SG51 & Preço & Nota_Fiscal & vários \\
\hline S.SG52 & Dados de Referência & - & - \\
\hline \multicolumn{4}{|c|}{ Trailer (S.UNS.SectionControl) } \\
\hline S.SG71 & Controle de Erros & - & - \\
\hline S.SG72 & Valores Totais & (calculado) & - \\
\hline S.CUXCurrency & \begin{tabular}{|c|}
$\begin{array}{c}\text { Dados sobre Moedas } \\
\text { e Cotações }\end{array}$ \\
\end{tabular} & Nota Fiscal & vários \\
\hline S.UNT.MessageTrailer & $\begin{array}{l}\text { Fim da Marcação do } \\
\text { Documento }\end{array}$ & - & - \\
\hline
\end{tabular}

Devido a obrigatoriedade da utilização completa da estrutura padrão do metadados, independente do tipo de documento representado na estrutura, será considerada a utilização do eFIDS apenas nos principais processos do sistema de rastreabilidade e nas integrações entre as empresas participantes do processo produtivo. Nas demais integrações, com os órgãos governamentais e o consumidor final, que utilizam dados mais específicos, serão consideradas a utilização de um 
padrão XML simplificado.

\subsubsection{DESCRIÇÃO DOS SERVIÇOS}

Após a definição dos casos de uso e do modelo de dados, são identificados os serviços de cada domínio da aplicação, juntamente com seus parâmetros de entrada e saída.

Como padrões foram adotados dois prefixos para a nomenclatura dos serviços. O Save é utilizado nos serviços que realizam o registro de informações na base de dados do sistema de rastreabilidade. O Get é utilizado nos serviços que retornam informações ou relatórios a partir da base de dados do sistema de rastreabilidade ou dos sistemas participantes do processo.

A seguir, são descritos alguns dos serviços definidos no sistema proposto:

- SaveApprovalAutex

Este serviço realiza o registro da aprovação de uma autorização para exploração florestal.

Como parâmetros de entrada são informados a empresa que recebeu a autorização, as informações sobre a autorização aprovada e uma lista de produtos e suas quantidades, que serão adicionadas ao estoque virtual da empresa nos sistemas de transporte.

O resultado obtido é a confirmação do registro desta informação.

\section{- SaveExtraction}

Este serviço realiza o registro da extração de uma árvore.

Como parâmetros de entrada são informados a empresa que está realizando a extração, a autorização que possibilita a realização desta atividade, o Lote que o produto fará parte e a identificação única da árvore extraída.

O resultado obtido é a confirmação do registro desta informação.

\section{- GetVehiclelnfo}

Este serviço realiza a consulta das informações de um veículo na base de dados do DENATRAN. Com isso, caso o veículo possua alguma pendência ou irregularidade, o mesmo não poderá ser utilizado no sistema de transporte. 
Como parâmetro de entrada é informado a placa do veículo, o Renavam ou o Chassi do veículo.

O resultado obtido são as informações detalhadas do veículo pesquisado.

\section{- GetProductOrigin}

Este serviço realiza a consulta da origem florestal de um produto florestal específico ou de um lote de produto. O mesmo pode ser utilizado pelas empresas envolvidas na cadeia de suprimentos, para garantir a origem legal dos insumos comprados, como também pelos consumidores finais, que podem consultar a origem do produto acabado antes de sua compra no varejo.

Como parâmetro de entrada é informado o número serial do produto (identificação única) ou o número do Lote do produto.

Os resultados obtidos são as informações detalhadas sobre a atividade de extração dos insumos utilizados e todas as etapas produtivas pelo qual o produto passou antes de sua venda.

No Apêndice A deste trabalho é apresentada a lista completa com os 41 serviços que são disponibilizados no sistema proposto.

\subsubsection{ESPECIFICAÇÃO DOS COMPONENTES}

Com a definição dos serviços e de suas interfaces, das classes de negócio e do modelo da base de dados, agora são definidos os componentes de negócio e os componentes arquiteturais, destinados as funções de apoio dentro da arquitetura.

Os serviços de negócio foram agrupados conforme o seu fornecedor. No Sistema de Monitoramento foi criado o componente Serviços de Negócios, enquanto nos demais sistemas, que possuem serviços definidos, foram criados componentes específicos conforme a natureza destes serviços.

Ainda no Sistema de Monitoramento, as classes de negócio foram agrupadas no componente Objetos de Negócio, onde os seus métodos utilizam o componente Persistência para realizar o acesso a base de dados do sistema. O componente Persistência é composto pelos objetos de acesso a dados (DAO) e os objetos de valor (VO). 
Os componentes arquiteturais definidos foram o componente Transformação de Dados, responsável pelo mapeamento dos metadados utilizados, o componente Segurança, que realiza a autenticação e controle de acesso das funções e serviços do sistema e o componente Log da Aplicação, que registra as transações ocorridas no sistema. Na Figura 40, são apresentados os componentes do Sistema de Monitoramento proposto e dos demais sistemas que fazem parte do domínio da aplicação.

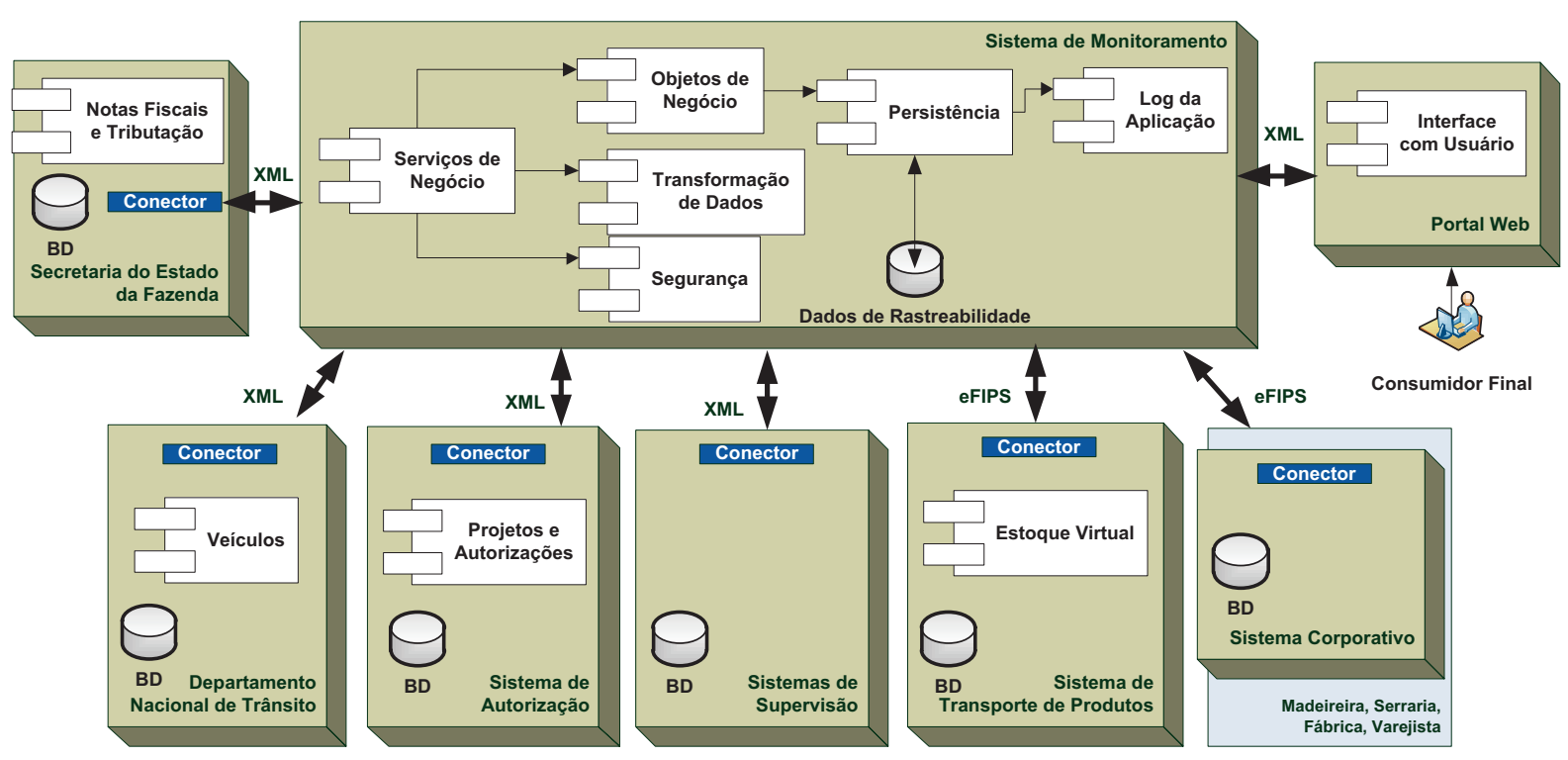

Figura 40 - Domínio da aplicação e seus respectivos componentes.

\subsection{PROTÓTIPO FUNCIONAL}

Com o objetivo de avaliar os resultados do sistema proposto, criou-se um protótipo funcional que implementa o processo de consulta da origem florestal de um produto acabado. Este processo foi escolhido devido sua importância no sistema proposto e pela possibilidade de se utilizar grande parte das informações armazenadas na base de dados do sistema de monitoramento.

O protótipo utilizou um ambiente com um servidor e dois clientes, sendo um computador pessoal (PC), que acessa o sistema de rastreabilidade por meio de um Portal Web e um celular iPhone ${ }^{10}$, que utiliza uma aplicação embarcada que

${ }^{10} \mathrm{O}$ iPhone é um smartphone desenvolvido pela Apple Inc. onde a interação com o usuário se faz por meio de 
consome os serviços Web disponibilizados pelo servidor.

O servidor que executa o Sistema de Monitoramento e disponibiliza os serviços Web possui as seguintes características:

- Sistema operacional Windows 2003.

- Internet Information Services (IIS) versão 6.0.

- SGBD SQL Server 2005.

- Aplicação desenvolvida na Linguagem de Programação C\#.

- . Net Framework 3.5.

O computador pessoal que hospeda o Portal Web possui as seguintes características:

- Sistema Operacional Windows 7 Ultimate Edition

- Internet Information Services (IIS) versão 7.5.

- Aplicação desenvolvida na linguagem de Programação C\#.

- Utilização da API do ASP.NET (.Net Framework 3.5).

Para o desenvolvimento da aplicação embarcada no iPhone foram utilizadas as seguintes tecnologias:

- Aplicação desenvolvida no MAC OS X 10.6.7.

- Utilização do SDK iOS SDK 4.1.

- Aplicação desenvolvida na Linguagem de Programação Objective-C

- Utilização da API COCOA TOUCH.

- Sistema Operacional iOS 4.3.

uma tela sensível ao toque. Tornou-se um campeão de vendas no mundo inteiro principalmente devido sua revolucionária interação com o usuário, seus poderosos recursos multimídia e a disponibilização de milhares de aplicativos próprios em sua loja virtual, a App Store. 


\subsubsection{DESENVOLVIMENTO DA APLICAÇÃO DO SERVIDOR}

No protótipo do Sistema de Monitoramento foram definidas as classes e relações que representam as entidades existentes no modelo da base de dados. $\mathrm{Na}$ Figura 41 é apresentada a visão geral do diagrama das classes de negócio e suas associações.

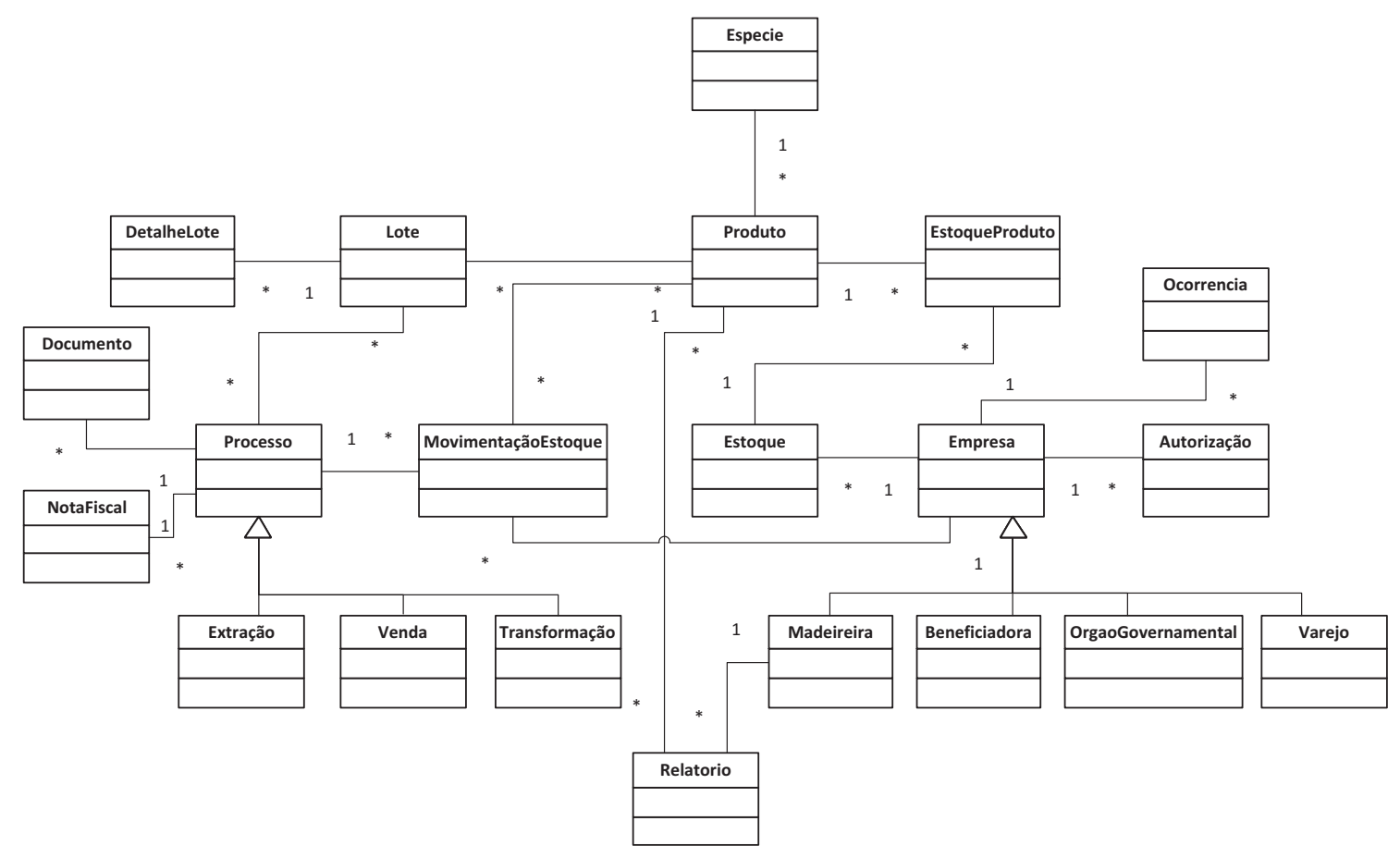

Figura 41 - Diagrama de classes do sistema e suas relações.

Estas classes compõem o componente Objetos de Valor (VO), dentro da arquitetura desenvolvida, apresentado na Figura 42. Além do VO, a arquitetura é composta pelos seguintes componentes:

- Objetos de Acesso a Dados (DAO). Implementa os métodos de acesso e consulta à base de dados.

- Objetos de Negócio. Implementa as regras de negócio da aplicação.

- Serviços de Negócio. Implementa os serviços Web disponibilizados. 


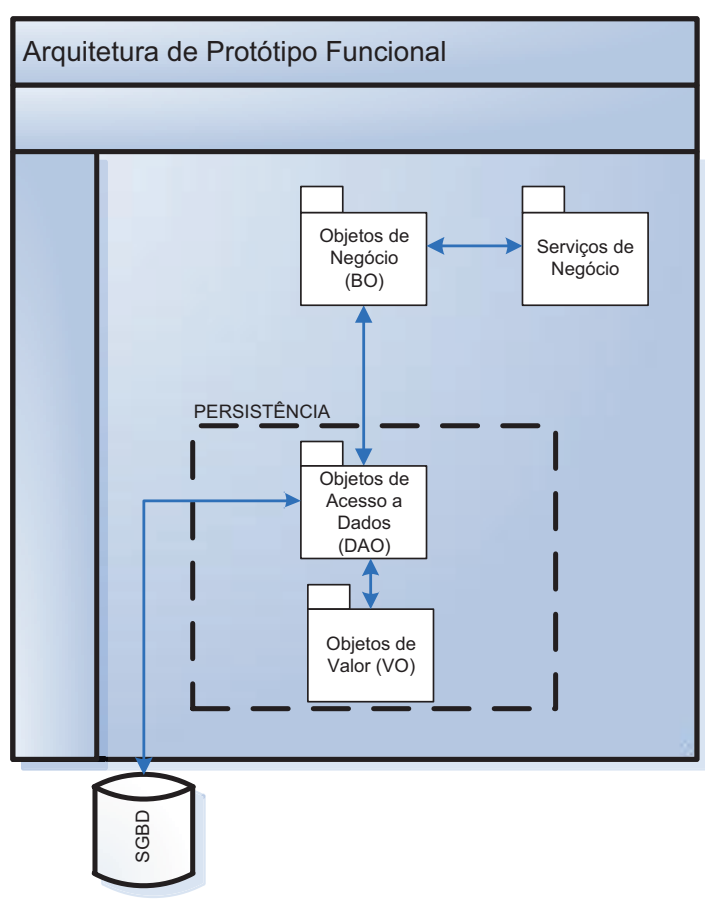

Figura 42 - Arquitetura desenvolvida para o Sistema de Monitoramento do Protótipo Funcional.

O serviço implementado no protótipo foi o GetProductOrigin, que recebe como parâmetro de entrada uma string, com o número serial do lote ou do produto acabado e retorna uma coleção de objetos da classe Processo, que descreve todos os processos pelo qual o produto passou durante o seu ciclo de vida.

\subsubsection{GERAÇÃO DO ARQUIVO WSDL}

Para a descrição dos serviços utilizou-se o arquivo WSDL, pois além do serviço de descrição dos serviços oferecidos serem um dos pré-requisitos das arquiteturas SOA, o processo de utilização dos serviços foi facilitado. Na Figura 43 é apresentado um fragmento do código WSDL gerado pelo protótipo. 


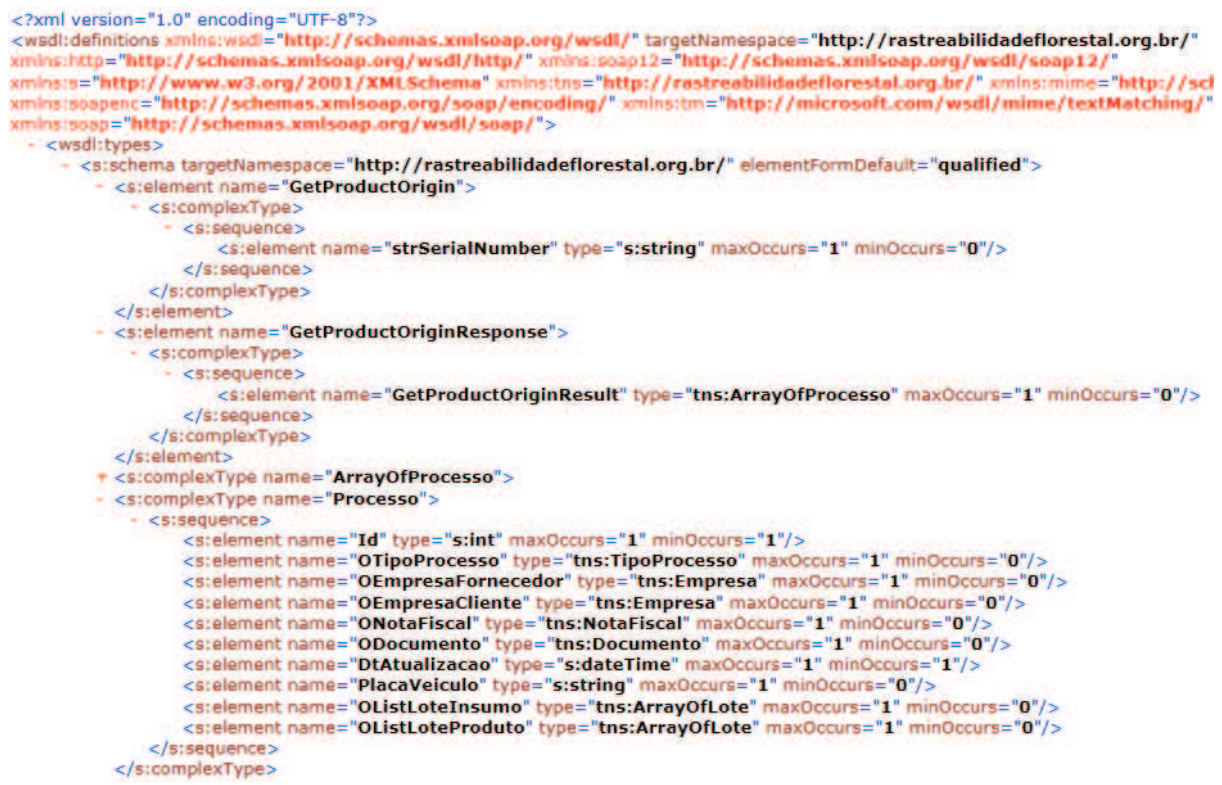

Figura 43 - Fragmento do Arquivo WSDL gerado pelo protótipo.

\subsubsection{TESTES DO PROTÓTIPO}

Foram desenvolvidos dois clientes, um Portal Web e um software embarcado para celular, que consumiram o mesmo serviço Web de consulta da origem do produto florestal.

Na Figura 44, são apresentadas as telas do Portal Web, no momento da consulta da origem de um produto válido no sistema de rastreabilidade. A partir desta consulta, o sistema de rastreabilidade retorna para o Portal Web informações sobre o produto, além de detalhes sobre o seu processo de extração e beneficiamento. Também são apresentas informações das empresas participantes do processo, como localização, certificações conquistadas e autorizações florestais vigentes. 


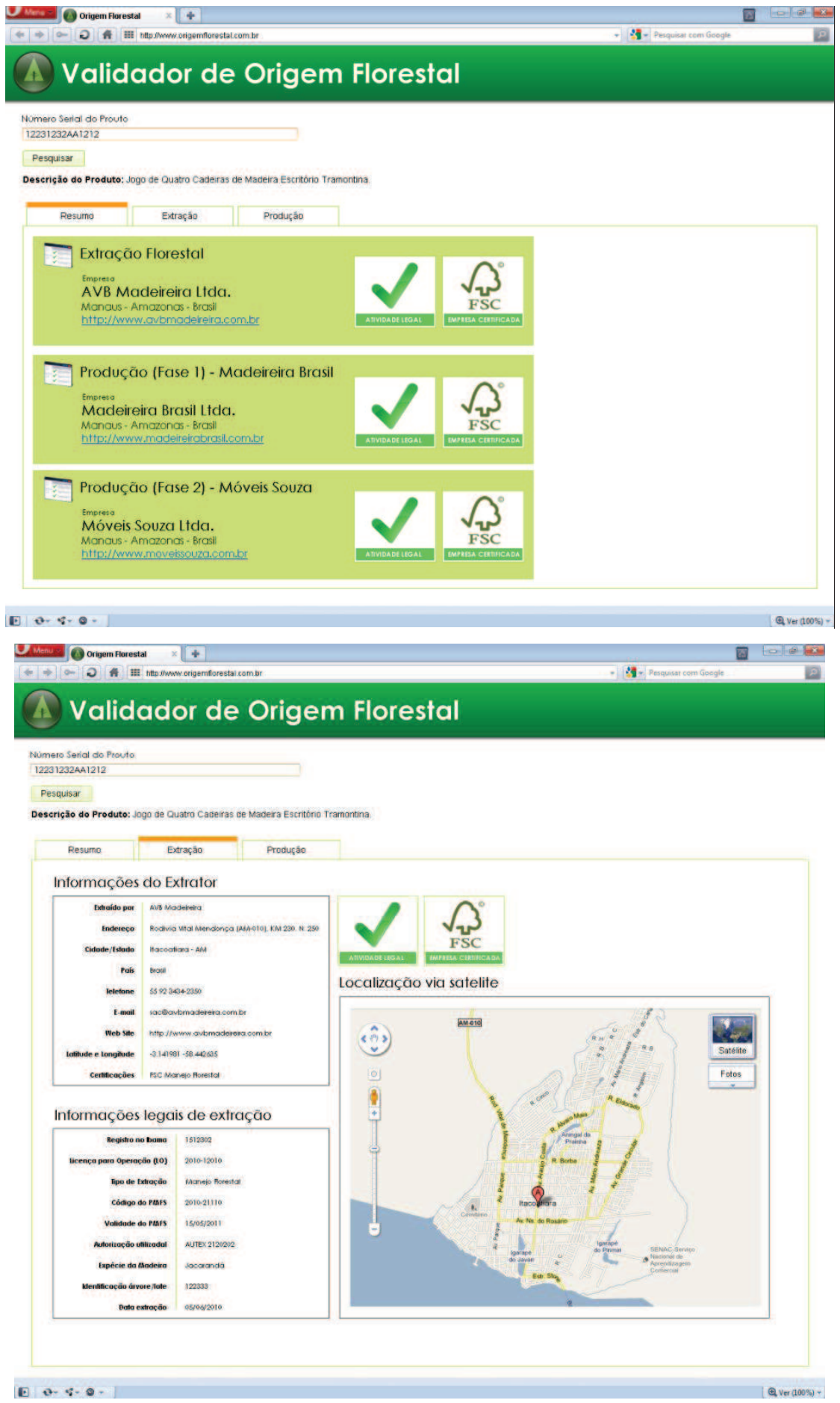

Figura 44 - Portal Web para validação da origem de um produto florestal.

A aplicação embarcada, ao consultar o mesmo número de série de produto, também retornou todas as informações apresentadas no Portal Web. A utilização de dispositivos móveis é um dos requisitos do sistema de rastreabilidade proposto devido sua portabilidade e facilidade na consulta das informações. Na Figura 45 são apresentadas as telas do software embarcado desenvolvido em execução. 


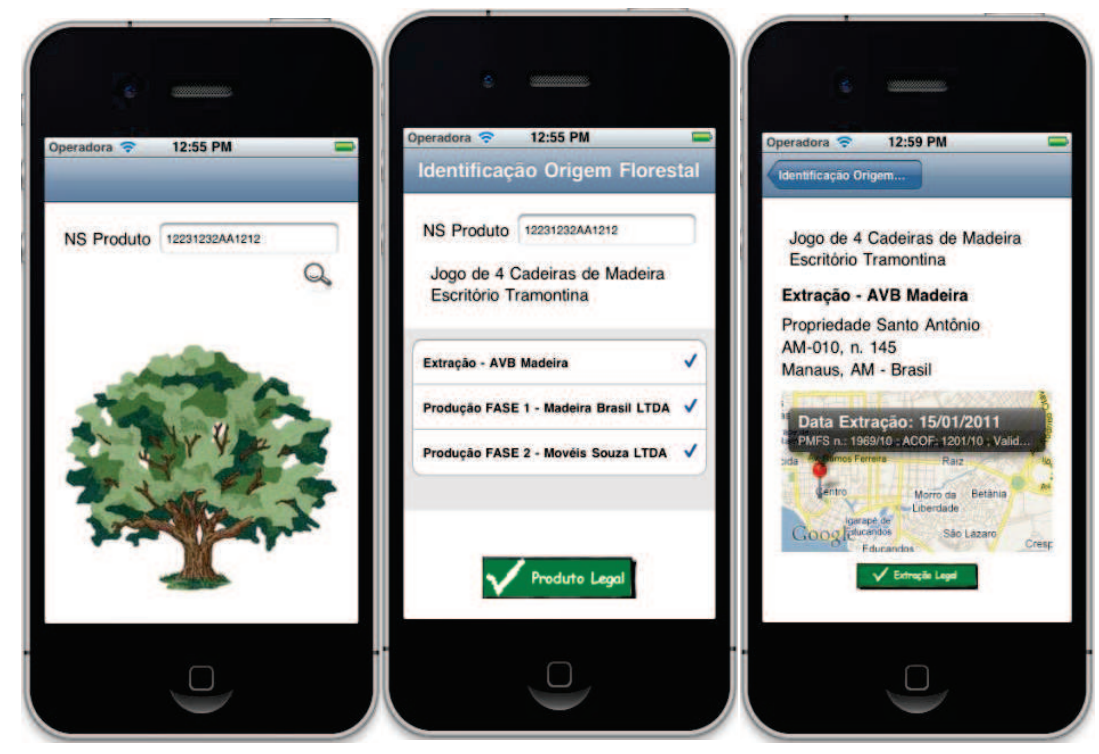

Figura 45 - Aplicativo embarcado para a consulta da origem de um produto florestal.

$\mathrm{Na}$ Figura 46 são apresentadas as mensagens SOAP de solicitação e de resposta (fragmento da mensagem) do serviço Web utilizado.

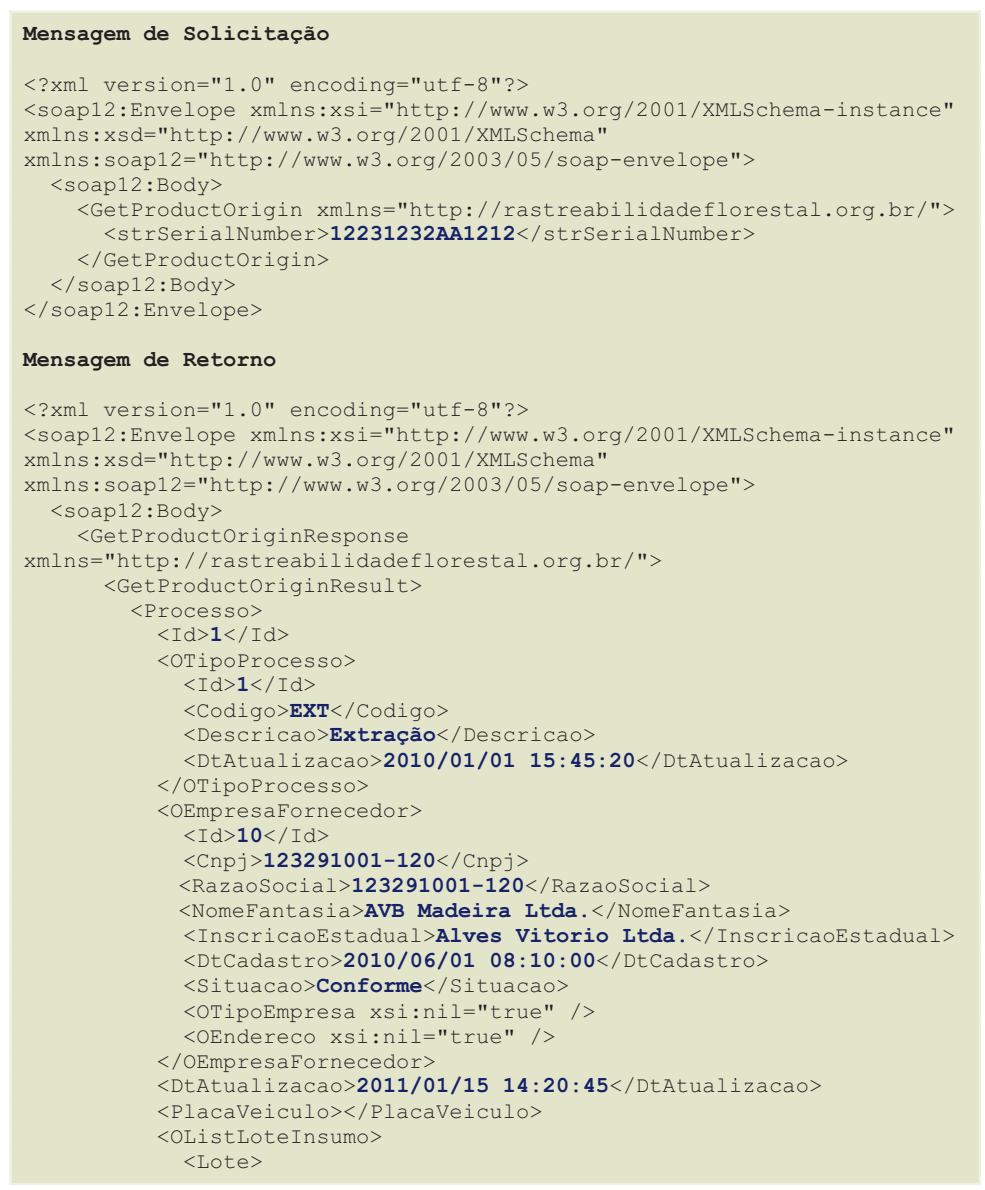

Figura 46 - Mensagens SOAP 1.2 de solicitação e resposta do serviço GetProdutOrigin. 


\subsubsection{CONSIDERAÇÕES FINAIS DO PROTÓTIPO}

O protótipo implementado permitiu a validação de duas tecnologias heterogêneas na consulta de informações disponibilizadas pelo sistema de rastreabilidade. Pôde-se verificar também que, a partir do registro e da interligação de informações do processo produtivo, antes segregadas em diversos sistemas, foi possível a obtenção de informações de grande importância para toda a cadeia de suprimentos e para os consumidores dos produtos florestais. 


\section{CONCLUSÃO}

Nesta capitulo apresentam-se os resultados e as conclusões obtidas após a modelagem do sistema de rastreabilidade proposto. Discute-se também sobre as contribuições do trabalho e as perspectivas para a sua continuidade.

\subsection{ATENDIMENTO AOS REQUISITOS PROPOSTOS}

Pela análise dos requisitos propostos no trabalho, pode-se concluir que 0 modelo desenvolvido atendeu as expectativas e possibilitou a comprovação de uma possível solução para os problemas de interoperabilidade entre os sistemas do processo produtivo florestal e na manutenção da origem destes produtos. Apesar de estar claro que uma validação real entre o sistema proposto e a cadeia de suprimentos dos produtos florestais seria um processo bem mais longo e detalhado, sendo necessário o envolvimento de diversas empresas e órgãos estaduais e federais, pôde-se constatar no protótipo que o modelo desenvolvido solucionou os problemas discutidos neste trabalho, sem a identificação de limitações ou falhas de modelagem.

\subsection{VALIDAÇÃO DO PROCESSO PRODUTIVO}

O sistema modelado e seus serviços foram desenvolvidos com base nas informações levantadas durante a realização deste trabalho, que possibilitou a identificação das etapas e dos participantes deste processo produtivo. Na sua grande maioria, estas informações foram baseadas em documentações técnicas, manuais e artigos científicos. Sendo que a falta de uma massa de dados reais de cada uma das etapas do processo, possibilita que detalhes e regras importantes não tenham sido consideradas. Apesar de não ter sido identificada nenhuma destas situações no trabalho, caso ocorram, será necessária a realização de ajustes no modelo desenvolvido.

\subsection{INDEPENDÊNCIA DE PLATAFORMAS}

Buscou-se com o protótipo funcional a validação da interoperabilidade de 
sistemas heterogêneos na arquitetura proposta. Por meio da disponibilização de um serviço Web, duas tecnologias distintas puderam utilizá-lo para consultar a base de dados do sistema de rastreabilidade.

A utilização de um celular para a consulta da origem florestal de um produto demonstrou a potencial influência que esta informação pode ter na comercialização dos produtos florestais legais. Com a popularização dos smartphones, uma aplicação como esta poderia ser rapidamente aceita pelos consumidores.

Além disso, identificou-se que outras atividades dentro do processo produtivo florestal também poderiam utilizar da tecnologia de sistemas embarcados para compartilhar de vantagens como a portabilidade e a facilidade na aquisição dos dados. Atividades como o inventário florestal e as fiscalizações rodoviárias podem alcançar melhorias significativas utilizando estes equipamentos.

\subsection{PRINCIPAIS CONTRIBUIÇÕES}

Inicialmente, o mapeamento das etapas do processo produtivo florestal, seus participantes e sistemas, além da identificação dos problemas e das deficiências do processo, possibilitaram a consolidação de uma documentação importante sobre esta cadeia de suprimentos. Estas informações são de grande importância para futuras pesquisas que possuam como foco este processo produtivo.

A utilização de um sistema de rastreabilidade para os produtos florestais é um grande aliado para o combate ao desmatamento ilegal das florestas nativas da Amazônia e as irregularidades existentes durante a sua cadeia de suprimentos. Além disso, a possibilidade de consulta da origem dos produtos florestais é um grande diferencial e agregador de valor aos produtos legais, que hoje se misturam aos produtos ilegais durante sua cadeia de suprimentos.

A garantia da origem destes produtos também possibilita que os mesmos alcancem novos mercados, como vários países da união europeia, que hoje exigem a comprovação da origem dos produtos florestais comprados. Além disso, no Brasil, grandes empresas já limitaram suas compras aos produtos florestais com origem legal garantida. A tendência é que o número de empresas com esta iniciativa cresça cada vez mais. 


\subsection{PERSPECTIVAS PARA CONTINUIDADE DO TRABALHO}

O sistema apresentado é uma primeira abordagem para a solução dos problemas existentes no processo produtivo florestal. Devido a possibilidade imediata de aplicação desta arquitetura, este modelo deve ser totalmente refinado e validado com informações reais do processo produtivo. Além disso, questões arquiteturais que não foram consideradas neste trabalho devem ser aprofundadas, como a segurança, a qualidade de serviço e a escalabilidade da solução.

Outro trabalho relacionado ao sistema proposto é a criação de padrões de identificação eletrônica para os produtos florestais. Apesar de ter sido definido inicialmente como um dos requisitos deste trabalho, os esforços concentraram-se no armazenamento e na distribuição destas informações pela cadeia de suprimentos. A definição de um padrão físico de identificação destes produtos e insumos, adequada às características do processo, são necessárias e de fundamental importância para o bom funcionamento do sistema de rastreabilidade.

\subsection{CONSIDERAÇÕES FINAIS}

Com a finalização da pesquisa, chegou-se a um modelo de rastreabilidade do processo produtivo florestal que possibilitou a identificação da origem dos produtos, além da integração entre os sistemas envolvidos no processo, garantindo o intercâmbio de informações entre eles. Espera-se que este modelo possa contribuir na solução dos problemas existentes hoje nesta cadeia de suprimentos. A realização de novas pesquisas neste tema possibilitará o desenvolvimento e o refinamento de soluções destes e de outros problemas, contribuindo cada vez mais para a melhoria do processo produtivo florestal. 


\section{REFERÊNCIAS}

ALIANÇA DA TERRA et al. Três estratégias fundamentais para a redução do desmatamento. Publicado em: Novembro, 2007. Disponível em: $<$ http://www.mudancasclimaticas.andi.org.br/content/tres-estrategias-fundamentaispara-reducao-do-desmatamento>. Acesso em: 08 Ago. 2009.

AMARAL, P. et al. Floresta para sempre: um manual para a produção de madeira na Amazônia. Belém IMAZON, 1998. 155 p.

BASSANI, C. T. Um modelo de rastreabilidade na industrialização de produtos derivados de suínos. Dissertação (Mestrado). Universidade Federal de Santa Catarina, Florianópolis, 2002.

BIOLCHINI, F. et al. Systematic review in software engineering. Technical Report ES 679/05. System Engineering and Computer Science Departament. COPPE, UFRJ, Rio de Janeiro, 2005.

BRASIL. Lei Federal 6.938/81. 31 Ago. 1981. Dispõe sobre a Política Nacional do Meio Ambiente, seus fins e mecanismos de formulação e aplicação, e dá outras providências.

. Ministério do Meio Ambiente. Instituto Brasileiro do Meio Ambiente e dos Recursos Naturais Renováveis. Instrução Normativa No 112/2006. 21 Ago. 2006a. In: Normas Florestais Federais para a Amazônia (2007). Brasília. IBAMA/Diretoria de Uso Sustentável da Biodiversidade e Florestas. Pag. 243.

- Ministério do Meio Ambiente. Conselho Nacional do Meio Ambiente. Resolução No 379/2006.19 Out. 2006b. In: Normas Florestais Federais para a Amazônia (2007). Brasília. IBAMA/Diretoria de Uso Sustentável da Biodiversidade e Florestas. Pag. 149. 
. Rondônia. Secretaria do Estado do Desenvolvimento Ambiental. Portaria $\mathbf{N}^{\circ}$ 186/GAB/SEDAM. 25 Out. 2006c.

BUENO, J.F.; CORREAA, P.L.P.; ONOE, A.Y.; BORSOI, B.T. KIRAMOTO A.T. OASIS, Modelo de Referência para Arquitetura Orientada a Serviço 1.0. Tradução para português do modelo de referência SOA da OASIS. Escola Politécnica da Universidade de São Paulo, 2006. Disponível em: <http://www.pcs.usp.br/ pcs5002/oasis/soa-rm-csbr.pdf>. Acesso em: 05 Ago. 2009.

CASTRO, A. M. G. et al. Cadeias Produtivas e Sistemas Naturais - Prospecção Tecnológica. EMBRAPA/Serviços de Produção de Informática, Brasília, 1998.

CPTEC. Centro de Previsão de Tempo e Estudos Climáticos. Desmatamento na Amazônia cai $46 \%$. Relatório mostra dados do INPE que apontam a queda da derrubada da floresta em 12 meses, porém junho e julho sinalizam uma inversão nesta curva. Disponível em: <http://www7.cptec.inpe.br/noticias/faces/impressao.jsp?idConsulta=12062\&idQuadr os>. Acesso em 16 Set. 2009.

CERAMI, Web Services Essencials. 1ª Edição. Sebastopol: O’Reilly Media, Inc, 2002.

CERUTI, F. C. Rastreabilidade de Grãos: Conceito, desenvolvimento de software e estudos de casos de manejo de insetos no armazenamento. Tese (Doutorado). Universidade Federal do Paraná. Curitiba, 2007.

CHAVES, H. C. DOF e estratégias para integração com os estados. Cooperação IBAMA, DBFLO e CGREF. Disponível em:

<http://4ccr.pgr.mpf.gov.br/institucional/grupos-de-trabalho/gt-forcatarefa/gt-forcatarefa-docs>. Acesso em: 02 Dez. 2009. 
CHEN, J. L. et al. Architecture design and performance evaluation of RFID object tracking systems. Computer Communications. v.30, p. 2070-2086, 2007.

CONSELHO BRASILEIRO DE MANEJO FLORESTAL, FSC BRASIL. Cartilha Institucional. Disponível em:

$<$ http://www.fsc.org.br/index.cfm?fuseaction=conteudo\&IDsecao=74>. Acesso em: 10 Abr. 2010.

CORREAA, P.L.P. “PCS 5002 - Integração de Componentes e Serviços”. Notas de Aula da Disciplina PCS 5002 - Programa de Pós-Graduação em Engenharia Elétrica da EPUSP. 2007.

DAI, W. et al. Services Oriented Knowledge-based Supply Chain Application. IEEE Internacional Conference on Services Computing (SCC 2007). 2007.

DYKSTRA, D. P. et al. Technologies for wood tracking - Verifying and Monitoring the Chain of Custody and Legal Compliance in the Timber Industry. Environment and Social Development East Asia and Pacific Discussion Paper. Dezembro, 2002.

ENDREI, M. et al. Patterns: Service-Oriented Architecture and Web Services. 1a ed. Armonk: IBM Corporation, 2004.

ERL, T. Service-Oriented Architecture. A field guide to integrating XML and Web Services. 1a ed. Upper Saddle River: Prentice Hall, 2004, 560 p.

FAO. Food and Agriculture Organization of the United Nations. Food and Agriculture Organization Corporate Statistical Database, FAOSTAT. Gerador de relatórios de 
informações sobre alimentos e agricultura no mundo. Disponível em:

<http://faostat.fao.org/site/626/DesktopDefault.aspx?PagelD=626\#ancor>. Acesso em 03 Nov. 2009.

FLORESTA VIDA AMAZONAS. Documento de Origem Florestal do Amazonas DOFAM. Dezembro, 2007. Relatório de avaliação do sistema DOF e proposta de melhorias para serem contempladas no sistema DOFAM. Disponível em: <http://www.florestavivaamazonas.org.br/download/relatorios/080128_Subsidios_DO FAM.pdf>. Acesso em 10 Ago. 2009.

FÓRUM BRASILEIRO DE SEGURANÇA PÚBLICA. A criminalidade ambiental organizada e o desmate ilegal em Mato Grosso. 16. Fev. 2009. Disponível em: <http://www.forumseguranca.org.br/artigos/a-criminalidade-ambiental-organizada-eo-desmate-ilegal-em-mato-grosso>. Acesso em 15. Nov. 2009.

FUNDAÇÃO DO MEIO AMBIENTE. Instruções para uso do Documento de Origem Florestal - DOF. Santa Catarina, Set. 2006. Disponível em: <http://www.fatma.sc.gov.br/index.php?option=com_content\&task=view\&id=88\&ltemi d=191>. Acesso em: 02 Dez. 2009.

GISDEVELOPMENT. Global Positioning System. Disponível em:

<http://www.gisdevelopment.net/tutorials/tuman004.htm>. Acesso em 02 Dez. 2009.

GLOBO AMAZÔNIA. Fiscalização flagra ação de madeireiras fantasmas em Mato Grosso. 11 Ago. 2009a. Disponível em:

<http://www.globoamazonia.com/Amazonia/0,,MUL1263223-16052,00.html>. Acesso em 15 Nov. 2009.

Consumidor paulistano tem dificuldade em encontrar móveis verdes. 
30 Nov. 2009b. Disponível em:

<http://www.globoamazonia.com/Amazonia/0,,MUL1395090-16052,00-

CONSUMIDOR+PAULISTANO+TEM+DIFICULDADE+EM+ENCONTRAR+MOVEIS+ VERDES.html>. Acesso em 03 Dez. 2009.

GOLAN, E. et al. Traceability in the U.S. Food Supply: Economic Theory and Industry Studies. Washington: United States Department of Agriculture, 2004.

GOTEL, O; FINKELSTEIN, A. An analysis of the requirements traceability problem. In: Proceedings of the First IEEE Internacional Conference on Requirements Engineering. p. 94-102. 1994.

GREENPEACE. IBAMA apreende madeira ilegal que embarcava na Europa. 11 Abr. 2008a. Disponível em:

<http://www.greenpeace.org/brasil/amazonia/noticias/ibama-apreende-madeirailegal>. Acesso em 20 Nov. 2009.

Madeireiras e hackers inventam o ciber-desmatamento. 12 Dez. 2008b. Disponível em: <http://www.greenpeace.org/brasil/amazonia/noticias/madeireiras-ehackers-inventam>. Acesso em 21 Nov. 2009.

Alguns aspectos observados sobre o SISFLORA. Relatório de avaliação do sistema SISFLORA. Disponível em:

<http://www.greenpeace.org/raw/content/brasil/documentos/amazonia/algunsaspectos-observados-sob.pdf>. Acesso em 10 Ago. 2009.

GRYNA, F. M. Planejamento da produção. In: JURAN, J. M.; GRYNA, F. M.(Org.) Controle da Qualidade: Handbook. São Paulo: Makron Books, v. 3, p. 244-332, 1992. 
GS1. GS1 Standards Document - Business Process and System Requirements for Full Chain Traceability. n. 1.1.0, 2009.

GS1 BRASIL. Guia de Codificação do Setor Moveleiro. Disponível em: <http://www.gs1 brasil.org.br/lumis/portal/file/fileDownload.jsp?fileld=480F89A821C45 7A80121C6C454801618>. Acesso em 10 Nov. 2009.

IMAFLORA. Instituto de Manejo e Certificação Florestal e Agrícola. Manual de certificação da Cadeia de Custódia no Sistema do Forest Stewardship Council - FSC. Piracicaba, SP, 2002. Disponível em: <http://www.gtz.de/de/dokumente/ptd56p-imaflora-manual-de-certificacao-cadeia-de-custodia-s.pdf>. Acesso em 12 Ago. 2009.

- Manual de certificação do Manejo Florestal no Sistema do Forest Stewardship Council - FSC. Disponível em:

<http://www.imaflora.org/arquivos/maual_manejo_final.pdf>. Acesso em 12 Ago. 2009.

IBAMA. Instituto Brasileiro do Meio Ambiente e dos Recursos Naturais Renováveis. Documento de Origem Florestal - Perguntas \& Respostas. 2006a.

Manual do Documento de Origem Florestal DOF - Manual Operacional. Versão № 01. Brasília, DF. 2006b.

IBAMA E IPAAM flagram manejo pirata no Amazonas. 15 Abr. 2009. Disponível em: <http://www.ibama.gov.br/2009/04/ibama-e-ipaam-flagram-manejopirata-no-amazonas/>. Acesso em 20 Nov. 2009.

IBGE. Instituto Brasileiro de Geografia e Estatística. Produção da Extração 
Vegetal e da Silvicultura 2007. v. 22, p. 11-23, 2008. Disponível em: <http://www.ibge.gov.br/home/estatistica/economia/pevs/2007/pevs2007.pdf>. Acesso em: 15 Ago. 2009.

. Produção da Extração Vegetal e da Silvicultura 2008. v. 23, p. 10-22, 2009. Disponível em:

<http://www.ibge.gov.br/home/estatistica/economia/pevs/2008/pevs2008.pdf>. Acesso em: 23 Nov. 2009.

IPAM. Instituto de Pesquisa Ambiental da Amazônia. Queda do desmatamento - A comemoração deve ser comedida. Disponível em: <http://www.climaedesmatamento.org.br/mais/blogpost/id/21>. Acesso em: 03 Nov. 2009.

INPE. Instituto Nacional de Pesquisas Espaciais. Desmatamento por Estado e na Amazônia Legal (2001-2009). Disponível em:

<http://www.inpe.br/noticias/arquivos/pdf/prodes2009tabela1.pdf>. Acesso em 16 Set. 2009.

JACOVINE, L. A. G. et al. Certificação florestal na visão gerencial e estratégica da indústria moveleira nacional. Semina: Ciências Agrárias. Londrina, V.27, n. 3, p. 367-378, 2006.

JANSEN-VULLERS, M. H.; VAN DORP, C. A.; BEULENS, A. J. M. Managing traceability information in manufacture. Internacional Journal of Information Management. v. 23, n. 5, p. 395-413, 2003.

JOSUTTIS, N. M. SOA na prática: A arte da modelagem de sistemas distribuídos. Editora Alta Books. Rio de Janeiro, 2008.

KARHUNEN, H.; EEROLA, A.; JANTTI, M. Improving Service Management in 
Supply Chains. Department of Computer Science, University of Kuopio, Kuopio, 2006.

KITCHENHAM, B. Procedures for Performing Systematic Reviews. Joint Technical Report SE0401 and NICTA Technical Report 0400011T.1. Software Engineering Group. Department of Computer Science. Keele University, Kelle, 2004.

KORTEN, S.; KAUL, Christian. Application of RFID (Radio Frequency Identification) in the Timber Supply Chain. Chair of Forest Work Science and Applied Computer Science. Alemanha, 10 Jun. 2008.

KUNISCH, M. et al. agroXML - a standardized language for data exchange in agriculture. EFITA Conference. Wageningen, 2009.

LAGO, P.; MUCCINI. H.; VLIET. H. V. A scoped approach to traceability management. The Journal of Systems and Software. v. 82, n. 1, p. 168.182, 2009.

LENTINI, M. Como funciona a indústria madeireira - 0 mercado mundial de produtos florestais. Artigo que descreve de uma forma simplificada o funcionamento da indústria madeireira. Disponível em:

<http://empresasefinancas.hsw.uol.com.br/industria-da-madeira.htm>. Acesso em 20. Nov. 2009.

LUMMUS, R.R.; VOKURKA, R.J. Defining supply chain management: a historical perspective and practical guidelines, Industrial Management \& Data Systems. MCB University Press, v. 1, p. 11-17, 1999.

MACHADO, R. T. M. Rastreabilidade, Teoria da informação e Coordenação de Sistemas Agroindustriais. Teste (doutorado) - Universidade de São Paulo, 
Faculdade de Economia, Administração e Contabilidade. São Paulo, 2000.

MILLER, F.; TAYLOR, R.; WHITE, G. Seja Legal - Boas práticas para manter a madeira ilegal fora de seus negócios. Adaptação de André Dias, Estevão Braga, Marcelo Arguelles e Sérgio Safe. World Wildlife Fund - WWF. Global Forest \& Trade Network, p. 08-15, 2006.

MOUTINHO, P. Desmatamento na Amazônia: desafios para reduzir as emissões de gases de efeito estufa no Brasil. Instituto de Pesquisa Ambiental da Amazônia. Brasília, DF, Brasil, 2009.

OASIS. Reference Model for Service Oriented Architecture 1.0. 02 Ago. 2006. . Organization for the Advancement of Structured Information Standards. eForestry Industry Data Standards Schema. Draft V1.1.1. Disponível em: <http://www.oasis-open.org/committees/download.php/30147/eFIDS_ Description.html>. Nov. 2008.

. OASIS Forest Industries Technical Committee. Disponível em: <http://www.oasis-open.org/committees/forest/charter.php>. Acesso em: 02 Dez. 2009

PAPINET. Global Transaction Standards for the Paper Industry Implementation Guide. Out. 2003. Disponível em:

<http://www.papinet.org/index.php?id=181>. Acesso em 25 Ago. 2009.

PMA. Produce Marketing Association. Fresh Produce Traceability - A Guide to Implementation. Versão 2. Out. 2006. 
PORTAL ECODEBATE. INPE estima 7.008 km2 de desmatamento por corte raso na Amazônia. 13 Nov. 2009. Disponível em:

<http://www.ecodebate.com.br/2009/11/13/inpe-estima-7-008-km2-dedesmatamento-por-corte-raso-na-amazonia/>. Acesso em: 10 Set. 2009

QUENTAL, A. J. J. Adoção e implantação de RFID, uma visão gerencial da cadeia de suprimentos. Pontifícia Universidade Católica, São Paulo, 2006.

REVISTA DA MADEIRA. Mercado para a madeira certificada é crescente. Set. 2003, n. 76. Disponível em:

<http://www.remade.com.br/br/revistadamadeira_materia.php?num=420\&subject=Ce rtifica\%E7\%E3o\&title=Mercado\%20para\%20a\%20madeira\%20certificada\%20\%E9\% 20crescente>. Acesso em 01 Dez. 2009.

REZENDE, M. T. R.; AMARAL, S. P. Avaliação dos principais sistemas de certificação florestal praticados no mundo de interesse para o Brasil. In: III Congresso Nacional de Excelência em Gestão, 2006, Niterói, RJ, 2006.

SCHMITZ, M. et al. agroXML: Enabling Standardized Plataform-Independent Internet Data Exchange in Farm Management Information Systems. Association for Technology and Structures in Agriculture, Darmstadt, Alemanha, 2008.

SEMA. Secretaria de Estado do Meio Ambiente. Manual de Operação do SISFLORA. v. 1.13.4.0, 02 Abr. 2008. Disponível em:

<http://monitoramento.sema.pa.gov.br/sisflora/arquivos/zip/Manual_Sisflora-PA.zip>. Acesso em 05 Ago. 2009.

. Maranhão adere ao sistema DOF para controle de fluxo de madeira.. Disponível em: 
<http://www.sema.ma.gov.br/portal/portaloo?idnot=191>. Acesso em: 03 Dez. 2009.

SOALHEIRO, M. A. IBGE não inclui extração ilegal no índice de redução na produção de madeira. Agência Brasil. EBC - Empresa Brasil de Comunicação. 12 Fev. 2008. Disponível em:

<http://www.agenciabrasil.gov.br/noticias/2008/02/12/materia.2008-0212.0011452348/view>. Acesso em: 10 Set. 2009.

SIRKKA, A. Modelling Traceability in the Forestry Wood Supply Chain. IEEE 24th Internacional Conference on Data Engineering Workshop. p. 104-105. 2008.

SOBRINHO, O. G. Modelagem de um sistema de informação para rastreabilidade na indústria vinícola baseado em uma arquitetura orientada a serviços. Dissertação (Mestrado). Universidade de São Paulo, Escola Politécnica da Universidade de São Paulo. São Paulo, 2008.

TFT. Tropical Forest Trust. TracElite - Always On. Disponível em:

http://www.tropicalforesttrust.com/tracelite.php. Acesso em 15 Ago. 2009a.

Site da Organização Não-Governamental Tropical Forest Trust. Disponível em:

<http://www.tropicalforesttrust.com/about-the-tft.php>. Acesso em: 15 Ago. 2009b.

VICAN, A. Technical Guidelines - Implementation of solutions based on GS1 and EPCGlobal standards for Asset Management. França, 2009.

VILLELA, F. Extração de madeira nativa em 2007 é a menor em sete anos, revela IBGE. Agência Brasil. EBC - Empresa Brasil de Comunicação. 26 Nov. 2008. Disponível em: 
<http://www.agenciabrasil.gov.br/noticias/2008/11/26/materia.2008-1126.3374896998/view>. Acesso em: 10 Set. 2009.

VOULODIMOS, A.S et al. A complete farm management system based on animal identification using RFID technology. Computers and Electronics in Agriculture. 2009.

WANG, L.C. et al. Dynamic mobile RFID-based supply chain control and management system in construction. Advanced Enginnering Informatics. v. 21, p. 377-390, 2007.

W3C. World Wide Web Consortium. Web Services @ W3C. Cambridge. 2007a. Disponível em: <http://www.w3.org/2002/desc/>. Acesso em 10 Set. 2009.

. Extensible Markup Language (XML). Cambridge. 2007b. Disponível em: <http://www.w3.org/TR/REC-xml/>. Acesso em 10 Set. 2009.

Web Services Description Working Group. Cambridge. 2007c. Disponível em: <http://www.w3.org/2002/ws/desc/>. Acesso em 10 Set. 2009.

SOAP Specifications. Cambridge. 2007d. Disponível em: <http://www.w3.org/TR/soap12-part1/>. Acesso em 10 Set. 2009.

WORLD WILDLIFE FUND, WWF. O que é certificação florestal? Disponível em: $<$ http://www.wwf.org.br/informacoes/questoes_ambientais/certificacao_florestal/index .cfm>. Acesso em 02 Dez. 2009.

Zhang, T. et al. A Modeling Framework for Service-Oriented Architecture. Proceedings of the Sixth Internacional Conference on Quality Software (QSIC'06). 2006. 


\section{APÊNDICE A}

\begin{tabular}{|c|c|}
\hline \multicolumn{2}{|c|}{ Serviços Disponibilizados } \\
\hline Serviço, Tipo de Retorno e Parâmetros & Descrição \\
\hline $\begin{array}{l}\text { SaveApprovalAuthorization: Boolean } \\
\text { (oEmpresa, oAutorizacao) }\end{array}$ & $\begin{array}{c}\text { É responsável por registrar a aprovação de } \\
\text { um projeto de PMFS ou uma exploração } \\
\text { florestal. }\end{array}$ \\
\hline $\begin{array}{l}\text { SaveApprovalPOA: Boolean } \\
\text { (oEmpresa, oAutorizacao) }\end{array}$ & $\begin{array}{l}\text { É responsável por registrar a aprovação de } \\
\text { um Plano Operacional Anual de uma empresa. }\end{array}$ \\
\hline $\begin{array}{l}\text { SaveApprovalLo: Boolean } \\
\text { (oEmpresa, oAutorizacao) }\end{array}$ & $\begin{array}{l}\text { É responsável por registrar a aprovação de } \\
\text { uma Licença de Operação de uma empresa. }\end{array}$ \\
\hline $\begin{array}{l}\text { SaveApprovalAutex: Boolean } \\
\text { (oEmpresa, oAutorizacao, } \\
\text { oMovimentacaoEstoque[]) }\end{array}$ & $\begin{array}{c}\text { É responsável por registrar a aprovação das } \\
\text { autorizações de exploração (AUTEX, AUTEF } \\
\text { ou ACOF). }\end{array}$ \\
\hline $\begin{array}{l}\text { SaveCTF: Boolean } \\
\text { (oEmpresa, oAutorizacao) }\end{array}$ & $\begin{array}{l}\text { É responsável por registrar o Cadastro } \\
\text { Técnico Federal de uma empresa. }\end{array}$ \\
\hline $\begin{array}{l}\text { SaveBlockLo: Boolean } \\
\text { (oEmpresa, oAutorizacao, strMotivo) }\end{array}$ & $\begin{array}{c}\text { É responsável por registrar e realizar o } \\
\text { bloqueio de uma Licença de Operação, } \\
\text { impedindo a empresa de realizar a produção } \\
\text { e/ou comercialização de qualquer produto } \\
\text { florestal. }\end{array}$ \\
\hline $\begin{array}{l}\text { GetActivitiesCompany: oProcesso[] } \\
\text { (oEmpresa) }\end{array}$ & $\begin{array}{l}\text { É responsável pela consulta das atividades } \\
\text { (extração, produção/transformação e } \\
\text { comercialização) de uma empresa. }\end{array}$ \\
\hline $\begin{array}{l}\text { SavelnfoOwnership: Boolean } \\
\text { (oPropriedade) }\end{array}$ & $\begin{array}{l}\text { É responsável por registrar os dados } \\
\text { referentes a propriedade florestal de uma } \\
\text { empresa (madeireira). }\end{array}$ \\
\hline $\begin{array}{l}\text { SaveForestrylnventory: Boolean } \\
\text { (oEmpresa, oPropriedade, } \\
\text { oMovimentacaoEstoque[]) }\end{array}$ & $\begin{array}{c}\text { É responsável por registrar as informações do } \\
\text { inventário florestal de uma propriedade } \\
\text { florestal. }\end{array}$ \\
\hline $\begin{array}{l}\text { GetInfoPMFS: oAutorizacao } \\
\text { (intCodAutorizacao) }\end{array}$ & $\begin{array}{c}\text { É responsável pela consulta das informações } \\
\text { de um PMFS ou de uma exploração florestal } \\
\text { aprovada. }\end{array}$ \\
\hline GetInfoLO: oAutorizacao & É responsável pela consulta das informações \\
\hline
\end{tabular}




\begin{tabular}{|c|c|}
\hline (intCodAutorizacao) & de uma Licença de Operação. \\
\hline $\begin{array}{l}\text { GetInfoPOA: oAutorizacao } \\
\text { (intCodAutorizacao) }\end{array}$ & $\begin{array}{c}\text { É responsável pela consulta das informações } \\
\text { de um Plano Operacional Anual. }\end{array}$ \\
\hline $\begin{array}{l}\text { UpdateVirtualStock: Boolean } \\
\text { (oEmpresa, oEstoque, } \\
\text { oMovimentacaoEstoque) }\end{array}$ & $\begin{array}{c}\text { É responsável pela atualização do estoque } \\
\text { virtual de uma empresa, devido uma operação } \\
\text { de transformação, venda ou destinação de } \\
\text { produtos florestais. }\end{array}$ \\
\hline $\begin{array}{l}\text { BlockVirtualStock: Boolean } \\
\text { (oEmpresa, oEstoque, strMotivo) }\end{array}$ & $\begin{array}{c}\text { É responsável por bloquear as } \\
\text { movimentações do estoque virtual de uma } \\
\text { empresa, ou pela fim de sua autorização para } \\
\text { exploração ou devido a verificação de uma } \\
\text { irregularidade nas suas atividades. }\end{array}$ \\
\hline $\begin{array}{l}\text { SaveExtraction: Boolean } \\
\text { (oEmpresa, oAutorizacao, oLoteDestino, } \\
\text { oDetalheLote) }\end{array}$ & $\begin{array}{c}\text { É responsável por registrar as árvores que são } \\
\text { extraídas, validar sua autorização e associar } \\
\text { um lote de identificação a elas. }\end{array}$ \\
\hline $\begin{array}{l}\text { SavePosInventory: Boolean } \\
\text { (oEmpresa, oAutorizacao, oProduto[]) }\end{array}$ & $\begin{array}{c}\text { É responsável por registrar o relatório pós- } \\
\text { corte que valida tudo que foi extraído no } \\
\text { processo de extração florestal. }\end{array}$ \\
\hline $\begin{array}{l}\text { GetPosInventoryResult: oProduto[] } \\
\text { (intCodPosInventory) }\end{array}$ & $\begin{array}{l}\text { É responsável por consultar as informações } \\
\text { do relatório pós-corte de uma empresa. }\end{array}$ \\
\hline $\begin{array}{l}\text { GetInfoExtraction: oProcesso[] } \\
\text { (intCodExtraction, oLote) }\end{array}$ & $\begin{array}{l}\text { É responsável por consultar as informações } \\
\text { de uma atividade de extração ou de um lote. }\end{array}$ \\
\hline $\begin{array}{l}\text { SavePosInventoryValidation: Boolean } \\
\text { (intCodPosInventory, strResultado, } \\
\text { strMotivo) }\end{array}$ & $\begin{array}{c}\text { É responsável por registrar o resultado da } \\
\text { avaliação realizada pelos órgãos de } \\
\text { fiscalização sobre as atividades de uma } \\
\text { empresa. }\end{array}$ \\
\hline $\begin{array}{l}\text { GetPosInventoryValidation: strResultado } \\
\text { (intCodPosInventory, oEmpresa) }\end{array}$ & $\begin{array}{c}\text { É responsável por consultar o resultado da } \\
\text { avaliação realizada pelos órgãos de } \\
\text { fiscalização sobre as atividades de uma } \\
\text { empresa. }\end{array}$ \\
\hline $\begin{array}{l}\text { SaveLOBlock: Boolean } \\
\text { (oEmpresa, oAutorizacao, strMotivo) }\end{array}$ & $\begin{array}{c}\text { É responsável por bloquear a Licença de } \\
\text { Operação de uma empresa devido a } \\
\text { descoberta de irregularidades nas suas } \\
\text { atividades. }\end{array}$ \\
\hline SaveCompanyRegister: Boolean & $\begin{array}{c}\text { É responsável por registrar a empresa que } \\
\text { deseja realizar atividades envolvendo }\end{array}$ \\
\hline
\end{tabular}




\begin{tabular}{|c|c|}
\hline (oEmpresa) & insumos/produtos florestais \\
\hline $\begin{array}{l}\text { SaveCompanyLicensing: Boolean } \\
\text { (oEmpresa, oAutorizacao) }\end{array}$ & $\begin{array}{c}\text { É responsável por registrar a aprovação e o } \\
\text { licenciamento das empresas de } \\
\text { beneficiamento que desejam realizar } \\
\text { atividades envolvendo insumos/produtos } \\
\text { florestais. }\end{array}$ \\
\hline $\begin{array}{l}\text { GetCompanyStatus: oEmpresa } \\
\text { (intCodEmpresa) }\end{array}$ & $\begin{array}{c}\text { É responsável por consultar a situação de } \\
\text { uma empresa pera os órgãos de autorização } \\
\text { florestal. }\end{array}$ \\
\hline $\begin{array}{l}\text { SaveCompanylnitialStatement: Boolean } \\
\text { (oEmpresa, oAutorizacao) }\end{array}$ & $\begin{array}{l}\text { É responsável por registrar a declaração inicial } \\
\text { realizada pelo IBAMA para possibilitar que a } \\
\text { empresa possa iniciar suas operações. }\end{array}$ \\
\hline $\begin{array}{l}\text { GetCompanyLicensing: oAutorizacao[] } \\
\text { (intCodEmpresa) }\end{array}$ & $\begin{array}{c}\text { É responsável por consultar informações } \\
\text { sobre o licenciamento de uma empresa de } \\
\text { beneficiamento. }\end{array}$ \\
\hline $\begin{array}{l}\text { SaveProductionProcess: Boolean } \\
\text { (oEmpresa, oLoteEntrada,oLoteSaida, } \\
\text { oProcesso, oMovimentacaoEstoque) }\end{array}$ & $\begin{array}{l}\text { É responsável por registrar os processos de } \\
\text { transformação de insumos florestais em } \\
\text { produtos ou sub-produtos. Neste serviço } \\
\text { também são registradas as movimentações de } \\
\text { estoque, a associação dos lotes de entrada e } \\
\text { saída e considerada a geração de resíduos } \\
\text { que serão aproveitados. }\end{array}$ \\
\hline $\begin{array}{l}\text { GetProductionProcess: Dataset } \\
\text { (oEmpresa, oProcesso) }\end{array}$ & $\begin{array}{l}\text { É responsável por consultar informações } \\
\text { sobre o processo produtivo de uma empresa. }\end{array}$ \\
\hline $\begin{array}{l}\text { SaveProductLot: Boolean } \\
\text { (oLote, oProduto[]) }\end{array}$ & $\begin{array}{l}\text { É responsável por registrar o lote de produto } \\
\text { no sistema de rastreabilidade. Este lote realiza } \\
\text { o agrupamento dos produtos que serão } \\
\text { comercializados e é utilizado para garantir a } \\
\text { rastreabilidade total da cadeia. }\end{array}$ \\
\hline $\begin{array}{l}\text { SaveProductSale: Boolean } \\
\text { (oProduto[], oEmpresaOrigem, } \\
\text { oEmpresaDestino) }\end{array}$ & $\begin{array}{c}\text { É responsável por registrar o processo de } \\
\text { venda de produtos florestais. }\end{array}$ \\
\hline $\begin{array}{l}\text { SavePrintTransportDocument: Boolean } \\
\text { (oProcesso, oDocumento) }\end{array}$ & $\begin{array}{c}\text { É responsável por registrar a impressão do } \\
\text { DOF (sistema DOF) e a GF (sistema } \\
\text { SISFLORA) }\end{array}$ \\
\hline SaveProductReceive: Boolean & É responsável por registrar o recebimento \\
\hline
\end{tabular}




\begin{tabular}{|c|c|}
\hline (oEmpresa, oProcesso, strNF) & $\begin{array}{l}\text { efetivo de uma carga negociada pelo sistema } \\
\text { de transporte. }\end{array}$ \\
\hline $\begin{array}{l}\text { SaveProductDestination: Boolean } \\
\text { (oProduto[],oEmpresaOrigem, } \\
\text { oEmpresaDestino) }\end{array}$ & $\begin{array}{l}\text { É responsável por registrar a destinação de } \\
\text { produtos florestais para empresas que não } \\
\text { utilizam o sistema de transporte florestal. }\end{array}$ \\
\hline $\begin{array}{l}\text { SaveVirtualStockUpdate: Boolean } \\
\text { (oEmpresa, oMovimentacaoEstoque[]) }\end{array}$ & $\begin{array}{c}\text { É responsável por registrar as movimentações } \\
\text { de estoque existentes nos estoques virtuais } \\
\text { dos sistemas de transporte florestal. }\end{array}$ \\
\hline $\begin{array}{l}\text { SaveRetailerProductReceive: Boolean } \\
\text { (oEmpresa, oProcesso, strNF) }\end{array}$ & $\begin{array}{l}\text { É responsável por registrar o recebimento } \\
\text { efetivo de uma carga de produtos florestais } \\
\text { comprada de uma empresa legalizada. }\end{array}$ \\
\hline $\begin{array}{l}\text { GetInvoiceDetailedInfo: oDocument } \\
\text { (strNF) }\end{array}$ & $\begin{array}{c}\text { É responsável por consultar informações } \\
\text { detalhadas sobre uma respectiva Nota Fiscal. }\end{array}$ \\
\hline $\begin{array}{l}\text { GetVehicleDetailedInfo: Dataset } \\
\text { (strPlacaVeiculo, strRenavam, strChassi) }\end{array}$ & $\begin{array}{l}\text { É responsável por consultar informações } \\
\text { detalhadas sobre um respectivo veículo. }\end{array}$ \\
\hline $\begin{array}{l}\text { GetTaxpayerActivities: Dataset } \\
\text { (oEmpresa, strDatalnicio, strDataFim) }\end{array}$ & $\begin{array}{l}\text { É responsável por consultar informações } \\
\text { sobre todos os processos (compra, } \\
\text { transformação e venda) de produtos florestais } \\
\text { realizados por uma empresa. }\end{array}$ \\
\hline $\begin{array}{l}\text { GetVehiclelnfo: Dataset } \\
\text { (strPlacaVeiculo, strRenavam, strChassi) }\end{array}$ & $\begin{array}{l}\text { É responsável por consultar informações } \\
\text { sobre um veículo e verificar se o mesmo pode } \\
\text { ser utilizado em um transporte de produtos } \\
\text { florestais. }\end{array}$ \\
\hline $\begin{array}{l}\text { GetInvoicelnfo: Dataset } \\
\text { (strNF) }\end{array}$ & $\begin{array}{c}\text { É responsável por consultar informações } \\
\text { sobre uma Nota Fiscal e verificar se a mesma } \\
\text { é legal para ser associada a um documento de } \\
\text { transporte (DOF ou GF). }\end{array}$ \\
\hline $\begin{array}{l}\text { GetProductOrigin: oProcesso[] } \\
\text { (strSerialNumber) }\end{array}$ & $\begin{array}{c}\text { É responsável por consultar informações } \\
\text { sobre a origem e as demais etapas do } \\
\text { processo produtivo do produto florestal }\end{array}$ \\
\hline
\end{tabular}

